University of Louisville

ThinkIR: The University of Louisville's Institutional Repository

$12-2011$

\title{
Role of HDACs and SAM in interferon-alpha signaling and epigenetic regulation of anti-HCV gene expression.
}

\author{
Stephanie A. Mathews \\ University of Louisville
}

Follow this and additional works at: https://ir.library.louisville.edu/etd

\section{Recommended Citation}

Mathews, Stephanie A., "Role of HDACs and SAM in interferon-alpha signaling and epigenetic regulation of anti-HCV gene expression." (2011). Electronic Theses and Dissertations. Paper 919.

https://doi.org/10.18297/etd/919

This Doctoral Dissertation is brought to you for free and open access by ThinkIR: The University of Louisville's Institutional Repository. It has been accepted for inclusion in Electronic Theses and Dissertations by an authorized administrator of ThinkIR: The University of Louisville's Institutional Repository. This title appears here courtesy of the author, who has retained all other copyrights. For more information, please contact thinkir@louisville.edu. 


\title{
ROLE OF HDACS AND SAM IN INTERFERON-ALPHA SIGNALING AND EPIGENETIC REGULATION OF ANTI-HCV GENE EXPRESSION
}

\author{
By \\ Stephanie A. Mathews \\ B.S., University of Kentucky, 2002 \\ M.S., University of Louisville, 2008 \\ A Dissertation Submitted to the Graduate Faculty of the \\ School of Medicine of the University of Louisville in \\ Partial Fulfillment of the Requirements \\ for the Degree of \\ Doctor of Philosophy \\ Department of Pharmacology and Toxicology \\ University of Louisville \\ School of Medicine \\ Louisville, KY
}

December 2011 
Copyright 2011

All rights reserved 
ROLE OF HDACS AND SAM IN INTERFERON-ALPHA SIGNALING AND EPIGENETIC REGULATION OF ANTI-HCV GENE EXPRESSION

\section{By}

Stephanie A. Mathews

B.S., University of Kentucky, 2002

M.S., University of Louisville, 2008

\section{A Dissertation Approved on}

November 28, 2011

By the following Dissertation Committee:

\begin{tabular}{c}
\hline Shtísh Barve, Ph.D. \\
\hline Craigh MicClain, Ph.D \\
\hline Theresa Cben, Ph.D. \\
\hline David Hein, Ph.D. \\
\hline Jill Suttles, Ph.D.
\end{tabular}




\section{DEDICATION}

This dissertation is dedicated to my family and friends who have supported me throughout my educational career. 


\section{ACKNOWLEDGEMENTS}

I would like to thank my mentors, Drs. Shirish Barve and Craig McClain, for their

invaluable insights, guidance, and patience. I would also like to thank Dr. Swati

Joshi-Barve for her assistance and willingness to explain difficult concepts. I

would also like to thank the lab members who have assisted me with

experiments and interpretation of data. Lastly, thank you to my family and

friends for their understanding and patience throughout my graduate career. 


\section{ABSTRACT \\ ROLE OF HDACS AND SAM IN INTERFERON-ALPHA SIGNALING AND EPIGENETIC REGULATION OF ANTI-HCV GENE EXPRESSION}

Stephanie A. Mathews

November 28, 2011

Hepatitis $\mathrm{C}$ virus (HCV) infection is a major cause of chronic liver disease in the United States and is a huge burden on the US healthcare system. The FDAapproved traditional standard of care for $\mathrm{HCV}$ is pegylated interferon-alpha (IFNa) combined with ribavirin, which is effective in about $50 \%$ of patients. The molecular mechanisms involved in resistance to IFNa therapy remain unclear. Recent data strongly suggest that histone deacetylases (HDACs) and methylation play critical roles in the regulation of IFNa anti-HCV signaling and gene expression. The present work was carried out to elucidate the roles of HDACs and S-adenosylmethionine (SAM) metabolism in regulating IFNa antiHCV signaling in human hepatoma cells.

Inhibition of HDACs, by pharmacologic HDAC inhibitors or siRNA, significantly suppressed IFNa-mediated antiviral gene expression and partially reversed the 
anti-HCV action of IFN $\alpha$ in human hepatoma cells. The decrease in antiviral gene expression correlated with decreased retention time of activated STATs in the nucleus, an increase in STAT acetylation, inhibition of the STAT1:HDAC1 complex, and decreased occupancy of STAT1 on antiviral gene promoters. We used siRNA to specifically identify HDACs 1 and 3 as being critical for IFNamediated anti-HCV activity. Finally, we showed that boosting HDAC gene expression by theophylline supplementation improved IFNa-mediated antiviral gene expression and anti-HCV activity, thus supporting the hypothesis that HDACs are critical for IFNa anti-HCV signaling.

Impaired SAM metabolism, as a result of increased intracellular Sadenosylhomocysteine, markedly reduced IFNa-mediated antiviral gene expression and anti-HCV activity, which correlated with a decrease in STAT phosphorylation and an increase in association between STAT1 and its negative regulator PIAS1. We also showed that impaired SAM metabolism downregulated expression of several HDACs, which may also impact IFNa antiviral signaling. Importantly, SAM supplementation restored the antiviral and anti-HCV properties of IFNa.

Acrolein, an environmental pollutant, significantly inhibited antiviral gene expression, which correlated to impaired STAT phosphorylation, decreased induction of class I HDAC mRNAs, and reduced HDAC activity in human hepatoma cells. The results presented herein reveal a critical role for HDACs 
and SAM metabolism in IFNa-mediated anti-HCV activity and support the use of SAM and/or inducers of HDACs as adjunct therapy in managing HCV infection. 


\section{TABLE OF CONTENTS}

PAGE

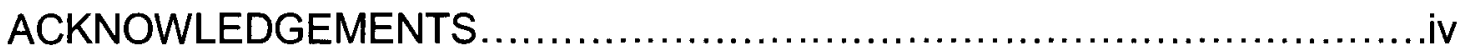

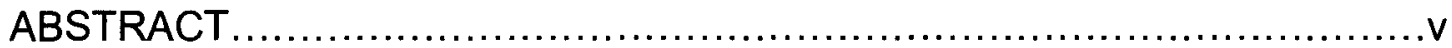

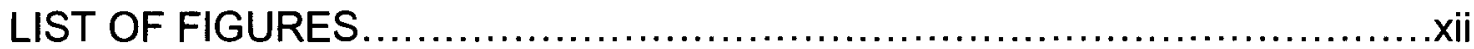

\section{CHAPTER}

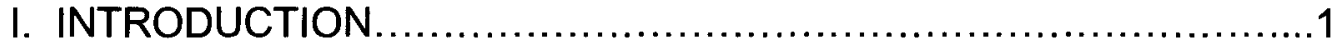

Hepatitis C Virus (HCV) .......................................1

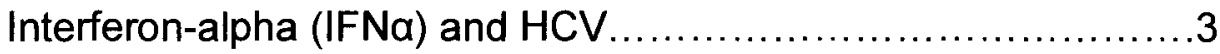

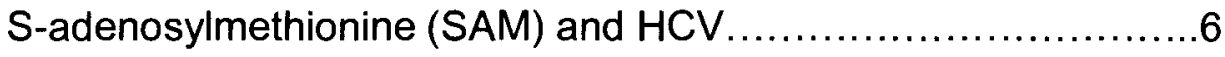

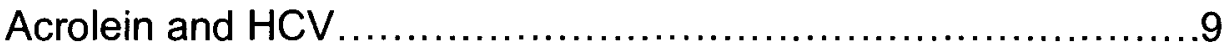

Epigenetics......................................................

Hypothesis..........................................................

II. MATERIALS AND METHODS .........................................

Cell Culture and Treatment.......................................14

Reagents and Antibodies..........................................

Western Blot....................................................

Immunoprecipitation................................................

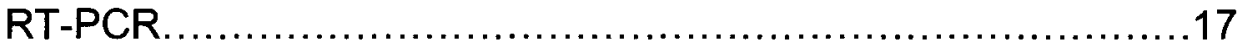

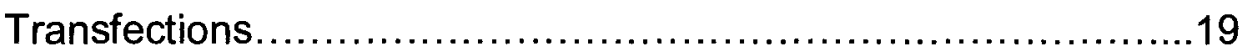

Luciferase Reporter Assay .......................................20 
Chromatin Immunoprecipitation (ChIP) Assay...................20

HDAC Activity Assay ................................................

SAM and SAH Measurement by HPLC ............................21

Statistical Analysis.................................................22

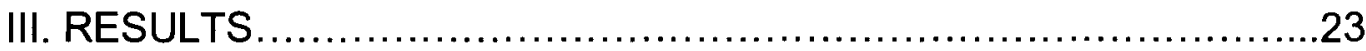

Histone Deacetylases and IFNa Signaling .........................23

Class I HDACs are required for IFNa-mediated antiviral signaling in

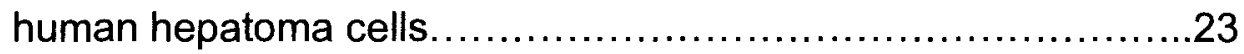

Class I HDACs are required for IFNa-mediated antiviral signaling in primary human hepatocytes......................................

Class I HDACs are required for retention of pSTAT1 in the nucleus

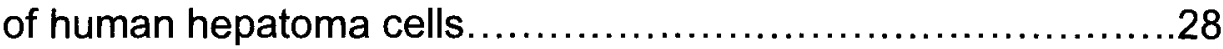
Inhibition of HDACs decreases STAT1:HDAC1 and correlates with increased STAT1 acetylation....................................30 Class I HDACs are required for IFNa-mediated PKR and ISG15 protein expression and suppression of viral NS5A protein

Class I HDACs are required for association of STAT1 with the IRF1 promoter

HDACs 1 and 3 are required for IFNa-mediated antiviral signaling in human hepatoma cells.

Theophylline boosts HDAC1 gene induction and improves IFNamediated anti-HCV gene induction and activity 39

Summary of data. 
Impaired SAM Metabolism and IFNa Signaling.

Impaired SAM metabolism decreases methylation potential in

human hepatoma cells.

Impaired SAM metabolism blocks IFNa-induced antiviral gene

expression in human hepatoma cells.

Impaired SAM metabolism blocks IFNa-induced activation of the

ISRE in antiviral gene promoters.

Impaired SAM metabolism inhibits IFNa-mediated pSTAT1, OAS,

and PKR protein expression in human hepatoma cells

Impaired SAM metabolism increases STAT1:PIAS1, which

correlates with decreased STAT1:PRMT1 in the nucleus of human

hepatoma cells.

.51

SAM supplementation boosts IFNa-mediated antiviral gene

induction and anti-HCV activity in human hepatoma cells.

Impaired SAM metabolism downregulates HDAC gene induction in

human hepatoma cells.........................................55

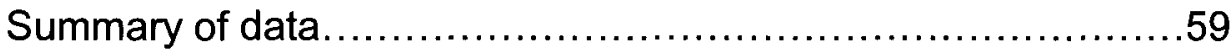

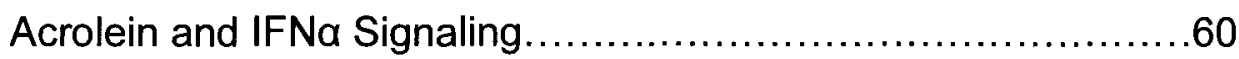

Acrolein inhibits IFNa-mediated antiviral gene expression and anti-

$\mathrm{HCV}$ activity in human hepatoma cells.

60

Acrolein suppresses class I HDAC activity and gene expression in

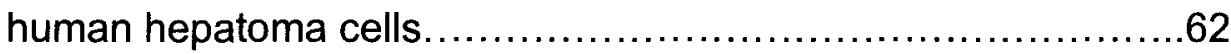

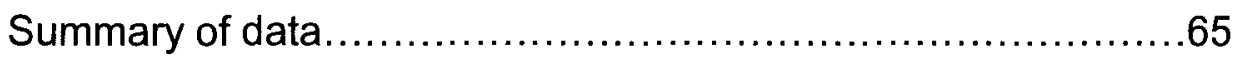




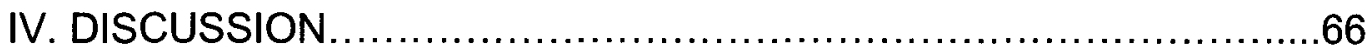

V. CONCLUSIONS.................................................... 74

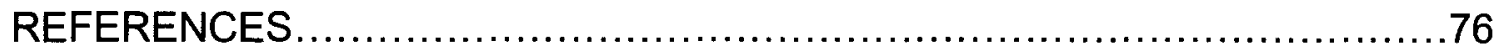

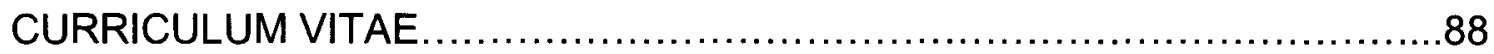




\section{LIST OF FIGURES}

FIGURE

PAGE

1. Schematic of IFNa-stimulated JAKISTAT signaling .........................5

2. SAM metabolism schematic .............................................

3. Effect of HATs and HDACs on chromatin structure ..........................12

4. Class I HDACs are required for IFNa-mediated antiviral gene expression via the ISRE in human hepatoma cells..........................................24

5. Class I HDACs are required for IFNa-mediated anti-HCV activity .............26

6. Class I HDACs are required for IFNa-mediated antiviral gene expression in

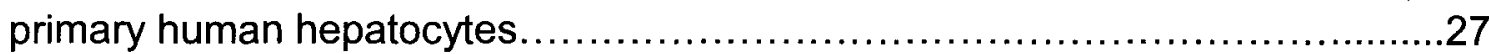

7. Class I HDACs are required for retention of PSTAT1 in the nucleus of human hepatoma cells.

8. Class I HDACs are required for IFNa-mediated STAT1:HDAC1 association and to prevent acetylation of STAT1 in the nucleus of human hepatoma cells...31 9. Class I HDACs are required for IFNa-mediated expression of the antiviral proteins PKR and ISG15 and suppression of viral NS5A protein in human hepatoma cells.

10. Class I HDACs are required for association of STAT1 with the IRF-1

promoter in human hepatoma cells. .34

11. Silencing of HDACs in human hepatoma cells. 
12. HDAC1 and HDAC3 are required for IFNa-mediated antiviral gene expression in human hepatoma cells.

13. HDAC1 and HDAC3 are required for IFNa-mediated PKR protein expression and IFNa-mediated STAT1:HDAC1 association in human hepatoma cells........38

14. Theophylline enhances IFNa-mediated PKR mRNA induction and anti-HCV activity and boosts HDAC1 mRNA induction in human hepatoma cells

15. Schematic representation of the role of HDACs in IFNa-mediated anti-HCV gene expression in hepatocytes.

16. Impaired SAM metabolism inhibits IFNa anti-HCV activity in human hepatoma cells.

17. Impaired SAM metabolism inhibits IFNa-mediated antiviral gene induction and anti-HCV activity in human hepatoma cells

18. Impaired SAM metabolism inhibits IFNa-mediated activation of the ISRE in human hepatoma cells

19. Impaired SAM metabolism inhibits IFNa-mediated pSTAT1, OAS, and PKR

protein expression in human hepatoma cells.

20. Impaired SAM metabolism decreases STAT1:PRMT1 and increases

STAT1:PIAS1 association in the nucleus of human hepatoma cells

21. SAM boosts IFNa-mediated antiviral gene induction and anti-HCV activity in human hepatoma cells 53

22. SAM restores IFNa-mediated anti-HCV activity that was blocked by inhibition of SAM metabolism 
23. Effect of impaired SAM metabolism on class I HDAC gene induction in

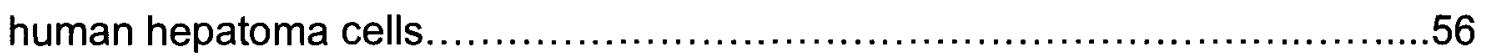

24. Effect of impaired SAM metabolism on class II HDAC gene induction in

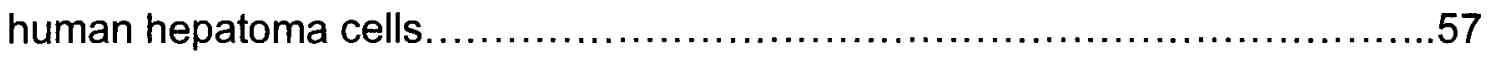

25. Acrolein inhibits IFNa-mediated antiviral gene expression and ant-HCV

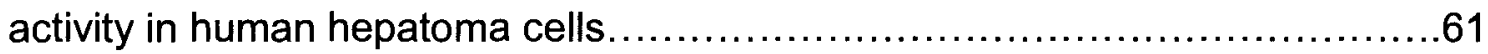

26. Acrolein decreases HDAC activity in human hepatoma cells.................62

27. Acrolein decreases HDAC gene induction in human hepatoma cells.........64 


\section{CHAPTER I \\ INTRODUCTION}

\section{Hepatitis C Virus}

Hepatitis $\mathrm{C}$ virus (HCV) infection is a major cause of acute hepatitis and chronic liver disease in the United States (US) and is known to be a precursor to cirrhosis, end-stage liver disease, hepatocellular carcinoma (HCC) and death. It is estimated that more than 170 million persons worldwide are chronically infected with HCV and approximately 3 million of those live in the US $S^{5,66,68,104}$. The most recent statistics from the Centers for Disease Control and Prevention suggest that $55-85 \%$ of $\mathrm{HCV}$ infected subjects will develop chronic infections. Additionally, HCV remains one of the leading causes of liver transplantation in the US and is a huge burden on the US healthcare system; it is estimated that annual total medical costs for HCV patients will exceed $\$ 80$ billion over the next 15 years $^{51,122}$.

$\mathrm{HCV}$ is an enveloped, single-stranded RNA virus of the family Flaviviridae. The $\mathrm{HCV}$ genome is comprised of a single open reading frame (ORF) that is flanked 
by $5^{\prime}$ and $3^{\prime}$ non-coding regions (NCR). The ORF encodes a polyprotein that is cleaved, both co- and post-translationally, to give rise to HCV core and envelope proteins as well as several nonstructural (NS) proteins. The NS5B protein functions as an RNA dependent RNA polymerase while other NS proteins function as proteases necessary for processing of the polyprotein ${ }^{17,55,68}$. Importantly, the NS5A protein contains the interferon sensitivity determining region (ISDR), which is highly susceptible to mutations and is thought to determine early response to IFNa therapy ${ }^{91,96,101,103}$. The $5^{\prime}$ NCR contains an internal ribosomal entry site (IRES) and the $3^{\prime}$ NCR contains elements that are required for efficient viral replication. The HCV genome has a great propensity for mutations, thereby producing many HCV variants, and this quality is thought to be related to its ability to induce chronic infection ${ }^{17,72,119}$. This high mutation rate may also make it difficult to develop vaccines against HCV.

$\mathrm{HCV}$ infection leads to the release of endogenous cytokines that invoke immune and inflammatory responses to aid in viral clearance. Of particular importance is induction of interferon alpha (IFNa), which activates the JAK/STAT signaling pathway, ultimately leading to expression of IFNa-stimulated antiviral genes. However, the virus also induces several countermeasures that inhibit the antiviral activity of IFNa including induction of protein phosphatase $2 A(P P 2 A)$ and suppressor of cytokine signaling 1 and 3 (SOCS-1, SOCS-3), which interfere with JAK/STAT signaling ${ }^{11,52,69,104 .}$ 
Unfortunately, more than $75 \%$ of individuals infected with HCV show no signs or symptoms and the disease is usually not detected until it is in the chronic stage. Additionally, $\mathrm{HCV}$ infection can worsen underlying disease if it coexists with other hepatic conditions, such as alcoholic liver disease ${ }^{122}$. There is no vaccine against $\mathrm{HCV}$ and the current FDA approved standard of care is pegylated-IFN $\alpha$ combined with ribavirin. Despite the antiviral properties of IFNa, up to $60 \%$ of patients fail to reach sustained virological response (SVR) particularly those infected with HCV genotype 1, which is most prevalent in the US. Response to IFNa therapy is dependent on several factors including viral load, obesity, alcohol consumption, smoking, and exposure to environmental pollutants ${ }^{35,117,122}$. In addition, the pegylated-IFNa/ribavirin treatment regimen is expensive and produces many harsh side effects. In 2011, two new protease inhibitors, boceprevir and telaprevir, were FDA-approved for treatment of HCV; however, they must be used in combination with pegylated-IFNa and ribavirin therapy and they are only effective against HCV genotype 1. Additionally, each of these protease inhibitors has a complicated dosing regimen, produces harsh side effects, and has numerous contraindications. Therefore, the need for enhancing the efficacy of the existing IFNa treatment is of critical importance.

\section{IFNa ANTIVIRAL SIGNALING and HCV}

IFNa is a ubiquitous cytokine with immunomodulatory and antiviral properties.

IFNa is released from host cells and given as medication during HCV infection to 
aid in clearance of the virus. The antiviral action of IFNa is mediated through binding with the cell surface receptors IFNAR1 and IFNAR2, which activates the JAK/STAT signaling pathway, ultimately leading to expression of IFNa-stimulated antiviral genes. Critical steps in this pathway include IFNa-mediated phosphorylation of the receptor-associated kinases Jak1 and Tyk2, which provides docking site for the inactive STAT proteins. Docking of STAT induces its phosphorylation on tyrosine residue 701 and serine residue 727 . Once activated, the pSTAT proteins dissociate from the receptor and form STAT dimers that are translocated to the nucleus. Tyrosine phosphorylation of cytoplasmic STAT proteins is necessary for their dimerization and subsequent nuclear import while serine phosphorylation is required for optimal transcriptional activity. Once inside the nucleus, pSTATs associate with the transcription factor IRF-9 to form the interferon stimulated gene factor 3 (ISGF 3) transcription complex. ISGF3 binds the interferon stimulated response element (ISRE) within the promoter of IFNa stimulated genes and induces expression of several antiviral proteins including dsRNA-activated protein kinase (PKR) and oligoadenylate synthetases (OAS), which arrest viral protein synthesis and degrade viral RNAs, respectively $38,42,63,67,93,100,107,121,127$. 


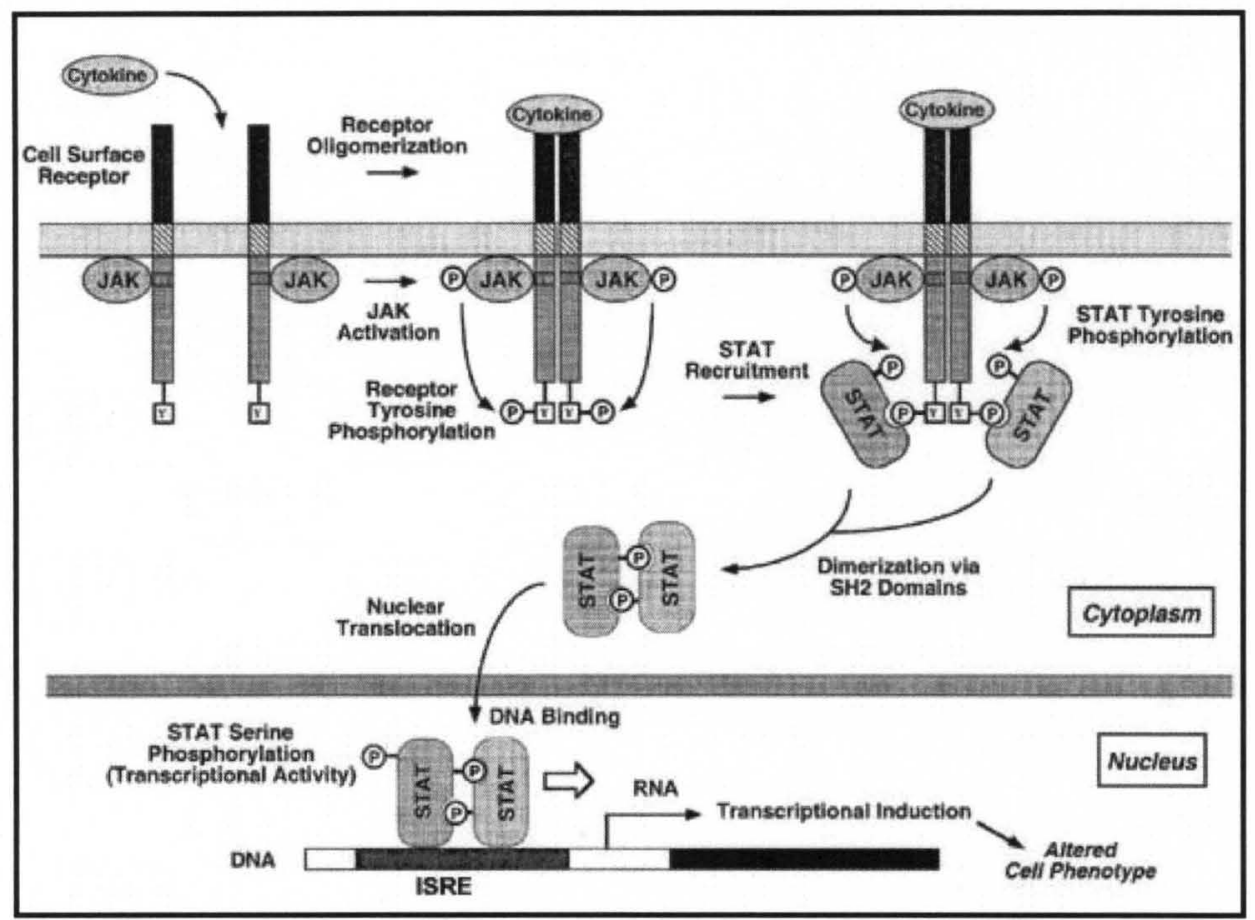

Figure 1: Schematic of IFNa-stimulated JAK/STAT signaling. Modified from http://www.springerimages.com/Images/MedicineAndPublicHealth/110.1007_s11154-008-9089-x-1

Negative regulation of JAKS/STAT signaling occurs via several mechanisms. Nuclear pSTATs can be deactivated by phosphatases, which inhibits IFNamediated transcription. Additionally, STAT forms a complex with the histone acetyltransferase (HAT) protein, CBP, inside the nucleus, thus causing acetylation of STAT, which subsequently leads to its nuclear export, and arrested transcription of IFNa-stimulated antiviral genes ${ }^{58,61,62}$. IFNa-mediated antiviral gene activation is also inhibited by association of STAT1 with protein inhibitor of activated STAT (PIAS1) inside the nucleus of cells ${ }^{73,120}$. Importantly, arginine methylation of STAT1 prevents the STAT1:PIAS1 association, and STAT1 
methylation is also required for optimal transcriptional activity ${ }^{85,120}$. Additionally, histone deacetylase (HDAC) activity, which recruits RNA polymerase to the promoter of IFNa stimulated genes, is required for antiviral gene expression ${ }^{99}$.

$\mathrm{HCV}$ induces several countermeasures to inhibit the antiviral activity of IFNa including induction of protein phosphatase $2 \mathrm{~A}$ (PP2A), SOCS-1, and SOCS-3, all of which interfere with JAK/STAT signaling ${ }^{11,27,42,43,73}$. Specifically, SOCS-1 and SOCS-3 interact with receptor associated JAK to block its kinase activity, thereby preventing STAT phosphorylation. PP2A interferes with the signaling cascade by inhibiting protein arginine methyltransferase (PRMT)-mediated methylation of STAT proteins, which allows for association between STAT1 and its negative regulator, PIAS1 ${ }^{11,27,107}$. HCV also induces oxidative stress that impacts HDAC activity ${ }^{84}$. These alterations in HDAC activity might also affect the anti-HCV action of IFNa as HDACs are required to recruit RNA polymerase to the promoters of IFNa-stimulated genes ${ }^{86,99}$.

\section{S-adenosylmethionine and HCV}

S-adenosylmethionine (SAM) is of pivotal importance in cellular metabolism, serving as the major donor of methyl groups in transmethylation and transsulfuration reactions $s^{6,14,18,76}$. The majority of SAM synthesis occurs in the liver, whereby the adenosyl group from ATP is transferred to the sulfur atom in 
methionine, in a reaction catalyzed by methionine adenosyltransferase (MAT). Once formed, SAM is rapidly metabolized to S-adenosylhomocysteine (SAH) by specific methyltransferases (MT) that transfer the methyl group from SAM to various molecules, including nucleic acids, proteins, and phospholipids. SAH hydrolase (SAHH) hydrolyzes SAH to yield adenosine and homocysteine, which is then converted back to methionine in a series of reactions catalyzed by homocysteine methyltransferase ${ }^{6,14,47,80}$. The reaction catalyzed by SAHH is the only reversible reaction in the SAM metabolism pathway and the equilibrium favors the formation of $\mathrm{SAH}$, however, the rapid uptake of adenosine and homocysteine by the cell drives the reaction in the direction of catalysis. Importantly, SAH is a potent inhibitor of cellular MTs, thus any increase in intracellular SAH levels will have detrimental effects on several transmethylation reactions. Methylation is essential for synthesis of several cellular components, including DNA and proteins, thus, intracellular SAM levels are critical for normal cell development and function. The ratio between SAM and SAH, called the methylation potential (MP), must be controlled for normal cellular function. Increases in intracellular SAH will decrease MP and block critical methylation reactions leading to abnormal cellular function ${ }^{6,14,47,80}$. Several studies have shown that MAT1A mRNA levels are markedly reduced in patients with chronic liver disease, liver cirrhosis, or $\mathrm{HCC}^{5,75}$. Importantly, elevated serum levels of SAH have been documented in patients with chronic liver disease ${ }^{6,75,77}$. 


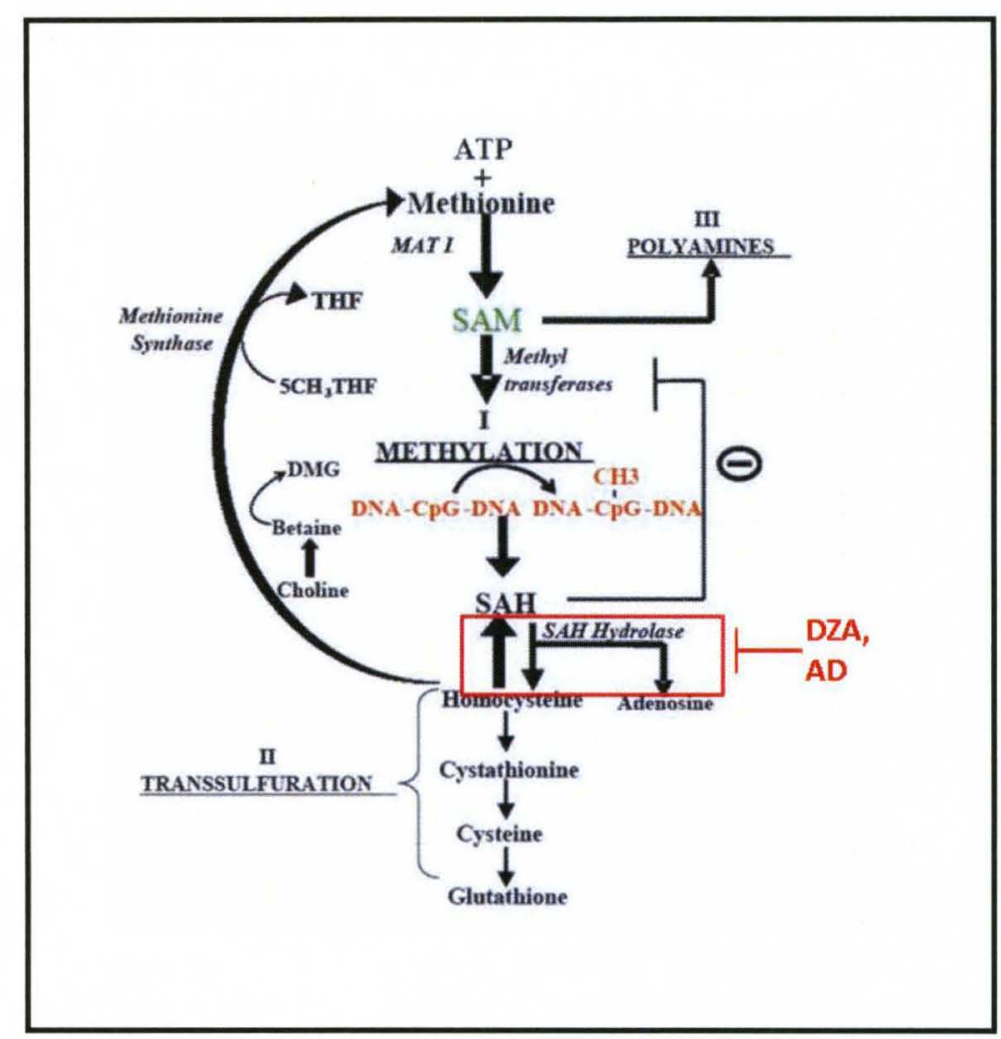

Figure 2: SAM metabolism schematic.

In cell culture systems, SAM metabolism can be disrupted by several mechanisms that raise intracellular SAH levels, thereby decreasing the SAM/SAH ratio and methylation potential. Targeting SAHH with pharmacologic inhibitors is an indirect mechanism to impair SAM metabolism. In 1977, Chiang et al. first reported the use of 3'-deazaadeonsine (DZA), a nucleoside analog of adenosine, as a potent inhibitor of SAHH that raised intracellular SAH and decreased SAM/SAH. Over the years, several other nucleoside analogs have been discovered that inhibit $\mathrm{SAHH}$, including adenosine dialdehyde $(A D)^{7,19,20}$. Both DZA and AD bind to and inhibit SAHH leading to an increase in intracellular $\mathrm{SAH}$ and a decrease in methylation potential. Pharmacologic SAHH inhibitors 
are a valuable tool for studying the effects of impaired SAM metabolism but inhibition of SAHH is only one mechanism that increases intracellular SAH.

Since the products of SAH hydrolysis are adenosine and homocysteine and the equilibrium of the reversible SAHH reaction lies in the direction of SAH synthesis, administration of exogenous adenosine and homocysteine will also impair SAM metabolism by increasing intracellular SAH levels ${ }^{47}$.

\section{Acrolein and HCV}

$\mathrm{HCV}$ disease progression and response to IFNa therapy depend on a variety of factors including obesity, oxidative stress, and external factors such as smoking, alcohol consumption, and exposure to environmental pollutants ${ }^{35,117,122 .}$ Acrolein is a highly reactive $\alpha, \beta$-unsaturated aldehyde that humans are exposed to in a variety of situations. Importantly, acrolein is found in all sources of smoke including cigarette smoke, car exhaust, overheated cooking oils, and smoke from burning wood. Acrolein is also formed endogenously as a product of lipid peroxidation, a process that is also stimulated by acrolein, and is associated with

oxidative stress $^{54,56,65,90}$. Recent studies also suggest that acrolein alters HDAC activity $^{2}$. HDAC activity is required to recruit RNA polymerase to the promoters of IFNa-stimulated antiviral genes and is critical for efficient transcription of these genes. Accordingly, it is reasonable to speculate that exposure to acrolein may contribute to poor response to anti-HCV therapy. 


\section{Epigenetics}

A growing body of evidence suggests that DNA methylation and posttranslational histone modifications are important changes that will impact disease progression by inducing alterations in gene transcription, chromatin configuration, and DNA integrity $1,41,60,86,111$. Generally, CpG island methylation, which is mediated by DNA methyltransferases (DNMTs), results in transcriptional repression due to recruitment of methyl-CpG binding proteins, HDACs, and chromatin remodeling complexes ${ }^{1}$. The modifications of lysine $(K)$ residues on histone tails are indeed more complex. Histones associate with DNA to form nucleosomes, the fundamental repeating unit of eukaryotic chromatin. Specifically, 2 copies of each of the core histone proteins (H2A, H2B, H3, and H4) come together to form a histone octomer, which wraps 147 basepairs of DNA, thus forming a nucleosome. Nucleosomes function to package DNA into chromatin: euchromatin is loosely packaged and associated with active transcription, whereas heterochromatin is tightly packaged and associated with repressed transcription. Importantly, the modifications of the highly conserved histone tails are what facilitate DNA packaging ${ }^{1,60,111}$. The well-characterized modifications of histones occur on lysine $(\mathrm{K})$ residues on the histone tails. In addition to methylation, it has been established that $\mathrm{K}$ residues are subject to modification by phosphorylation, acetylation, and ubiquitination. The most characterized modifications are methylation and acetylation, which are generally thought to repress and activate transcription, respectively ${ }^{64,111,124}$. Importantly, these modifications are driven by various MTs, HDACs, and histone acetyl 
transferases (HATs). It should be noted, however, that each $\mathrm{K}$ residue may be subject to more than one type of modification and these modifications may have different effects depending on the nature of local chromatin structure ${ }^{60,64,111,124}$.

DNA methylation and histone modifications work together to regulate gene transcription. In most cases, transcriptionally repressed genes are hypermethylated at $\mathrm{CpG}$ islands and associated with hypoacetylated histone $\mathrm{H} 3$ that is methylated on the $\mathrm{K} 9$ residue $(\mathrm{H} 3 \mathrm{~K} 9 \mathrm{Me})$. Transcriptionally active genes are hypomethylated at $\mathrm{CpG}$ islands and associated with hyperacetylated and $\mathrm{K} 4$ methylated $\mathrm{H} 3(\mathrm{H} 3 \mathrm{~K} 4 \mathrm{Me})^{111,124}$. Importantly, SAM functions as the major methyl donor during epigenetic modifications, so maintaining SAM and SAM/SAH levels are critical for methylation of DNA and histones.

HDACs and HATs were historically named based on their ability to modify $\mathrm{K}$ residues on histone tails. HATs add negatively charged acetyl groups to $\mathrm{K}$ residues, which repel the negatively charged DNA, and are associated with loosely packed euchromatin and active transcription. HDACs remove the acetyl groups, which leads to attract of the histones to the DNA, and correlate with tightly packed heterochromatin and repressed transcription. 


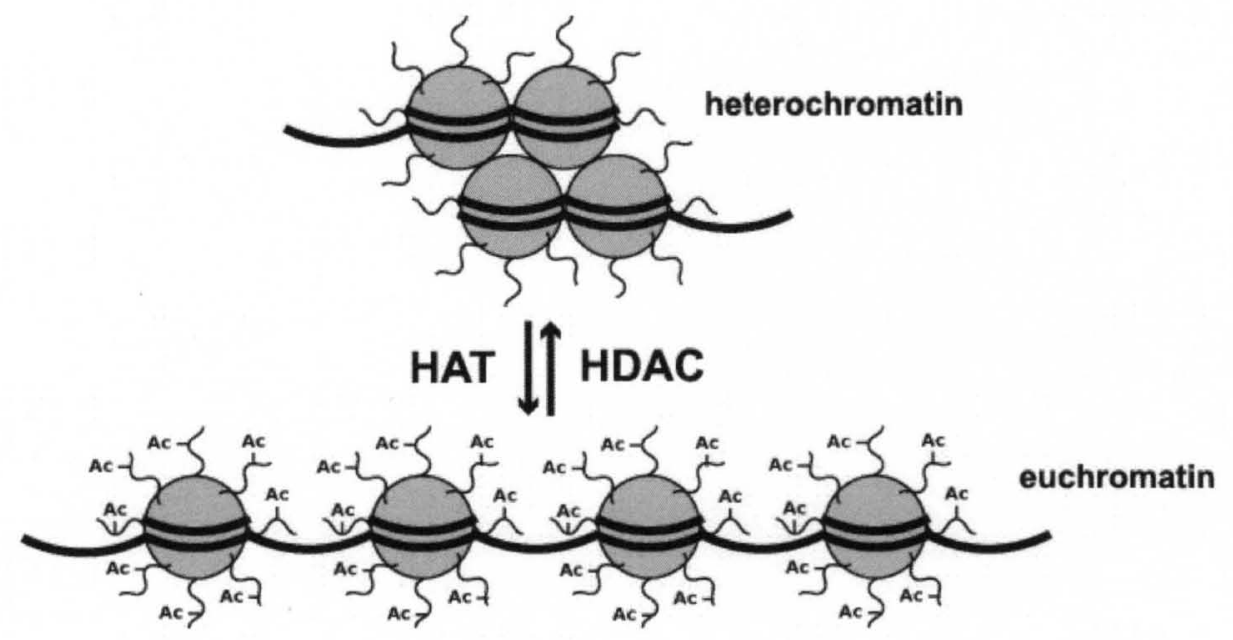

Figure 3: Effect of HATs and HDACs on chromatin structure. Modified from http://missinglink.ucsf.edu/lm/genes_and_genomes/acetylation.html

More recently, there has been an increasing body of evidence showing that HDACs and HATs, as well as MTs, also work on non-histone proteins ${ }^{41,87,124}$. Importantly, HDACs have been implicated in the regulation of signaling by various transcription factors ${ }^{41}$. IFNa-mediated antiviral gene expression relies on phosphorylation and nuclear import of STAT. Nuclear STAT proteins can be acetylated by CBP, a HAT protein, which marks STAT for nuclear export and leads to reduced antiviral gene transcription ${ }^{58,62}$. In addition to being required to recruit RNA polymerase to IFNa-stimulated gene promoters, HDACs may play a role in IFNa anti-HCV gene expression by preventing STAT acetylation and increasing nuclear retention of activated STAT proteins. 


\section{Overall Hypothesis:}

The molecular mechanisms, which include both viral and host factors, involved in resistance to IFNa anti-HCV therapy are only beginning to be understood. A better understanding of these regulatory mechanisms may prove to be beneficial for enhancing the efficacy of IFNa. Recent data strongly suggest that HDACs and methylation play a critical role in regulation of IFNa signaling and antiviral gene expression. Importantly, HCV is known to modify HDAC activity and impaired SAM metabolism is a well-documented feature of chronic liver injury ${ }^{6,77}$,

84. Based on these findings, we hypothesized that HDACs and SAM play critical roles in regulating IFNa signaling and epigenetic regulation of antiHCV gene expression in hepatocytes. 


\section{CHAPTER \|}

\section{MATERIALS AND METHODS}

\section{Cell Culture and Treatment:}

Huh7 cells (Apath, LLC, St. Louis, MO) were gown in Dulbecco's modified eagle medium (DMEM) supplemented with $10 \%$ fetal bovine serum (FBS), $10 \mathrm{U} / \mathrm{ml}$ penicillin, $10 \mu \mathrm{g} / \mathrm{ml}$ streptomycin, and $1 \mathrm{x}$ non-essential amino acids (NEAA). Huh7 cells stably transfected with an HCV replicon (HCVR) (clone B (S1179I), Apath, LLC, St. Louis, MO) were grown in DMEM media supplemented with $10 \%$ FBS, $10 \mathrm{U} / \mathrm{ml}$ penicillin, $10 \mu \mathrm{g} / \mathrm{ml}$ streptomycin, $1 \times$ NEAA, and $1 \mathrm{mg} / \mathrm{ml} \mathrm{G418}$. Primary human hepatocytes were purchased from Zen-Bio (Research Triangle Park, NC) and maintained as per manufacturer's protocol. All cells were maintained in a $37^{\circ} \mathrm{C}$ and $5 \% \mathrm{CO}_{2}$ incubator. Cells were treated at a density of $1.0 \times 10^{6} \mathrm{cell} / \mathrm{s} / \mathrm{ml}$ in all experiments unless otherwise noted. For HDAC studies, cells were treated with the HDAC inhibitors tricostatin A (TSA, $400 \mathrm{ng} / \mathrm{ml}$ ) or suberic bishydroxamate (SBHA, $10 \mu \mathrm{g} / \mathrm{ml}) 30$ minutes before stimulation with IFNa. Alternatively, cells were treated with the HDAC inducer, theophylline (1 $\mathrm{mM}$ ), for 24 hours prior to IFNa treatment. For SAM metabolism studies, cells were treated with the SAM metabolism disruptors, adenosine + homocysteine 
(AdenHcy, $1 \mathrm{mM})$, adenosine dialdehyde $(\mathrm{AD}, 80 \mu \mathrm{M})$, or 3-deazaadeonsine (DZA, $80 \mu \mathrm{M}) 3$ hours prior to IFNa. For SAM supplementation studies, cells were treated for 24 hours with $1 \mathrm{mM}$ SAM prior to IFNa treatment. To study the effects of SAM supplementation on impaired SAM metabolism, cells were treated with SAM metabolism inhibitors for 3 hours, then SAM for 24 hours, prior to stimulation with IFNa. For acrolein (ACR) studies, cells were treated with 25 or $50 \mu \mathrm{M}$ ACR in serum-free DMEM for 30 minutes prior to IFNa treatment.

Reagents and Antibodies:

AD, DZA, adenosine, homocysteine, SAM, TSA, SBHA, ACR, theophylline and protease inhibitor cocktail were purchased from Sigma-Aldrich (St. Louis, MO). Total STAT1 and phospho-STAT1 (Tyr 701 and Ser 727) primary and goat antirabbit horseradish peroxidase conjugated secondary antibodies were purchased from Cell Signaling (Danvers, MA). Anti-dimethyl arginine primary antibody was purchased from Abcam, Inc (Cambridge, MA). HCV NS5A antibody was a kind gift from Dr. Charles M. Rice (Rockefeller University). Protein A/G plus agarose was purchased from Santa Cruz Biotechnology, Inc (Santa Cruz, CA). Fetal bovine serum was purchased from Atlanta Biologicals (Norcross, GA). Trisbuffered saline (TBS), DMEM, G418, NEAA, Trizol, and pre-stained protein ladder were purchased from Invitrogen (Carlsbad, CA). ECL western blotting detection reagent was purchased from Amersham Biosciences (Piscataway, NJ). Human IFNa was purchased from PBL Biomedical Laboratories (Piscataway,

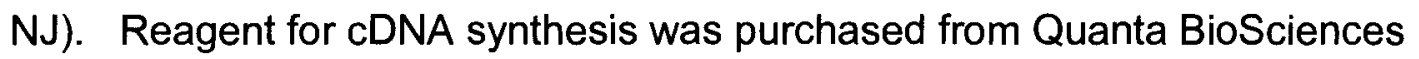


(Gaithersburg, MD). SYBR Green RT-PCR reagent was purchased from Applied Biosystems (Foster City, CA). HCV PCR primer was purchased from Alpha DNA (Montreal, Canada). All other PCR primers were purchased from Integrated DNA Technologies (Coralville, IA).

\section{Western Blot:}

Cytoplasmic and nuclear protein extracts were prepared according to Dignam ${ }^{23}$. For whole cell lysates, cells were washed twice with cold PBS and lysed with NETN buffer (150 mM NaCl, 1mM EDTA, 20 mM Tris-HCl pH 8.0, 10\% glycerol, $0.5 \%$ Nonidet $P-40,1 \times$ protease inhibitor cocktail, sodium vanadate). Extraction buffers were supplemented with $1 \mu \mathrm{M} \mathrm{TSA} / \mathrm{ml}$ for acetylation studies. Proteins were separated by SDS-PAGE and transferred to PVDF membranes. Membranes were incubated in the appropriate primary antibodies overnight with gentle agitation at $4^{\circ} \mathrm{C}$, washed with TBS-Tween, and incubated with the appropriate secondary antibodies for 1 hour. Proteins were visualized using ECL detection reagent as per the manufacturer's protocol. Pre-stained protein ladder was used to estimate the size of the transferred proteins.

Immunoprecipitation:

$5 \times 10^{6}$ hepatoma cells were untreated or treated with SAM metabolism inhibitors for 3 hrs, HDAC inhibitors for 24 hours, and/or IFNa for 30 minutes. Following treatment, cells were washed 2 times with cold PBS and proteins were extracted as for western blot. Protein concentration was determined using Bio-Rad protein 
assay per the manufacturer's protocol. Equivalent amounts of protein (250-500 $\mu \mathrm{g}$ protein/sample) were adjusted to a volume of $500 \mu \mathrm{l}$ in PBS and incubated with immunoprecipitation antibody overnight with gentle agitation at $4^{\circ} \mathrm{C}$. The following day, $20 \mu$ of protein A/G plus agarose beads was added for 3 hours with gentle agitation at $4^{\circ} \mathrm{C}$. The immunoprecipitates were washed 4 times with PBS and the beads were subsequently resuspended in $40 \mu$ of $3 x$ SDS-PAGE sample buffer, heated for 3 minutes at $95^{\circ} \mathrm{C}$, briefly centrifuged, and $30 \mu \mathrm{l}$ of sample was separated by SDS-PAGE and subjected to the Western blotting procedure.

\section{RT-PCR:}

Real-time polymerase chain reaction (RT-PCR) assays were used to assess 2'5' OAS and PKR mRNA levels in Huh7 cells and HCV RNA levels in HCVR cells. Total RNA was isolated from treated cells, after 2 hours (Huh7) or 24 hours (HCVR) of stimulation with IFNa, using TRIzol according to manufacturer's instructions. For real time PCR, the first strand cDNA was synthesized using 200 ng of total RNA and qScript cDNA SuperMix (Quanta BioSciences) according to manufacturer's protocol. The RT conditions were 5 minutes at $25^{\circ} \mathrm{C}, 30$ minutes at $42^{\circ} \mathrm{C}$ and 5 minutes at $85^{\circ} \mathrm{C}$. Reactions in which the RNA was omitted served as negative controls. Real time PCR was performed with an ABI prism 7500 sequence detection system using SYBR green I dye reagents. The specific primers were designed for human GAPDH, 2'5' OAS, PKR, ISG15, and HDACs 
1-10, as well as HCV, using Primer3 software program. The following primers were used in real-time PCR:

hGAPDH-RT-FP: 5' CTCTGCTCCTCCTGTTCGAC 3' hGAPDH-RT-RP: 5' TTAAAAGCAGCCCTGGTGAC 3' h 2'5'-OAS-RT-FP: 5' GCAGAAAGAGGGCGAGTTCT 3' h 2'5'-OAS-RT-RP: 5' CCTGGGCTGTGTTGAAATGT 3' hPKR-RT-FP: 5' CTTTGGCACCCAGATTTGAC 3' hPKR-RT-RP: 5' AAACTTGGCCAAATCCACCT 3' hISG15-RT-FP: 5' CCCACAGCCATGGGCT 3' hISG15-RT-RP: 5' CGATCTTCTGGGTGATCTGC 3' hHDAC1-RT-FP: 5' CATCTCCTCAGCATTGGCTT 3' hHDAC1-RT-RP: 5' GACGGGGATGTTGGAAATTA 3' hHDAC2-RT-FP: 5' CAGCAAGTTATGGGTCATGC 3' hHDAC2-RT-RP: : ' CCATGGCGTACAGTCAGGGA 3' hHDAC3-RT-FP: 5' GTTGTTCAGCTGGGTTGCTC 3' hHDAC3-RT-RP: 5' GAGAGTCAGCCCCACCAATA 3' hHDAC4-RT-FP: 5' AGGATTCAGCAGCTCCACTG 3' hHDAC4-RT-RP: 5' GAGCTCGTTGGAGCTATCGT 3' hHDAC5-RT-FP: 5' AGTGTGGGGTCCACAGAGC 3' hHDAC5-RT-RP: 5' ACTTCTCTGCACAGCATCCC 3' hHDAC6-RT-FP: 5' TCCAAGGCACATTGATGGTA 3' hHDAC6-RT-RP: 5' CACAGTTCACCTTCGACCAG 3' hHDAC7-RT-FP: 5' CACTGGTGCTTCAGCATGAC 3' 
hHDAC7-RT-RP: 5' GGCTCAGTCTTCCCCAGC 3'

hHDAC8-RT-FP: 5' CCAGCACATAATCAGGACCA 3'

hHDAC8-RT-RP: 5' ATTTTGGGAGGAGGAGGCTA 3'

hHDAC9-RT-FP: 5' CCTCTCACGGACAACAGGGT 3'

hHDAC9-RT-RP: 5' TGCACAGTATGATCAGCTCAG 3'

hHDAC10-RT-FP: 5' GGCTGGAGTGGCTGCTATAC 3'

hHDAC10-RT-RP: 5' CTGAGGGAGGAGACAGAAGC 3'

HCV-RT-FP: 5' ATGGCGTTAGTATGAGTGTC 3'

HCV-RT-RP: 5' GGCATTGAGCGGGTTGATC 3'

The relative gene expression was analyzed using $2^{-\Delta \Delta \mathrm{Ct}}$ method by normalizing with GAPDH gene expression in all experiments.

\section{Transfections:}

For siRNA transfections, Huh7 cells were plated in a 6 -well plate at $0.3 \times 10^{6}$ cells/well the day before transfection. On the day of transfection, cells were placed in serum- and additive-free DMEM prior to transfection. The siRNA transfection complex was prepared in sterile PBS using Fugene HD transfection reagent at the 3:2 ( $\mu$ l Fugene: $\mu \mathrm{g} \mathrm{DNA}$ ) ratio according to manufacturer's protocol and was allowed to incubate at room temperature for 15 minutes before dropwise addition to the appropriate wells, with swirling. After 6 hours, media was replaced with complete DMEM and transfection was continued for 48 hours (RNA) or 72 hours (protein) prior to stimulation with IFNa. After 48 hours, cells 
that were transfected for protein extraction were trypsinized, transferred to new 6-well plates, and allowed to incubate an additional 24 hours. For ISREluciferase transfections, Huh7 cells were plated at $7 \times 10^{6}$ cells in a T75 flask the day before transfection. On the day of transfection, transfection complex was made by adding $18 \mu$ l of Fugene HD and $6 \mu$ ISRE-luciferase cis-reporting plasmid (Sratagene, La Jolla, CA) to $562 \mu$ of serum-free DMEM containing pen/strep. Transfection complex was allowed to incubate at RT for 15 minutes before dropwise addition to the flask with swirling. The flask was incubated for 24 hours and cells were then replated in a 24 -well plate at $0.5 \times 10^{6}$ cells $/$ well. Cells were allowed to adhere for 2 hours before treatment.

\section{Luciferase Reporter Assay:}

For cell lysis and detection of luciferase activity, a commercial luciferase assay kit (Promega, Madison, WI) was used according manufacturer's protocol. Luciferase activity was quantified in an Orion luminometer and normalized to protein concentration.

Chromatin Immunoprecipitation (ChIP) Assay: Appropriately treated Huh7 or HCVR cells were fixed with $1 \%$ formaldehyde for 10 minutes at RT. To stop fixation, $1.25 \mathrm{M}$ glycine was added to a final concentration of $0.125 \mathrm{M}$ in media and allowed to incubate for 5 minutes at RT. Media was removed from cells and cells were washed twice with PBS containing 1x protease inhibitor cocktail (Sigma Aldrich) and $5 \mathrm{mM}$ sodium butyrate. 
Following the wash, PBS was drained from the cells and chromatin was digested using the SimpleChIP Enzymatic Chromatin IP Kit (Cell Signaling, Danvers, MA) according to manufacturer's protocol. Chromatin concentration was measured as DNA using Nanodrop and digestion of chromatin was analyzed using $6 \%$ acrylamide gel. For immunoprecipitation, $20 \mu \mathrm{g}$ of chromatin was diluted in ChIP dilution buffer and incubated with $10 \mu \mathrm{g}$ STAT1 antibody and $20 \mu \mathrm{l}$ protein A magnetic beads overnight at $4^{\circ} \mathrm{C}$ with rotation. The next day, the immunocomplexes were washed and crosslinking was reversed following manufacturer's protocol. After reversal of crosslinking, DNA was purified using the UltraClean DNA Purification Kit (MO BIO Laboratories, Carlsbad, CA) and subject to real-time PCR with specific primers for IRF-1 (SABiosciences, Frederick, MD). To determine changes in STAT1 occupancy at the IRF-1 promoter, data were normalized to input and compared to UT cells.

\section{HDAC Activity Assay:}

The Epigenase HDAC Activity/Inhibition Direct Assay Kit (Epigentek, Farmingdale, NY) was used according to manufacturer's protocol to measure HDAC activity in nuclear lysates.

\section{SAM and SAH Measurement by HPLC:}

Intracellular SAM and SAH levels were measured in deproteinized extracts as described previously (Song, Zhou et al. 2007). 


\section{Statistical Analysis:}

All data are presented as mean \pm standard deviation of the mean (SDM). The method of analysis used was one-way analysis of variance (ANOVA) with the Tukey-Kramer multiple-comparison test. Differences were considered statistically significant for $\mathrm{P} \leq 0.05$. 


\section{CHAPTER III}

\section{RESULTS}

\section{HISTONE DEACETYLASES AND INTERFERON-ALPHA SIGNALING}

Class I HDACs are required for IFNa-mediated antiviral signaling in human hepatoma cells.

The anti-HCV action of IFNa is due, in part, to its activation of antiviral genes such as PKR, OAS, and ISG15. To examine the possible role of HDACs in regulation of IFNa-mediated anti-HCV gene expression, a human hepatoma cell line stably transfected with an HCV replicon (HCVR cells) was pretreated for 30 minutes with two class I HDAC inhibitors (HDACi), TSA and SBHA, followed by stimulation with IFNa for 2 hours. Our data revealed that inhibition of class I HDACs significantly downregulated induction of the IFNa-stimulated antiviral genes. To confirm that this result was not an artifact of using a transfected cell line, we conducted the same experiment in the parental Huh7 cell line. As seen with HCVR, pretreatment of Huh7 cells with HDACi significantly inhibited IFNamediated induction of PKR, OAS, and ISG-15 (Fig. 4). 

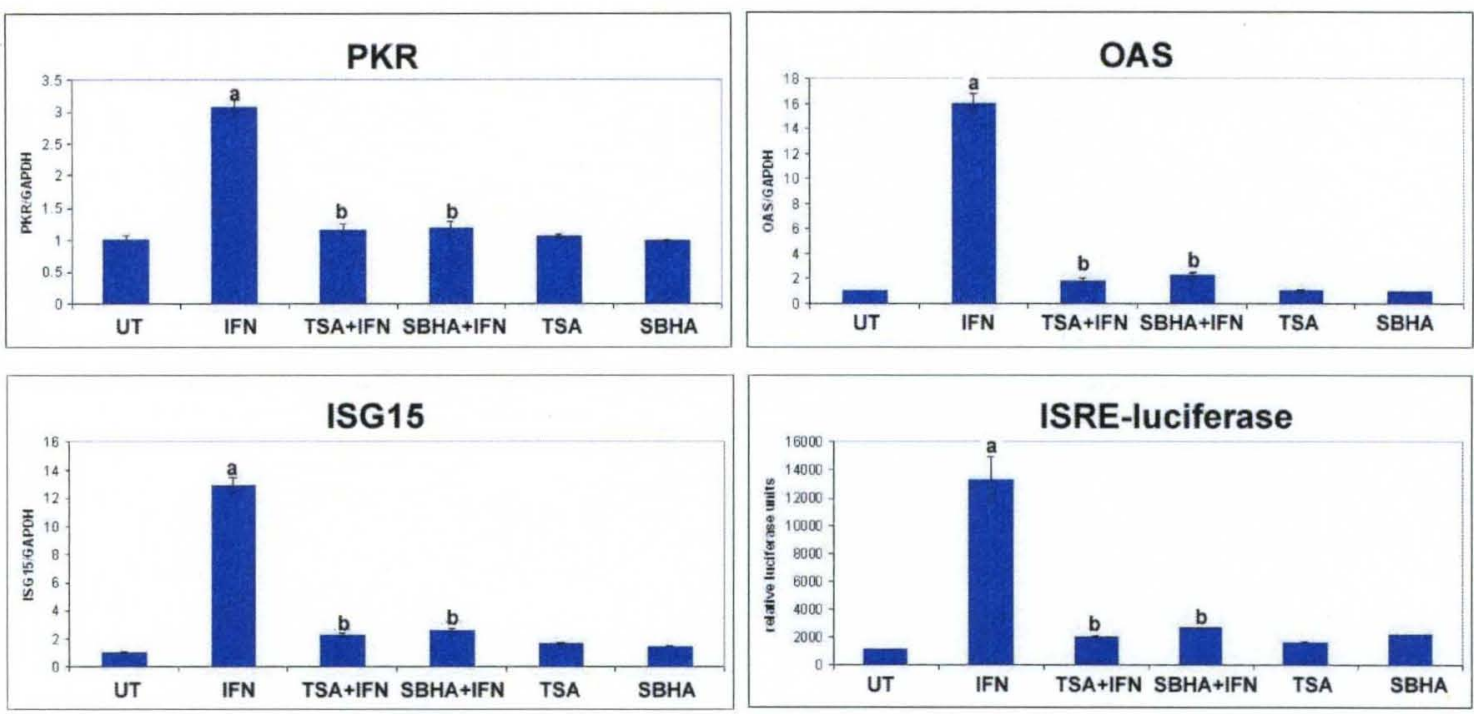

Figure 4: Class I HDACs are required for IFNa-mediated antiviral gene expression via the ISRE in human hepatoma cells. Human hepatoma cells treated for 2 hours with 100U/mI IFNa showed robust induction of the antiviral genes PKR, OAS, and ISG15, which was significantly reduced by pretreatment with TSA or SBHA. Pretreatment with TSA or SBHA also blocked IFNastimulated ISRE activation. Error bars indicate SDM ( N=3; $a=P \leq 0.05$ vs UT, $b=$ $P \leq 0.05$ vs (FN).

IFNa-mediated transcription of anti-HCV genes requires binding of the ISGF3 transcription complex to the ISRE, a cis-acting DNA sequence that is common in antiviral gene promoters ${ }^{38,42,63,100}$. To determine if HDACi-induced suppression of IFNa anti-HCV gene expression was due to impaired activation of the ISRE, we analyzed ISRE-driven luciferase activation in Huh7 cells. Briefly, cells were transiently transfected with an ISRE-luciferase reporter plasmid and reseeded into 24-well plates prior to treatment with HDACi for 30 minutes and stimulation 
with IFNa for 6 hours. Following stimulation, cells were lysed and equivalent amounts of lysates were measured for luciferase activity. Treatment with IFNa alone caused robust activation of the ISRE, which was markedly inhibited by pretreatment with $\mathrm{HDACi}$ (Fig. 4). These data suggest that the suppression of IFNa stimulated antiviral genes caused by HDACi is partially due to impaired transcriptional activation of ISRE in the promoters of the genes.

After evaluating the effects of $\mathrm{HDACi}$ on the host antiviral response, we were interested in the effect of HDAC inhibition on IFNa-mediated suppression of HCV RNA replication. Preliminary experiments revealed that $10 \mathrm{U} / \mathrm{ml}$ IFNa was sufficient to suppress HCV RNA induction by $50 \%$ after 24 hours of exposure. To determine how HDACs affect the anti-HCV action of IFNa, HCVR cells were pretreated for 30 minutes with HDACi prior to stimulation with $10 \mathrm{U} / \mathrm{ml}$ IFNa for 24 hours. Interestingly, cells that were pretreated with HDACi showed significant inhibition of IFNa-mediated suppression of HCV (Fig. 5). Taken together, these results show that HDACi significantly inhibited expression of IFNa-stimulated anti-HCV genes, which correlated to impaired activation of the ISRE and an increase in HCV RNA induction. These data suggest a critical role for class I HDACs in the regulation of IFNa-mediated anti-HCV activity. Importantly, these data are comparable to data from other published reports that show a need for HDACs in activation of inducible gene systems ${ }^{41,124}$. 


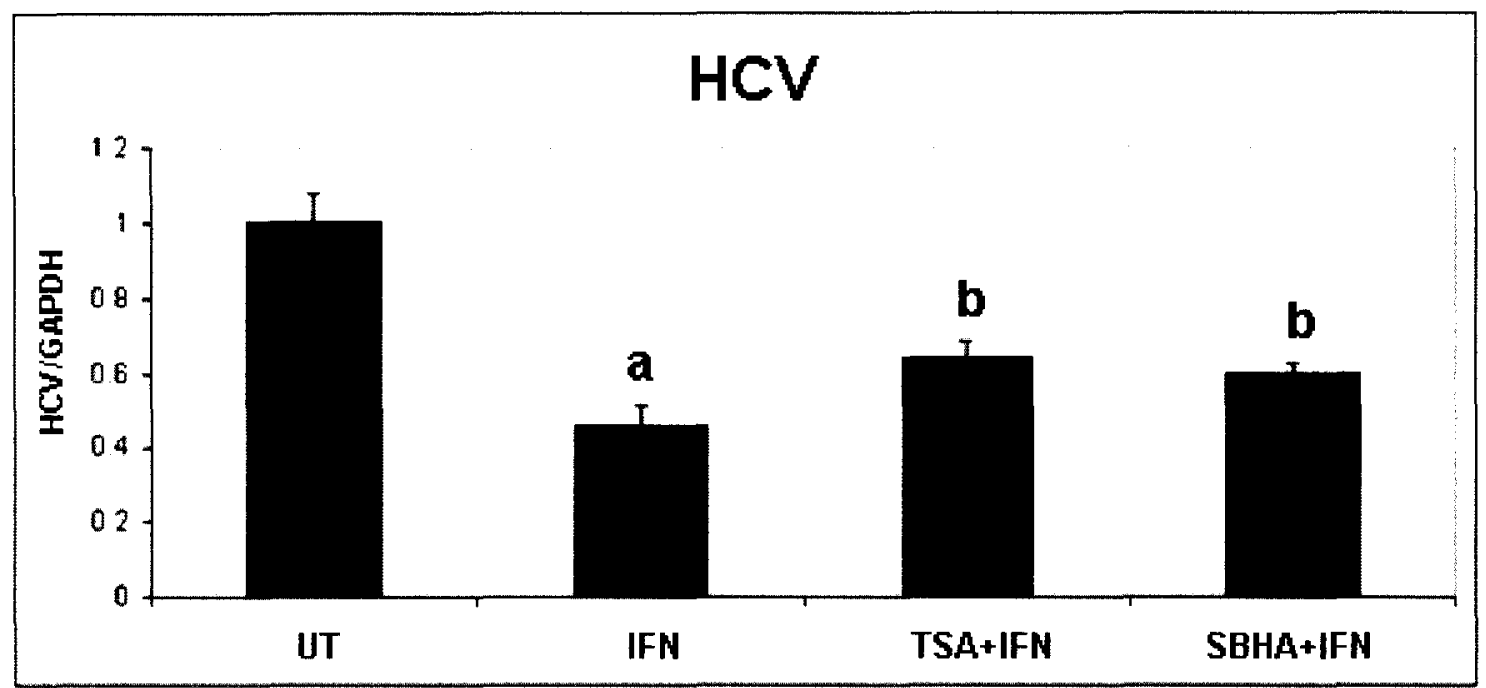

Figure 5: Class I HDACs are required for IFNa-mediated anti-HCV activity. IFNa suppressed HCV RNA induction by $50 \%$ in HCVR cells, which was partially reversed by pretreatment with $T S A$ or $S B H A$. Error bars indicate $S D M(N=3$; a = $P \leq 0.05$ vs UT, $b=P \leq 0.05$ vs (FN).

Class I HDACs are required for IFNa-mediated antiviral signaling in primary human hepatocytes.

Huh7 cells are a well established model system for studying human hepatocytes but consideration must be given to the fact they are cultured hepatoma cells and may not exhibit the same response as primary human hepatocytes. To address this issue, we analyzed the effects of HDACi on IFNa-mediated antiviral gene expression in commercially available primary human hepatocytes. The primary hepatocytes were stimulated for 3 hours with $1000 \mathrm{U} / \mathrm{ml}$ IFNa alone or after exposure to HDACi for 30 minutes. Total RNA was extracted and RT-PCR was used to analyze mRNA induction of the antiviral genes PKR, OAS, and ISG15. IFNa alone led to a 3- to 15-fold induction of all antiviral genes, which was 
significantly inhibited by pretreatment with HDACi (Fig. 6). These results agree with our data from the hepatoma cell lines and confirm the requirement of class I HDACs in IFNa-mediated antiviral gene expression in human hepatocytes.
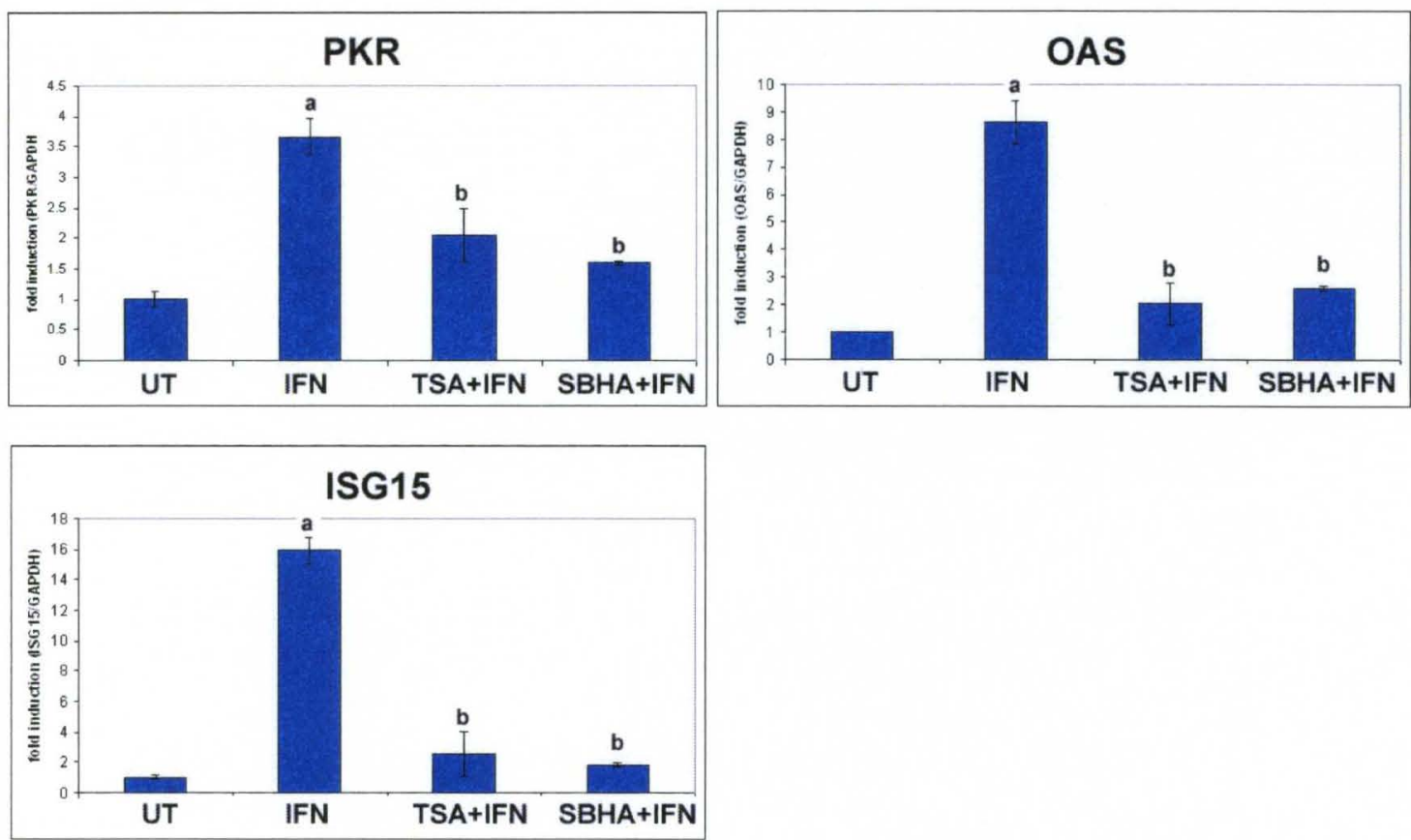

Figure 6: Class I HDACs are required for IFNa-mediated antiviral gene expression in primary human hepatocytes. Primary human hepatocytes treated for 3 hours with 1000U/mI IFNa showed robust induction of the antiviral genes PKR, OAS, and ISG15, which was significantly reduced by pretreatment with TSA or SBHA. Error bars indicate $S D M(N=3 ; a=P \leq 0.05$ vs UT, $b=P \leq 0.05$ vs IFN). 


\section{Class I HDACs are required for retention of pSTAT1 in the nucleus of human hepatoma cells.}

The antiviral action of IFNa is mediated through activation of the JAK/STAT pathway. Critical steps in this pathway include the phosphorylation and nuclear import of STAT1. IFNa treatment leads to phosphorylation of STAT1 on Y701 and S727, which is required for nuclear translocation and transcriptional activity, respectively ${ }^{38,100,121,127}$. To determine if HDACs play a role in JAKISTAT signaling, human hepatoma cells were pretreated with HDACi for 30 minutes prior to stimulation with IFNa for various time points. Nuclear and cytoplasmic proteins were analyzed by Western blot for PSTAT1 protein expression. $\mathrm{HDACi}$ did not inhibit phosphorylation of STAT1, however, compared to cells stimulated with IFNa alone, there was an obvious difference in partitioning of pSTAT1. Expression of pSTAT1 (Y701 and S727) in cells exposed to only IFNa was mostly localized to the nucleus whereas pretreatment with HDACi led to cytoplasmic accumulation of pSTAT1. The partitioning of pSTAT1 was evident as early as 15 minutes after exposure to IFNa and could still be seen after 60 minutes. Here, we show the partitioning 45 minutes after exposure to IFNa (Fig. 7). Blots were also probed with total STAT1 and showed equal loading between samples except total STAT levels were markedly less in cytoplasmic lysates that received IFNa. To ensure our result was not due to uneven loading of our protein samples, blots were probed with $\beta$-actin or histone $\mathrm{H} 3$ to confirm equal loading in the cytoplasmic and nuclear extracts, respectively (Fig. 7, bottom 
panel). These data reveal of role for HDACs in the nuclear retention of activated STATs during IFNa signaling.

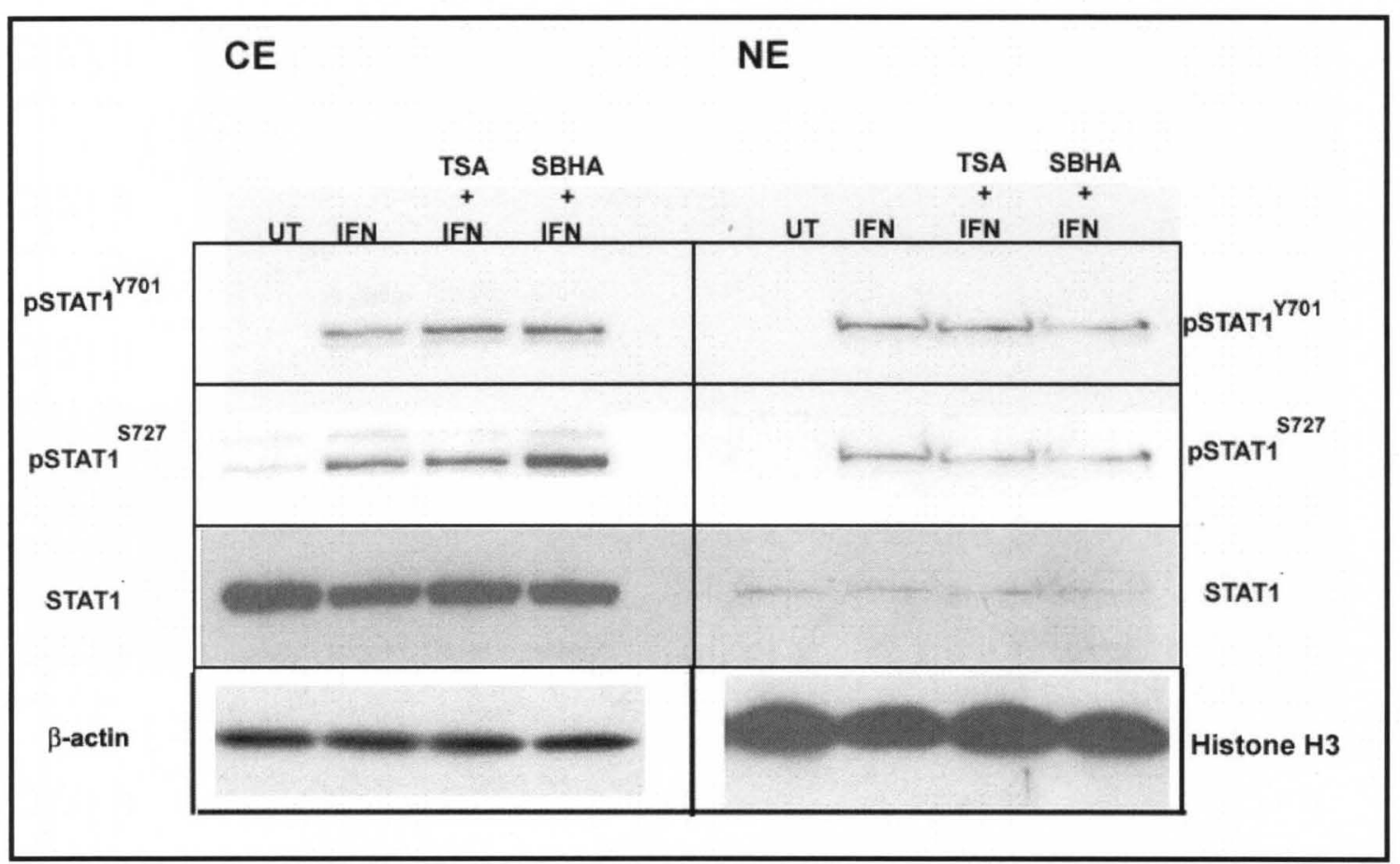

Figure 7: Class I HDACs are required for retention of pSTAT1 in the nucleus of human hepatoma cells. Cytoplasmic (CE) and nuclear (NE) protein extracts were collected from Huh7 cells stimulated with IFNa alone, or after pretreatment with TSA or SBHA, and analyzed by Western blot.

Pretreatment with HDACi decreased retention of pSTAT1 in the nucleus, which correlated with accumulation of pSTAT1 in the cytoplasm, compared to cells stimulated with IFN $\alpha$ alone. $\quad \beta$-actin and histone $\mathrm{H} 3$ antibodies were used to confirm equal loading of proteins between cytoplasmic and nuclear samples, respectively. 
Inhibition of HDACs decreases the association between HDAC1 and STAT1 in the nucleus of human hepatoma cells and correlates with increased STAT1 acetylation.

It has been established that STAT1 can be acetylated in the nucleus, due to binding with HATs such as CBP, which will lead to its translocation back out to the cytoplasm ${ }^{58,61,62}$. Since the acetylation status is due, in part, to a balance between the activities of HATs and HDACs, we determined: 1) STAT1 interaction with HDACs in the nucleus; and 2) STAT1 acetylation status in response to inhibition of HDACs. Using nuclear extracts from Huh7 cells treated with IFNa alone or after HDACi pretreatment, we performed immunoprecipitations with an antibody against STAT1 and probed the nuclear STAT1 proteins by Western blot for association with HDACs. In cells stimulated with IFNa alone, there was a marked increase in association between STAT1 and HDAC1, which was blocked by pretreatment with HDACi (Fig. 8, top). Next, we determined whether or not HDACi-induced dissociation of the IFNastimulated STAT1:HDAC1 complex correlated to an increase in acetylation of STAT1. Nuclear lysates were immunoprecipitated with an acetylated-lysine antibody and probed for STAT1 by Western blot. The impaired association between STAT1 and HDAC1, caused by HDACi pretreatment, correlated with an increase in STAT1 acetylation not seen in cells that only received IFNa (Fig. 8, bottom). These results suggest HDACs play a role in regulation of IFNamediated antiviral gene expression by binding STAT proteins to keep them 
deacetylated, thereby enhancing their retention in the nucleus and allowing for active transcription.

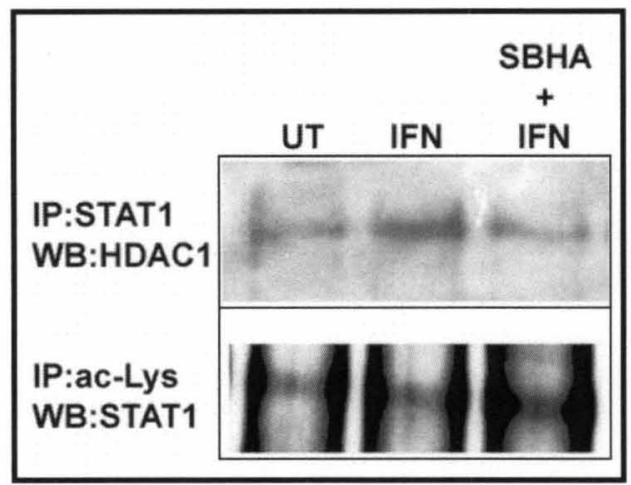

Figure 8: Class I HDACs are required for IFNa-mediated STAT1:HDAC1 association and to prevent acetylation of STAT1 in the nucleus of human hepatoma cells. (Top) Pretreatment with SBHA inhibited IFNa-stimulated formation of STAT1:HDAC1 complex in the nucleus of Huh7 cells. (Bottom) Pretreatment with SBHA enhanced acetylation of STAT1 and correlated with inhibition of the IFNa-stimulated STAT1:HDAC1 complex.

Class I HDACs are required for IFNa-mediated antiviral PKR and ISG15 protein expression and suppression of viral NS5A protein expression. RT-PCR data showed that HDACi caused significant inhibition of IFNa-mediated host antiviral mRNA induction and suppression of HCV RNA, hence we wanted to verify that these results correlated to suppression of host antiviral proteins and viral proteins. We performed Western blots using whole cell lysates from HCVR 
cells that were stimulated for 24 hours with IFNa alone and after 30 minute pretreatment with HDACi. Using antibodies for the antiviral PKR and ISG15 proteins and the viral NS5A protein, we found that HDACi blocked both IFNastimulated antiviral protein expression and IFNa-mediated suppression of NS5A (Fig. 9). These results are consistent with our PCR data and further support the hypothesis that HDACs play a critical role in the anti-HCV actions of IFNa.

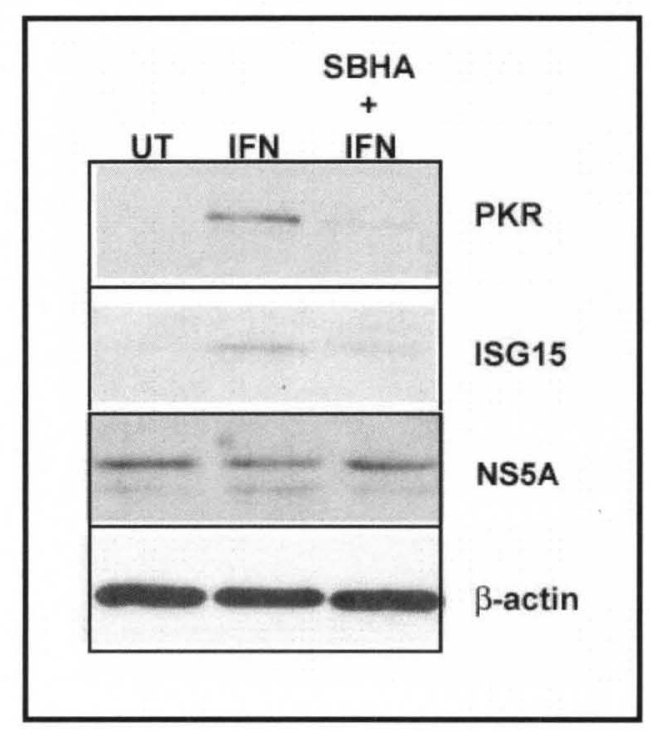

Figure 9: Class I HDACs are required for IFNa-mediated expression of the antiviral proteins PKR and ISG15 and suppression of viral NS5A protein in human hepatoma cells. Western blot analysis of whole cell lysates from IFNastimulated HCVR cells revealed an increase in antiviral PKR and ISG15 protein expression, which correlated with a decrease in viral NS5A protein expression. Pretreatment with SBHA inhibited IFNa-mediated antiviral protein expression and suppression of NS5A. $\beta$-actin antibody was used to confirm equal loading of protein between samples. 


\section{Class I HDACs are required for association of STAT1 with the IRF-1}

promoter.

The results presented thus far clearly show that class I HDACs play an important role in IFNa-stimulated activation of the JAK/STAT signaling cascade, host antiviral gene induction and protein expression, and IFNa-mediated suppression of HCV RNA and NS5A protein. Since HDACs also modify chromatin, we wanted to determine if inhibition of HDACs modified the epigenetic landscape at the promoter of the IFNa stimulated gene IRF-1 (interferon response factor 1). We performed chromatin immunoprecipitation (ChIP) analysis using an antibody for STAT1 and primers specific for the IRF-1 promoter. Briefly, appropriately treated HCVR cells were fixed with formaldehyde to crosslink proteins to DNA, nuclei were isolated and subjected to enzymatic digestion to cleave chromatin, and the digested chromatin was incubated with primary STAT1 antibody and magnetic beads. Following incubation, the immunocomplexes were washed, crosslinking was reversed, and DNA was purified prior to analysis by RT-PCR. As seen in Figure 10, HDACi pretreatment significantly decreased the association of STAT1 with the IRF-1 promoter. This result correlated with the significant downregulation of IFNa-stimulated antiviral genes seen previously as STAT1 is part of the ISGF3 transcription complex that must be bound to the promoter for active transcription of those genes. Taken together, our results show that class I HDACs are essential for IFNa-mediated activation of the JAK/STAT signaling cascade, association of transcription factors with the promoters of ISGs, and IFNa-mediated suppression of HCV. 


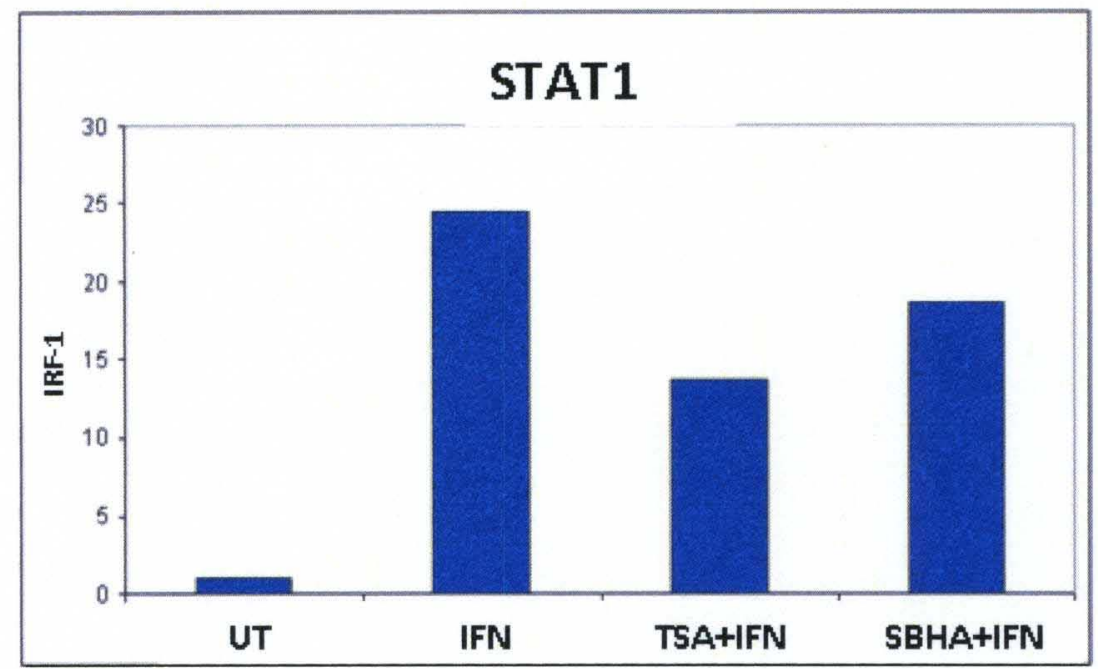

Figure 10: Class I HDACs are required for association of STAT1 with the IRF-1 promoter in human hepatoma cells. Chromatin was isolated from HCVR cells stimulated with IFNa alone, or after pretreatment with TSA or SBHA, and STAT1 occupancy at the IRF-1 promoter was analyzed by ChIP assay. HDACi pretreatment decreased the IFNa-stimulated association of STAT1 with the IRF-1 promoter. Result is representative of 2 independent experiments.

HDACs 1 and 3 are required for IFNa-mediated antiviral gene expression in human hepatocytes.

Since the pharmacologic HDAC inhibitors SBHA and TSA block the activity of all class I HDACs, we used siRNA to determine if any or all of the class I HDACs were necessary for IFNa-mediated anti-HCV gene expression. Huh7 were plated at a density of $0.3 \times 10^{6}$ cells/well and transfected for 72 hours with siRNA specific for HDACs 1, 2, 3, or 8. Cells were transfected with a nonspecific 
scramble siRNA to serve as a negative control. Following transfection, total RNA and protein extracts were collected and used to verify knockdown of the respective HDAC mRNAs and proteins (Fig. 11).

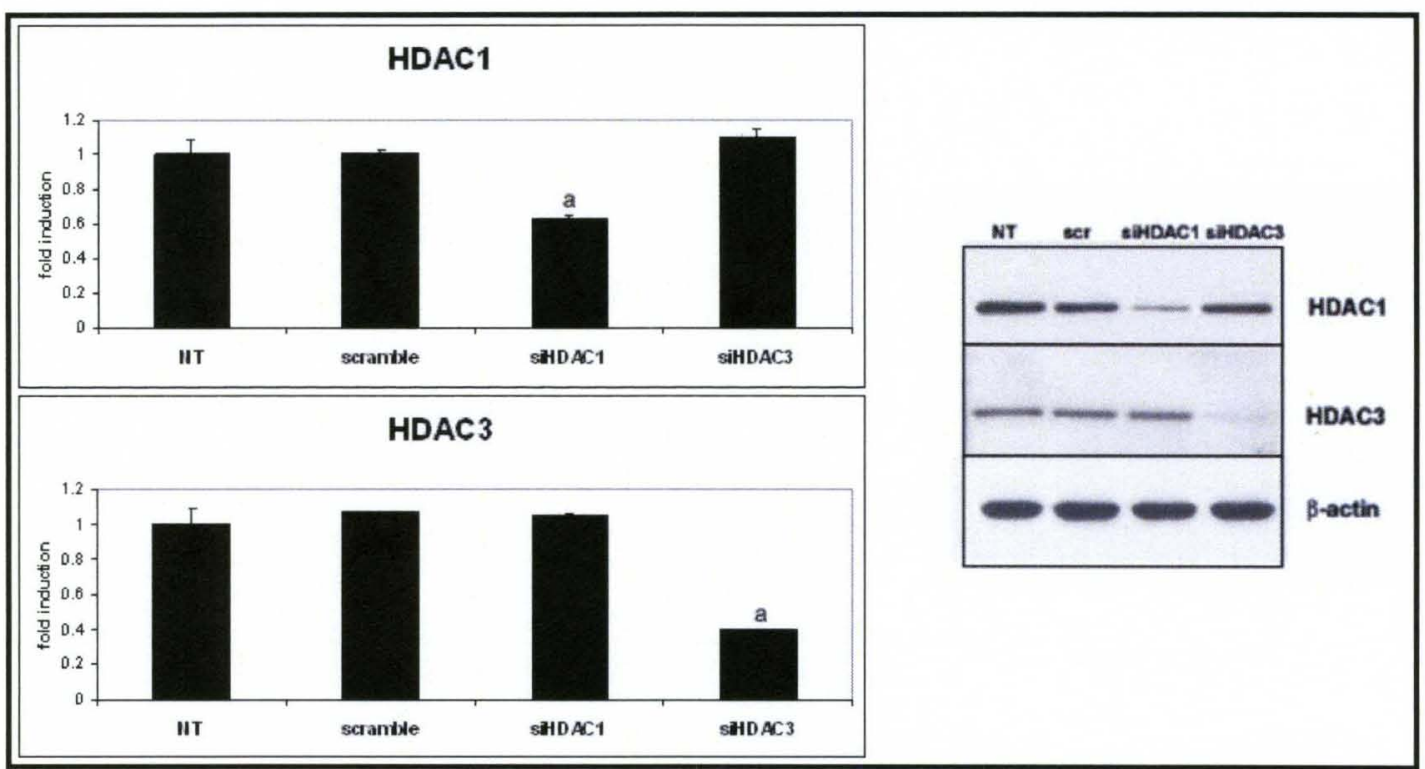

Figure 11: Silencing of HDACs in human hepatoma cells. Human hepatoma cells were transfected with siRNA specific for HDACs 1 and 3 for 72 hours (RNA) or 96 hours (protein), following the manufacturer's protocol. As negative controls, cells were either treated with transfection reagent alone (NT) or nonspecific scramble siRNA (scr). (Left) Real-time PCR showed specific knockdown of HDAC1 and HDAC3 mRNA induction by siHDAC1 and siHDAC3, respectively. Error bars indicate $S D M(N=3 ; a=P \leq 0.05$ vs NT).

(Right) Western blot analysis of whole cell protein lysates revealed that siHDAC1 and siHDAC3 specifically suppressed expression of HDAC1 and HDAC3 proteins, respectively. $\beta$-actin antibody was used to verify equal loading between protein samples. 
Once the specific knockdown of each HDAC was confirmed, the transfections were repeated and cells were stimulated with IFN $\alpha$ to determine the specific class I HDAC(s) that are critical for IFNa-mediated antiviral gene induction and protein expression. We found HDACs 1 and 3 to be critical for IFNa-mediated antiviral genes as silencing of those HDACs led to a partial, yet significant, decrease in IFNa-mediated induction of PKR, OAS, and ISG15 (Fig. 12). Silencing of HDACs 2 and 8 had no effect on induction of those antiviral genes.

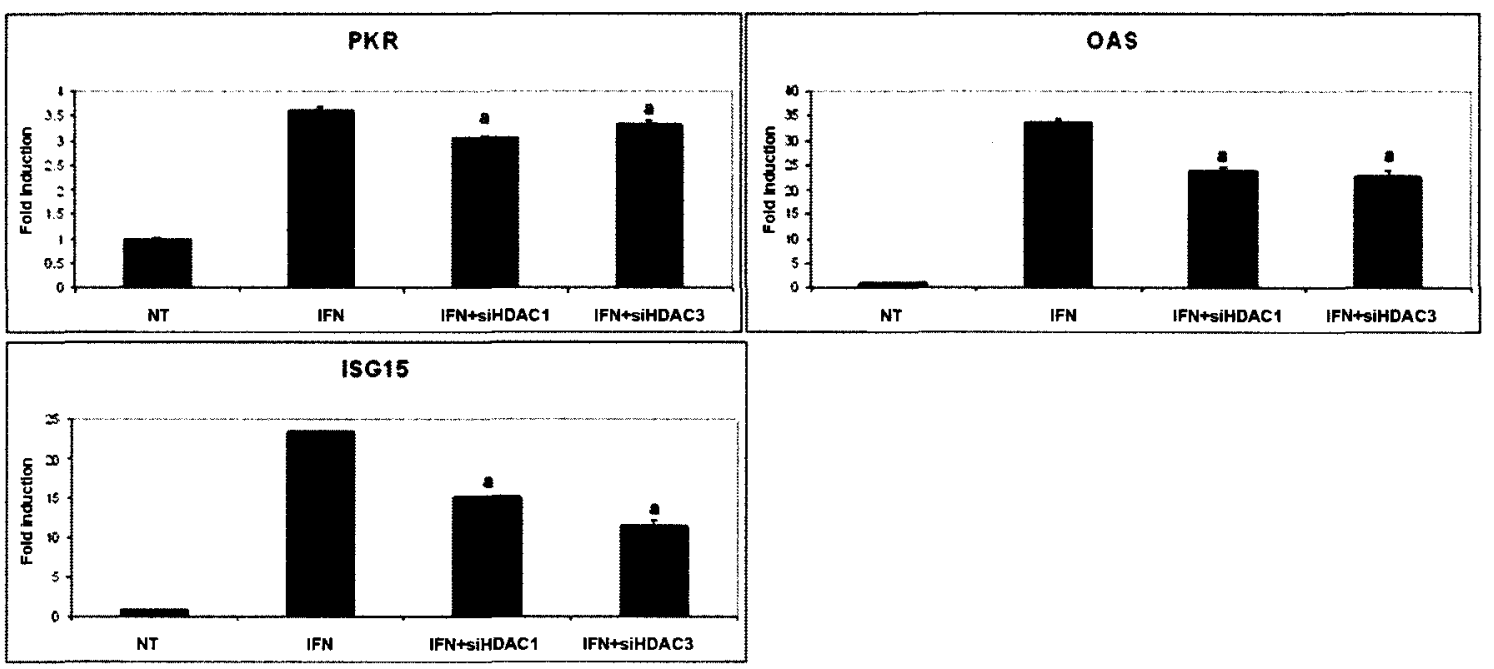

Figure 12: HDAC1 and HDAC3 are required for IFNa-mediated antiviral gene expression in human hepatoma cells. Human hepatoma cells were transfected with siRNA specific for HDAC1 or HDAC3 for 72 hours prior to stimulation with 100U/mI IFNa for 2 hours. Nontransfected (NT) cells were treated with transfection reagent alone and served as the negative control. Realtime PCR analysis showed transfection with siHDAC1 or siHDAC3 caused partial, but significant, inhibition of IFNa-stimulated induction of PKR, OAS, and ISG15. Error bars indicate $S D M(N=3 ; a=P \leq 0.05$ vs IFN). 
After identifying HDACs 1 and 3 as being critical for IFNa-mediated antiviral gene induction, we wanted to determine if silencing of these HDACs affected the STAT1:HDAC1 association and/or expression of the antiviral protein, PKR. Using whole cell lysates from siRNA transfected cells, we performed an immunoprecipitation using STAT1 antibody and looked for HDAC1 by western blot. As expected, cells that did not express HDAC1 did not show a STAT1:HDAC1 association. Interestingly, silencing of HDAC3 also inhibited the STAT1:HDAC1 association (Fig. 13). Finally, silencing of both HDAC 1 and 3 decreased expression of the antiviral protein PKR (Fig. 13). These results support the previous data using pharmacologic class I HDAC inhibitors and specifically identify HDACs 1 and 3 as being critical for induction of IFNamediated anti-HCV gene expression. 


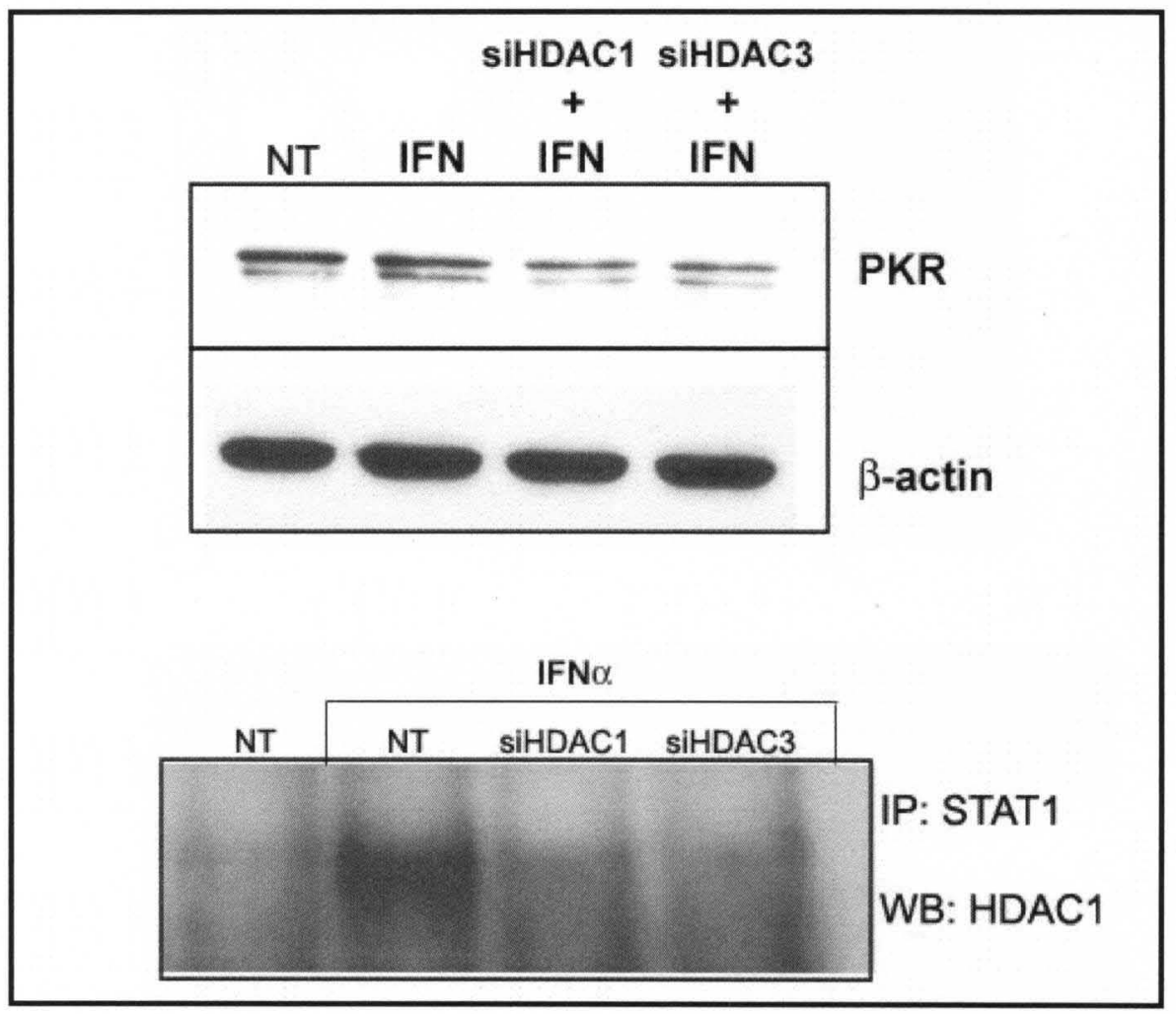

Figure 13: HDAC1 and HDAC3 are required for IFNa-mediated PKR protein expression and IFNa-mediated STAT1:HDAC1 association in human hepatoma cells. Huh7 cells were transfected with siRNA specific for HDAC1 or HDAC3 for 96 hours prior to stimulation with 1000U/mI IFNa for 1 hour. Nontransfected (NT) cells received transfection reagent alone and served as negative control. (Top) Western blot analysis showed that siHDAC1 and siHDAC3 suppressed IFNo-stimulated PKR protein expression. $\beta$-actin antibody was used to ensure equal loading of protein between samples. (Bottom) siHDAC1 and siHDAC3 inhibited IFNa-induced STAT1:HDAC1 complex formation in whole cell protein lysates. 
Theophylline boosts HDAC1 gene induction and improves IFNa-mediated anti-HCV gene induction and activity.

After confirming the requirement for HDACs in the regulation of IFNa-mediated anti-HCV activity, we wanted to determine if boosting HDACs could improve the antiviral actions of IFNa. Recent reports implicate theophylline in boosting HDAC activity and modifying inducible signaling pathways ${ }^{22,53,128}$. To elucidate the role of theophylline in IFNa-mediated anti-HCV activity, HCVR cells were treated for 48 hours with increasing doses of theophylline prior to stimulation with IFNa for 24 hours. Total RNA was extracted and used to analyze PKR mRNA induction and HCV RNA by RT-PCR. As seen in Figure 14, theophylline boosted IFNamediated PKR mRNA induction and enhanced its anti-HCV action. Importantly, theophylline alone induced PKR and HDAC1 mRNA and suppressed HCV. These data provide additional support to the hypothesis that HDACs are critical for the antiviral actions of IFNa and suggest a role for theophylline, or other inducers of HDACs, in the management of HCV by the current treatment regimen. 

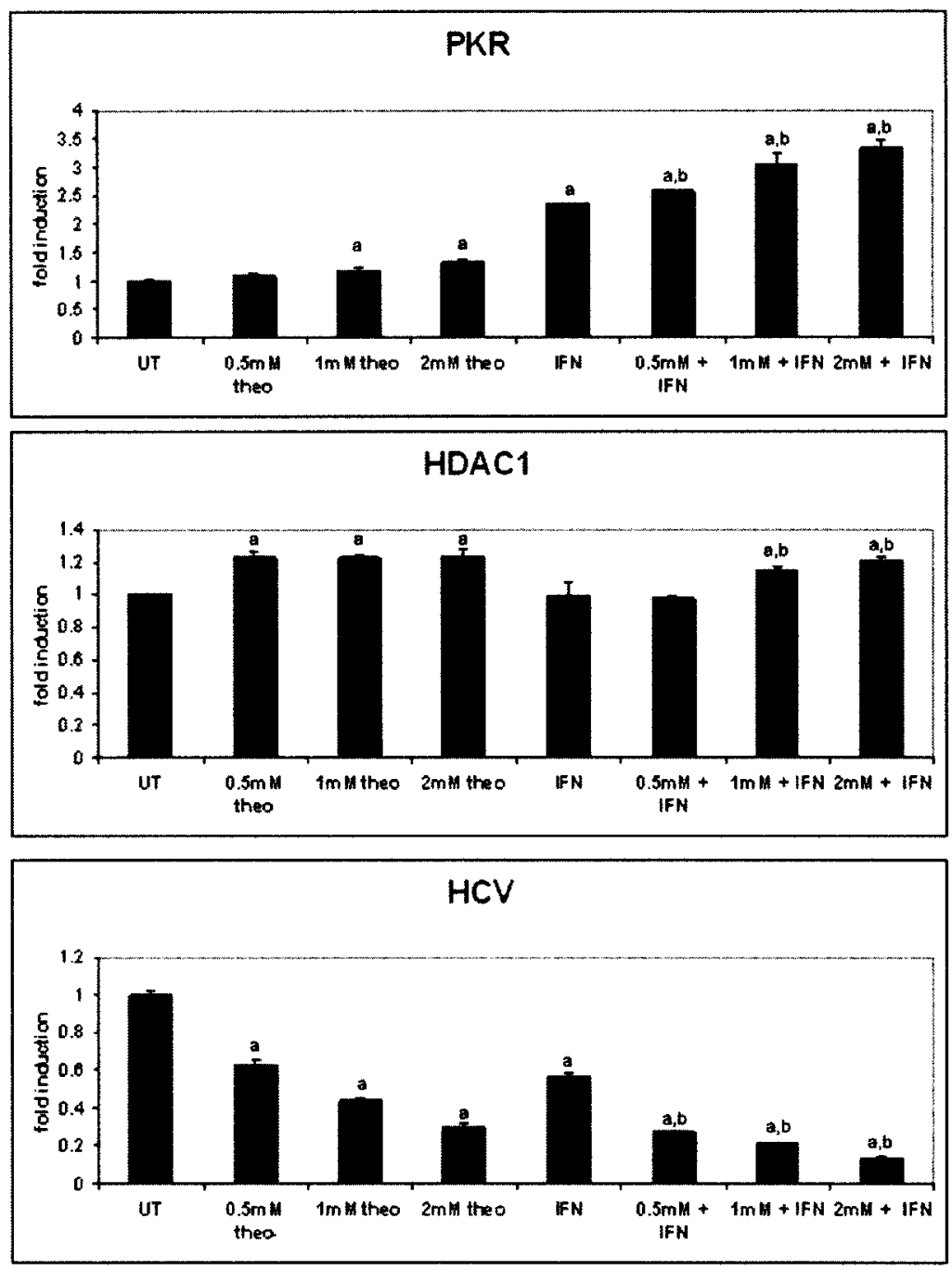

Figure 14: Theophylline enhances IFNa-mediated PKR mRNA induction and anti-HCV activity and boosts HDAC1 mRNA induction in human hepatoma cells. Theophylline pretreatment enhanced IFNa-stimulated PKR mRNA induction and suppression of HCV RNA. Theophylline alone significantly induced PKR and HDAC1 mRNA induction and suppressed HCV RNA. Error bars indicate $\operatorname{SDM}(N=3 ; a=P \leq 0.05$ vs $U T, b=P \leq 0.05$ vs IFN). 


\section{Summary of data:}

* Pharmacological inhibition of Class I HDACs showed that HDACs are required:

- for IFNa-mediated antiviral gene expression and anti-HCV activity

- for retention of pSTAT1 in the nucleus

- for STAT1:HDAC1 association in the nucleus

- to prevent acetylation of STAT1

* Studies with siRNA identified HDACs 1 and 3 as being critical for IFNamediated antiviral activity.

* Theophylline boosted HDAC1 mRNA induction and enhanced IFNamediated antiviral gene induction and anti-HCV activity. 


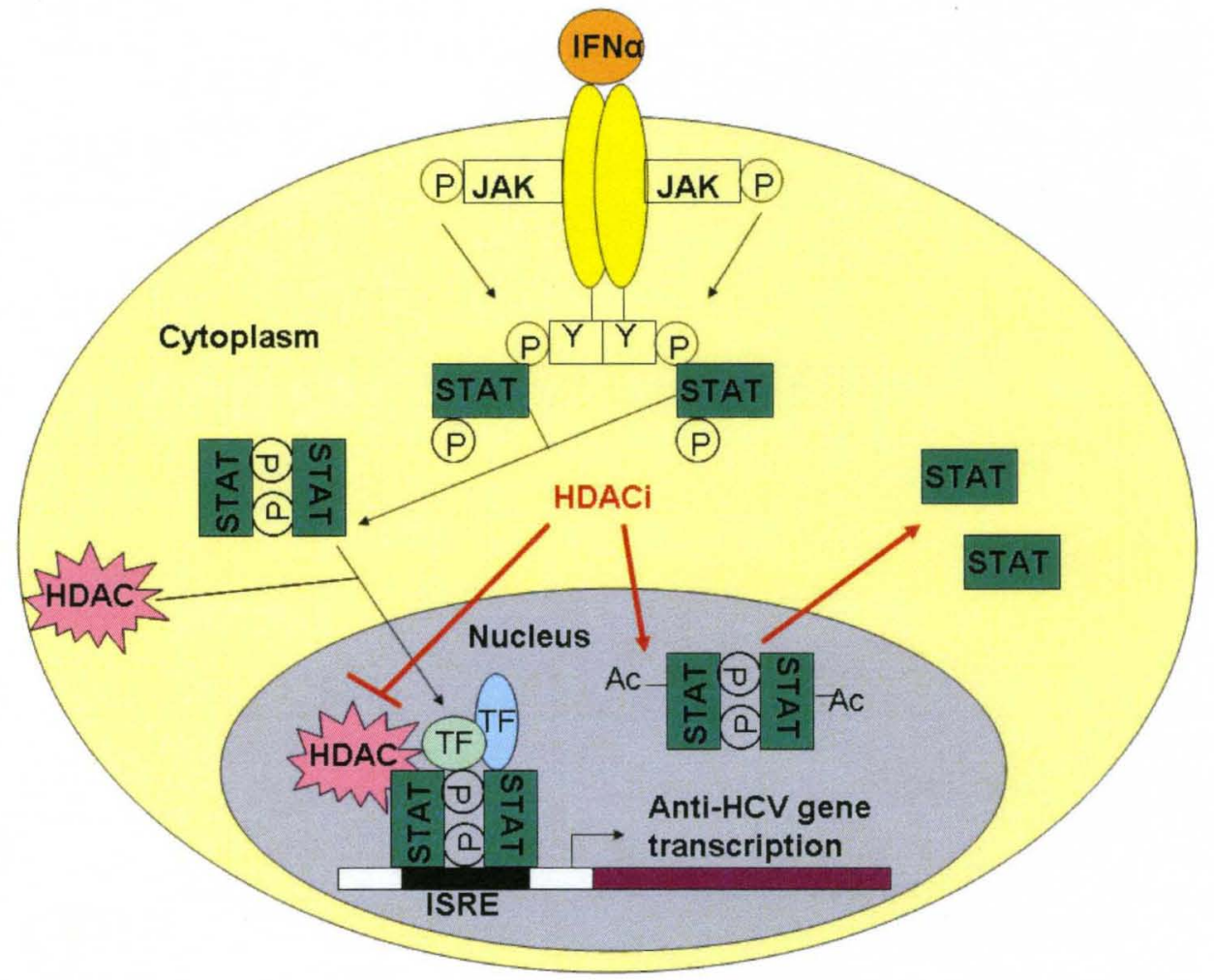

Figure 15: Schematic representation of the role of HDACs in IFNamediated anti-HCV gene expression in hepatocytes. 


\section{IMPAIRED SAM METABOLISM AND INTERFERON-ALPHA SIGNALING}

Impaired SAM metabolism decreases methylation potential in human hepatoma cells.

SAM serves as the major methyl donor in transmethylation reactions and is converted to SAH after transfer of its methyl group. SAH, a potent inhibitor of methyltransferases, is rapidly broken down to homocysteine and adenosine by the enzyme SAHH, which is critical for removal of SAH and maintaining the SAM:SAH ratio (methylation potential). The reaction catalyzed by SAHH is reversible and the equilibrium favors the formation of $\mathrm{SAH}$, but rapid cellular uptake of adenosine and homocysteine drives the reaction in the other direction ${ }^{6}$, $14,47,80$ (Fig. 2). We used the pharmacological SAHH inhibitors AD and DZA, as well as equimolar amounts of adenosine plus homocysteine (AdenHcy), to increase intracellular SAH and decrease methylation potential in human hepatoma cells. Cells were treated with these SAM metabolism disruptors for 3 hours and deproteinized extracts were analyzed by HPLC. All the SAM metabolism disruptors induced an increase in intracellular SAH and this correlated to a decrease in SAM:SAH, or in methylation potential. These results clearly showed that AD, DZA, and AdenHcy are useful tools for decreasing methylation potential and supported the use of these SAM metabolism disruptors for studying the effects of impaired transmethylation on IFNa-mediated anti-HCV gene expression. 
Impaired SAM metabolism blocks IFNa-inducible antiviral gene expression in human hepatoma cells.

Decreased methylation potential, due to increased SAH and impaired SAM metabolism, has been documented in persons with chronic liver disease ${ }^{5,6,69}$. To determine how impaired SAM metabolism affects IFNa anti-HCV signaling, we used an Huh7 cell line stably transfected with an HCV replicon (HCVR cells). Preliminary experiments revealed that $10 \mathrm{U} / \mathrm{ml}$ IFNa was sufficient to suppress HCV RNA induction by $50 \%$ after 24 hours of exposure. To analyze the effects of impaired SAM metabolism on the anti-HCV action of IFNa, HCVR cells were pretreated with SAM metabolism disruptors for 3 hours prior to stimulation with $10 \mathrm{U} / \mathrm{ml}$ IFNa for 24 hours. Cells treated with IFNa alone showed a $50 \%$ suppression of HCV RNA, which was significantly reversed by pretreatment with SAM metabolism disruptors. AD partially reversed the action of IFNa, resulting in $40 \%$ suppression of $\mathrm{HCV}$, while AdenHcy and DZA completely blocked IFNamediated anti-HCV activity. Importantly, DZA and AdenHcy treatment alone led to increased HCV RNA induction (Fig. 14). These data clearly show that impaired SAM metabolism, induced by either SAHH inhibition or exogenous AdenHcy supplementation, decreased the anti-HCV activity of IFNa. Importantly, DZA and AdenHcy alone led to an increase in HCV RNA replication, which suggest that the HCV promoter may be under methylation control. 


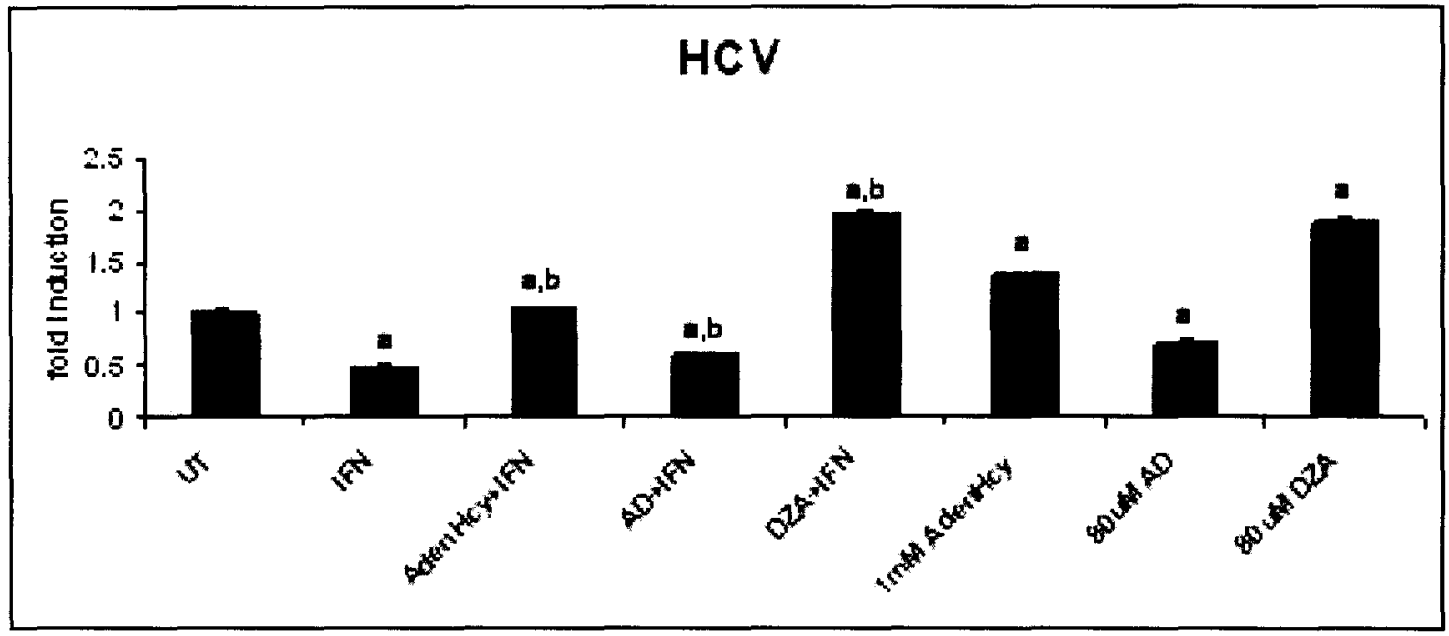

Figure 16: Impaired SAM metabolism inhibits IFNa anti-HCV activity in human hepatoma cells. SAM metabolism disruptors (AdenHcy, AD, and DZA) significantly reversed IFNa-mediated suppression of HCV RNA. AdenHcy and DZA treatment alone enhanced HCV RNA induction. Error bars indicate SDM $(N=3 ; a=P \leq 0.05$ vs $U T, b=P \leq 0.05$ vs IFN $)$.

Next, we wanted to determine if the blockade of IFNa anti-HCV activity caused by SAM metabolism disruptors would correlate with reduced induction of IFNastimulated antiviral genes PKR, OAS, and ISG15. IFNa led to marked induction of all the antiviral genes, which was significantly reduced by pretreatment with SAM metabolism disruptors. To confirm that these results were not an artifact of using a transfected cell line, we conducted the same experiments in the parental Huh7 cell line. Similar to the results obtained in HCVR, pretreatment of Huh7 cells with SAM metabolism disruptors inhibited IFNa-mediated induction of PKR, OAS, and ISG15 (Fig. 17). Taken together, these results clearly demonstrate 
the role of SAM metabolism for the anti-HCV action of IFNa in human hepatoma cells.
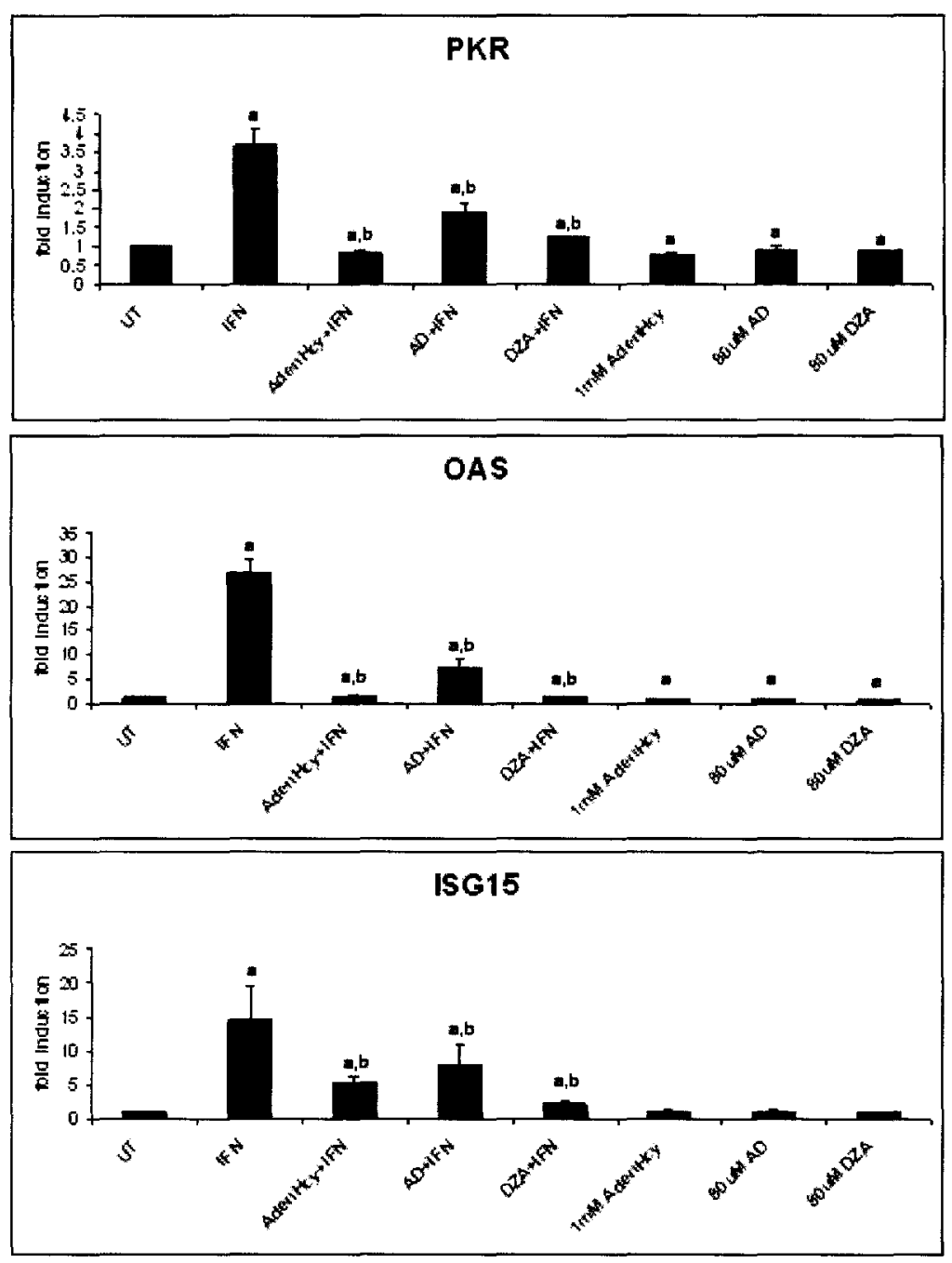

Figure 17: Impaired SAM metabolism inhibits IFNa-mediated antiviral gene induction and anti-HCV activity in human hepatoma cells. SAM metabolism disruptors (AdenHcy, $A D$, and DZA) significantly reduced IFNa-mediated antiviral gene induction. Error bars indicate $S D M(N=3 ; a=P \leq 0.05$ vs $U T, b=P \leq 0.05$ vs IFN). 
Impaired SAM metabolism blocks IFNa-induced activation of the ISRE in antiviral gene promoters.

Transcription of IFNa-stimulated antiviral genes is dependent on activation of the ISRE found in their promoters. Based on our data showing that SAM metabolism disruptors significantly inhibited IFNa-mediated antiviral gene induction and antiHCV activity, we hypothesized that impaired SAM metabolism may also block activation of the ISRE. Human hepatoma cells were transiently transfected in a large batch with an ISRE-luciferase reporter construct. Following transfection, cells were reseeded into 24-well plates and treated for 6 hours with IFNa alone, or stimulated with IFNa after 3 hour pretreatment with SAM metabolism disruptors. As expected, treatment with IFNa alone led to robust activation of the ISRE-luciferase reporter and pretreatment with SAM metabolism disruptors led to almost a complete attenuation of activation (Fig. 18). Previously data from our lab showed that treatment with $A D$ inhibited binding of transcription factors to the ISRE in electrophoretic mobility shift assays. Taken together, these data support the idea that maintaining proper SAM metabolism is critical for activation of IFNastimulated antiviral genes via ISRE. 


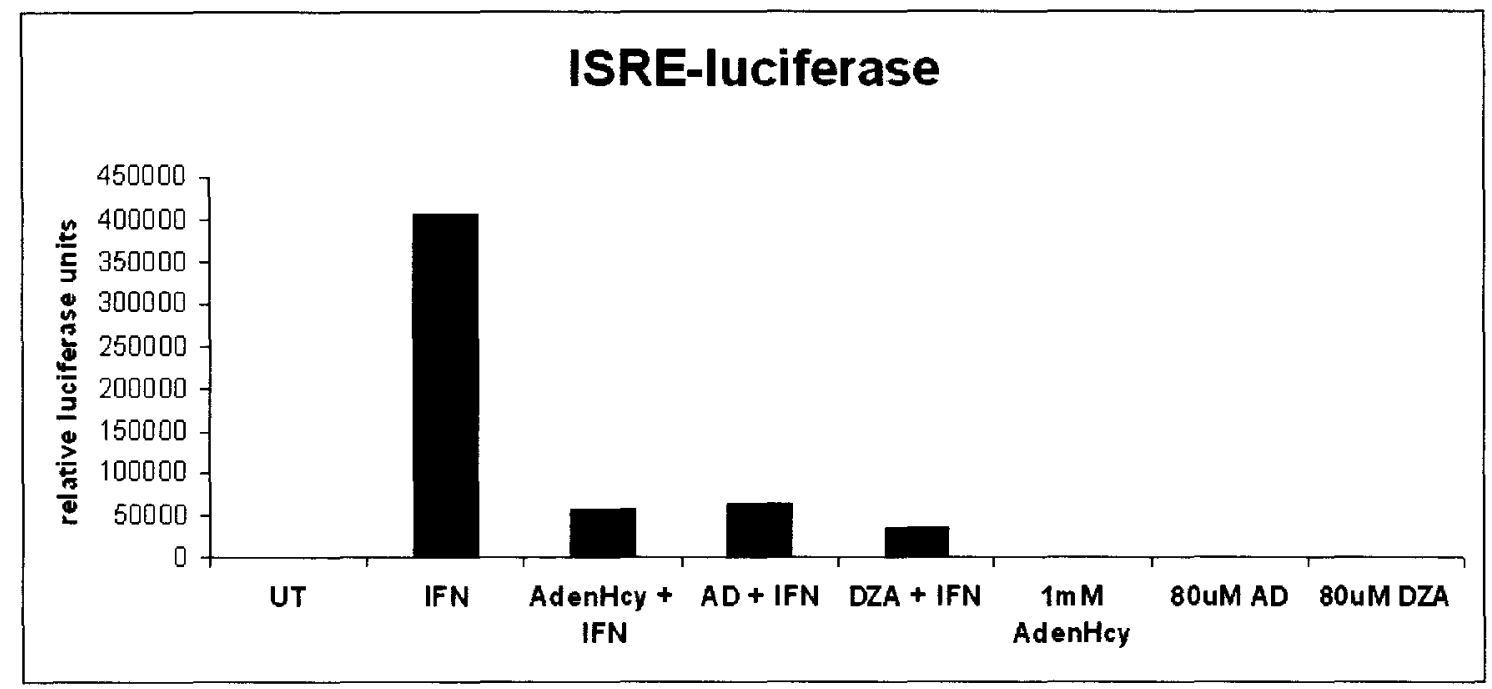

Figure 18: Impaired SAM metabolism inhibits IFNa-mediated activation of the ISRE in human hepatoma cells. SAM metabolism disruptors (AdenHcy, $A D$, and DZA) blocked IFNa-stimulated ISRE activation in Huh7 cells. SAM metabolism disruptors did not activate the ISRE.

Impaired SAM metabolism inhibits IFNa-mediated pSTAT1, OAS, and PKR protein expression in human hepatoma cells.

IFNa exerts its antiviral action by activating the JAK/STAT signaling cascade so it was important to determine if impaired SAM metabolism alters critical steps in the signaling pathway. IFNa binds cell surface receptors leading to activation of JAK/STAT signaling. Of particular importance in this cascade is phosphorylation of STAT proteins on tyrosine residue 701 (Y701), which causes them to dimerize and translocate to the nucleus where they associate with IRF9 to form the ISGF3 transcription complex that binds the ISRE leading to antiviral gene induction.

This pathway is regulated in several ways including dephosphorylation of STATs by phosphatases, and binding of STATs to their negative regulator protein 
inhibitor of activated STATs (PIAS) ${ }^{73,120}$. We performed western blots using whole cell lysates from human hepatoma cells and analyzed the effects of DZA on IFNa-stimulated STAT1 Y701 phosphorylation. Cells treated with IFNa alone showed robust STAT1 Y701 phosphorylation, which was reduced in cells that received DZA prior to stimulation with IFNa (Fig. 19). To determine if DZA inhibits STAT1 Y701 phosphorylation by inducing phosphatases, we treated cells in the presence of sodium vanadate $\left(\mathrm{Na}_{3} \mathrm{VO}_{4}\right)$ and sodium flouride $(\mathrm{NaF})$, which inhibit tyrosine and serine/threonine phosphatases, respectively ${ }^{54}$. Interestingly, STAT1 Y701 phosphorylation was rescued with $\mathrm{NaF}$ but not $\mathrm{Na}_{3} \mathrm{VO}_{4}$, thus suggesting that impaired SAM metabolism inhibits IFNa-mediated anti-HCV signaling by interfering with STAT1 serine phosphorylation. Several reports have indicated that phosphorylation of STAT1 on S727 is required for the optimal transcriptional activity of STAT1 ${ }^{106,121,127}$. To determine if STAT1 S727 phosphorylation was affected, the membrane was stripped and reprobed with primary antibody against pSTAT1 S727. As seen in Figure 19, cells treated with DZA showed a marked decrease in PSTAT1 $\$ 727$ when compared to cells treated with IFNa alone. To ensure that our results were not due to uneven loading of our protein samples, we also probed the blot with a total STAT1 antibody. Total STAT1 was equal in all lanes confirming that DZA blocks IFNamediated phosphorylation of STAT1 on both its $\mathrm{Y} 701$ and S727 residues.

RT-PCR data revealed that impaired SAM metabolism downregulated IFNastimulated antiviral gene induction. We treated human hepatoma cells for 24 
hours with IFNa alone or after 3 hour pretreatment with DZA. Whole cell protein lysates were collected and analyzed by Western blot for antiviral PKR and OAS protein expression. IFNa treatment induced expression of both PKR and OAS. Pretreatment with DZA inhibited IFNa-stimulated OAS protein expression and slightly reduced PKR protein expression. $\beta$-actin antibody was used to confirm equal loading between samples (Fig. 19). Taken together, these data show that impaired transmethylation affects IFNa-mediated anti-HCV action by disrupting critical steps in the JAK/STAT signaling cascade, which subsequently inhibits antiviral protein expression.

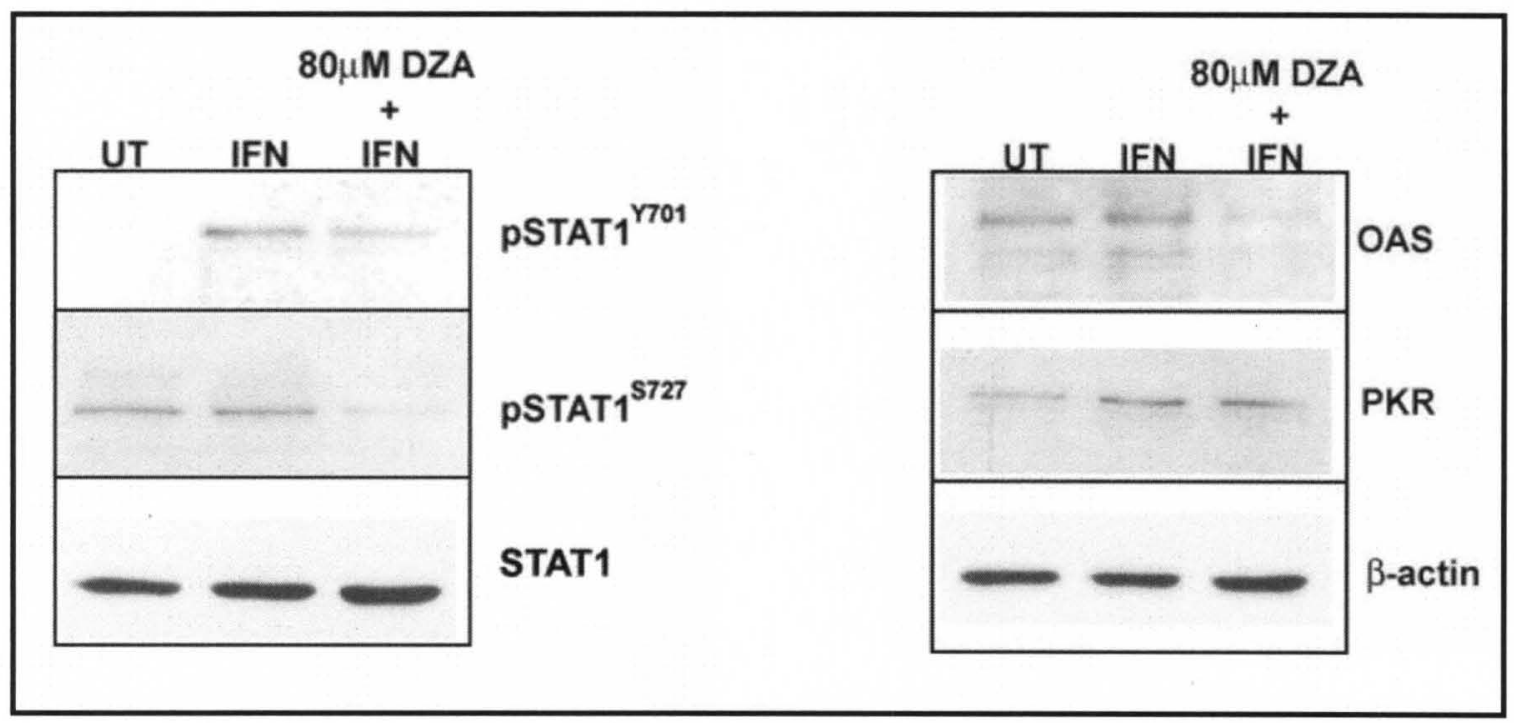

Figure 19: Impaired SAM metabolism inhibits IFNa-mediated pSTAT1, OAS, and PKR protein expression in human hepatoma cells. DZA inhibited IFNamediated STAT1 phosphorylation and expression of the antiviral proteins, PKR and OAS, in whole cell protein lysates from Huh7 cells. Total STAT1 and $\beta$-actin antibodies were used to confirm equal loading of proteins between samples. 
Impaired SAM metabolism increases STAT1:PIAS1, which correlates with decreased STAT1:PRMT1 in the nucleus of human hepatoma cells.

One mechanism by which JAK/STAT signaling is negatively regulated is through association of STAT1 with PIAS1 in the nucleus of cells. Importantly, formation of the STAT1:PIAS1 complex is prevented by methylation of STAT1, which is catalyzed by association of STAT1 with the methyltransferase PRMT1 $1^{73,85}$. Impaired SAM metabolism leads to an increase in intracellular SAH that inhibits methyltransferase reactions. To analyze the affects of impaired SAM metabolism on STAT1:PIAS1, human hepatoma cells were treated with IFNa for 30 minutes alone or after 3 hour pretreatment with DZA or AD. Nuclear protein lysates were collected and equal amounts of protein were immunoprecipitated with STAT1 antibody. The immunocomplexes were analyzed by Western blot for association with PIAS1 and PRMT1. As seen in Figure 20, pretreatment with DZA or AD blocked IFNa-induced formation of STAT1:PRMT1 complex, which correlated with an increase in STAT1:PIAS1. These data support a role for SAM metabolism in regulation of IFNa-HCV signaling by controlling negative inhibition of the JAK/STAT signaling pathway. 


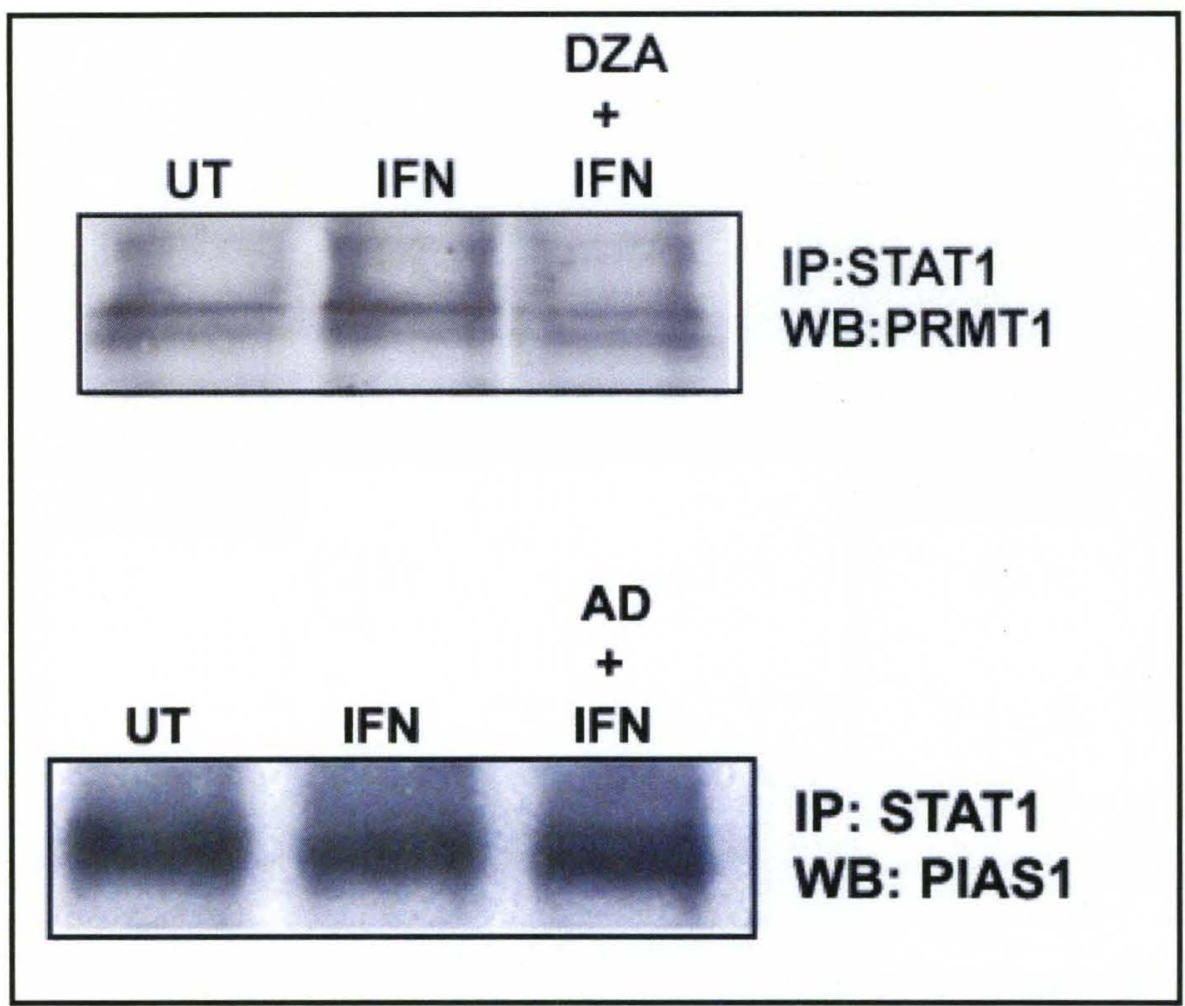

Figure 20: Impaired SAM metabolism decreases STAT1:PRMT1 and increases STAT1:PIAS1 association in the nucleus of human hepatoma cells. Immunoprecipitation of Huh7 nuclear protein lysates with STAT1 antibody revealed an IFNa-stimulated STAT1:PRMT1 complex that is inhibited by DZA (top). IFNa reduced STAT1:PIAS1 association, which was reversed by pretreatment with $A D$ (bottom).

SAM supplementation boosts IFNa-mediated antiviral gene induction and anti-HCV activity in human hepatoma cells.

Our data clearly show that impaired SAM metabolism downregulates IFNa antiviral gene induction and anti-HCV activity and suggest that SAM plays a critical role in managing HCV by the current treatment regimen. Next, we wanted 
to determine if SAM supplementation would enhance the anti-HCV actions of IFNa. HCVR cells were treated for 24 hours with $1 \mathrm{mM}$ SAM prior to stimulation with $10 \mathrm{U} / \mathrm{ml}$ IFNa for 24 hours. Total RNA was extracted and used to analyze mRNA levels of PKR, OAS, and ISG15, as well as HCV RNA levels, by RT-PCR. IFNa treatment alone led to significant activation of the antiviral genes and SAM pretreatment caused at least a 2-fold enhancement of induction of each gene. Interestingly, SAM treatment alone cause significant induction of the antiviral genes. SAM pretreatment also enhanced the anti-HCV action of IFNa resulting in $75 \%$ suppression compared to $50 \%$ suppression seen in cells treated with IFNa alone. Importantly, SAM itself suppressed HCV RNA by 23\% (Fig. 21).

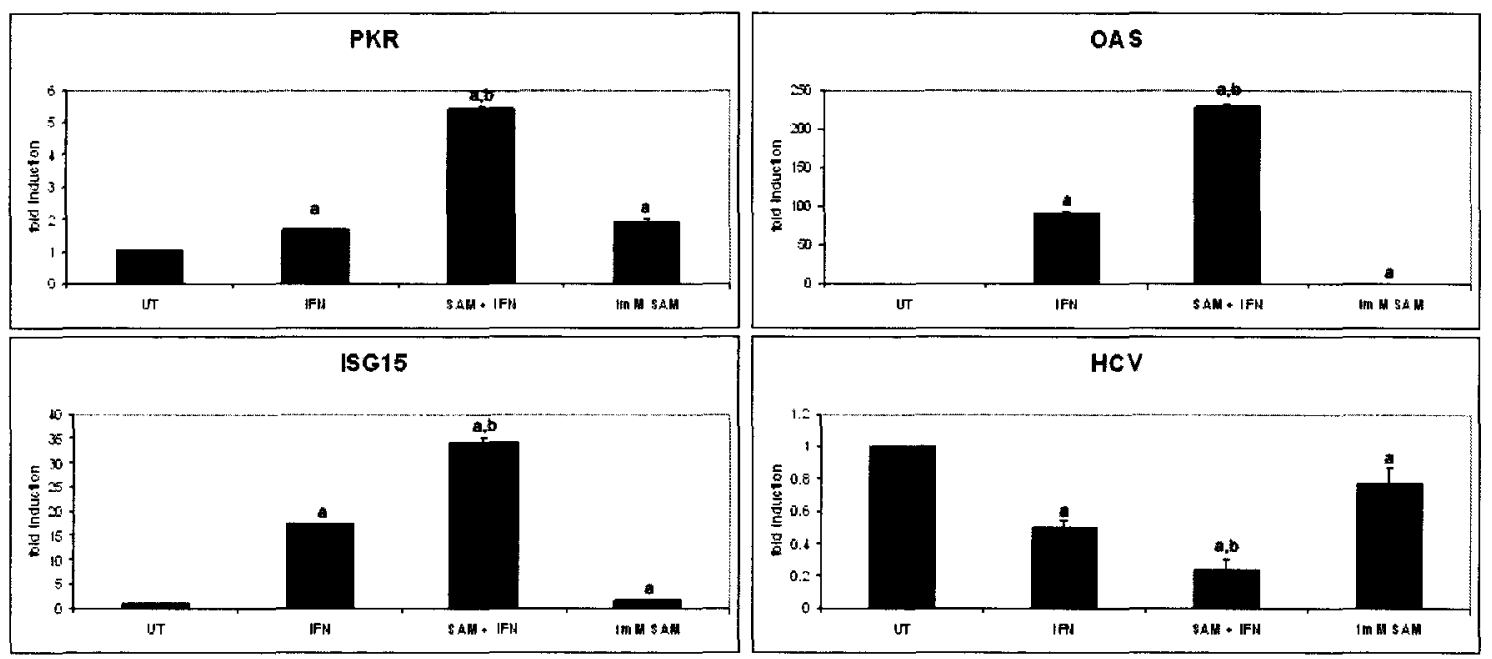

Figure 21: SAM boosts IFNa-mediated antiviral gene induction and antiHCV activity in human hepatoma cells. SAM enhanced IFNa-mediated PKR, OAS, and ISG15 mRNA induction and suppression of HCV RNA. SAM treatment alone significantly induced antiviral mRNA induction and suppressed HCV. Error bars indicate $\operatorname{SDM}(N=3 ; a=P \leq 0.05$ vs $U T, b=P \leq 0.05$ vs IFN). 
Next, we wanted to determine if SAM supplementation would restore the antiHCV action of IFNa that was inhibited by SAM metabolism disruptors. HCVR cells were treated with DZA for 3 hours, then SAM for 24 hours, prior to stimulation with IFNa for 24 hours. HCV RNA was suppressed by $45 \%$ in cells that received IFNa and DZA blocked this effect, which brought HCV RNA levels back to baseline. Importantly, SAM supplementation restored the anti-HCV activity of IFNa, resulting in $49 \%$ suppression of HCV RNA (Fig. 22). Taken together, these data indicate a role for SAM supplementation, by enhancing IFNa antiviral activity, in management of HCV.

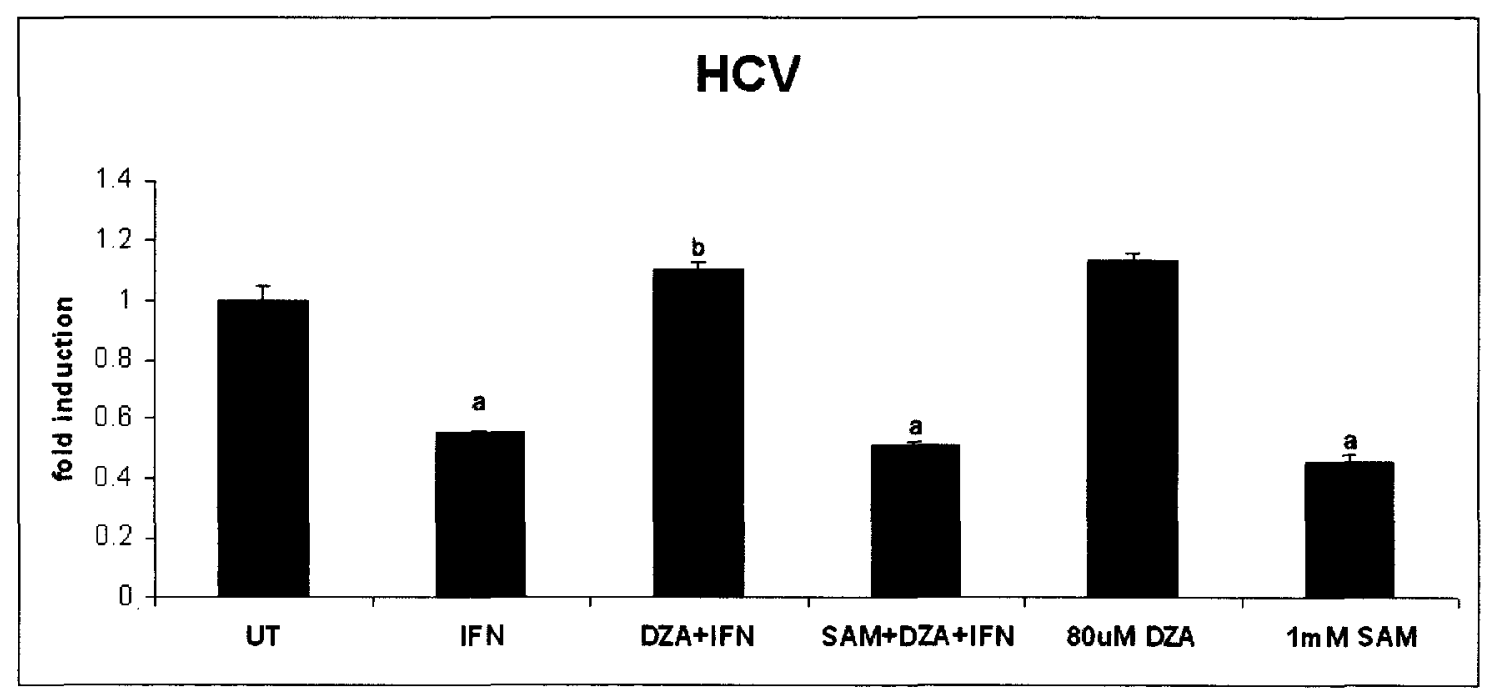

Figure 22: SAM restores IFNa-mediated anti-HCV activity that was blocked by inhibition of SAM metabolism. DZA reversed the anti-HCV action of IFNa in HCVR cells and this effect was blocked by SAM. Error bars indicate SDM $(N=3 ; a=P \leq 0.05$ vs UT, $b=P \leq 0.05$ vs IFN). 
Impaired SAM metabolism downregulates HDAC gene induction in human hepatoma cells.

Our previous studies using HDACi and siRNA demonstrated the critical need for HDAC1 and HDAC3 in IFNa-mediated anti-HCV activity. To expand on these findings, we wanted to determine if impaired SAM metabolism modified HDAC gene expression. Human hepatoma cells were treated with SAM metabolism disrupters for 3 hours then stimulated with IFNa for 2 hours. Total RNA was extracted and used to analyze induction of class I HDACs (1, 2, 3, and 8) and class II HDACs $(4,5,6,7 a, 9$, and 10) by RT-PCR. As seen in Figures 23 and 24, none of the SAM metabolism disruptors induced significant changes in HDAC3 or HDAC5. HDAC1, HDAC6, and HDAC8 gene inductions were significantly reduced in cells that received AD. Cells treated with AdenHcy or DZA showed reduced induction of HDAC2 and HDAC9. Importantly, all of the SAM metabolism disruptors caused significant reduction in HDAC4, HDAC7, and HDAC10 gene induction (Fig. 24). These results support our previous data showing the requirement of HDACs in IFNa anti-HCV activity. The differential effects of the SAM metabolism disruptors on HDACs 1, 2, 6, 8, and 9 are possibly due to their specific chemical properties as opposed to being an effect of impaired SAM metabolism. Induction of HDACs 4,7 , and 10 was suppressed by all SAM metabolism disruptors indicating these HDACs may play a critical role in maintaining proper SAM metabolism and suggest the need for further studies in this area. 

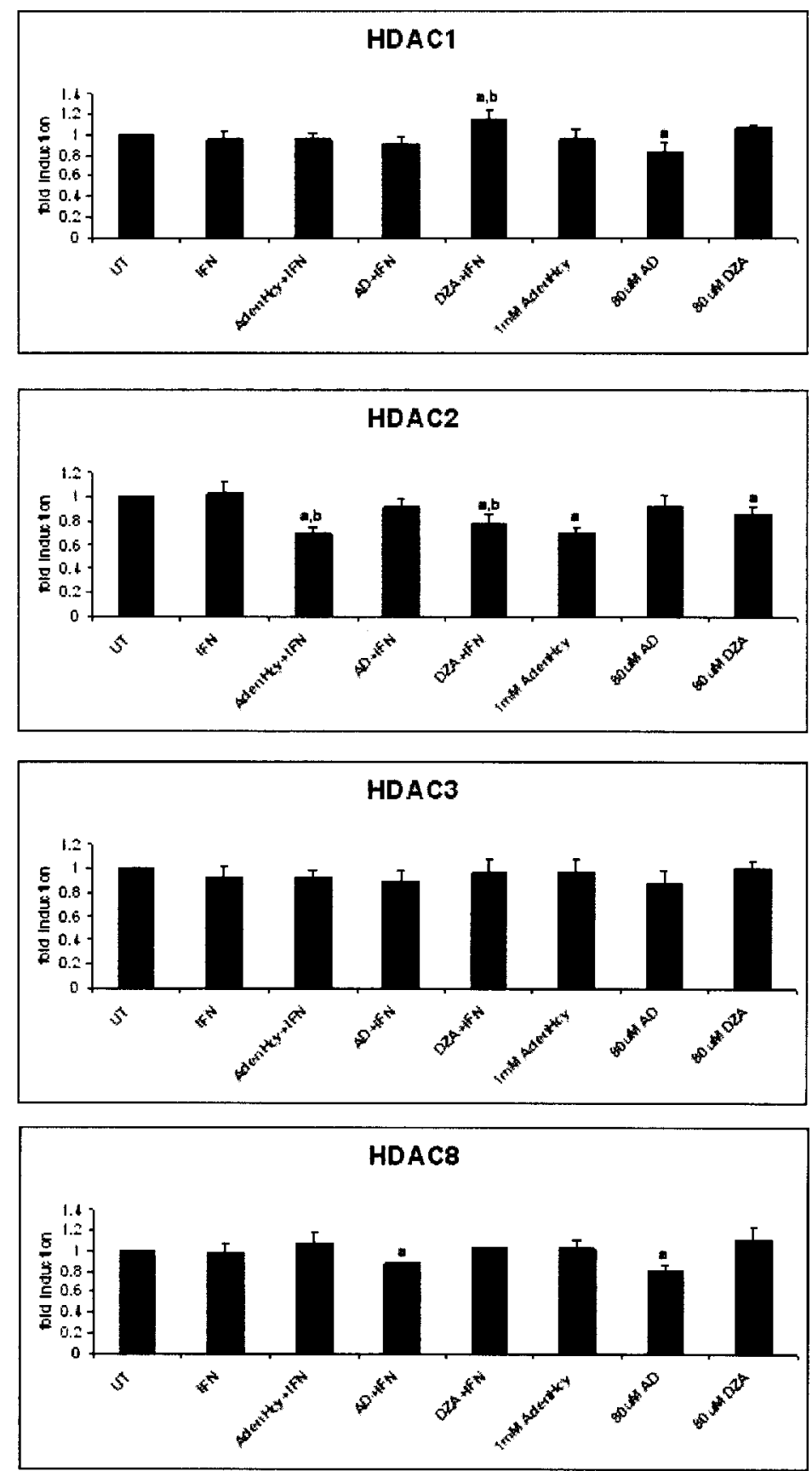

Figure 23: Effect of impaired SAM metabolism on class I HDAC gene induction in human hepatoma cells. Error bars indicate $\operatorname{SDM}(N=3 ; a=P \leq$ 0.05 vs $U T, b=P \leq 0.05$ vs (FN). 

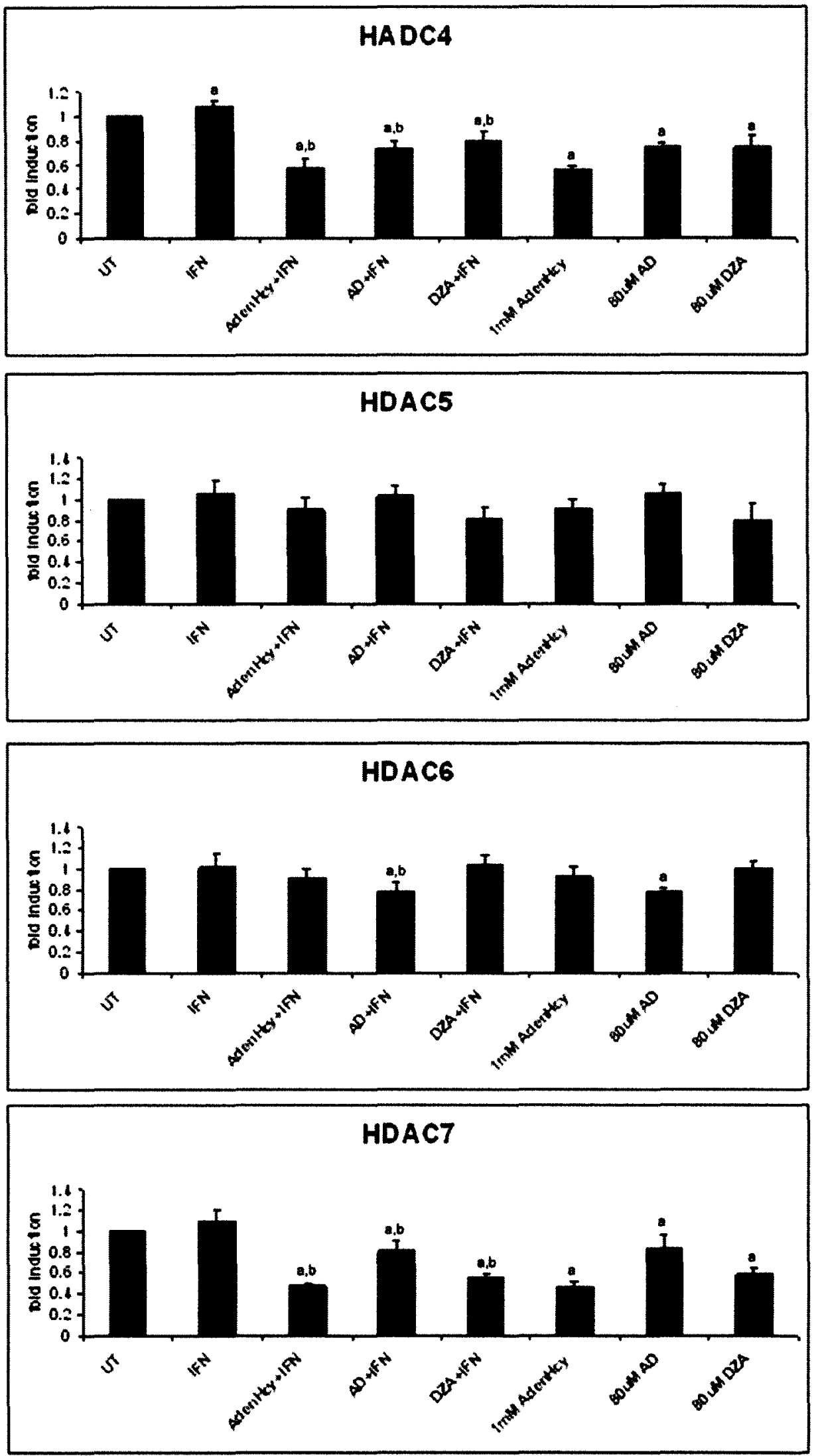

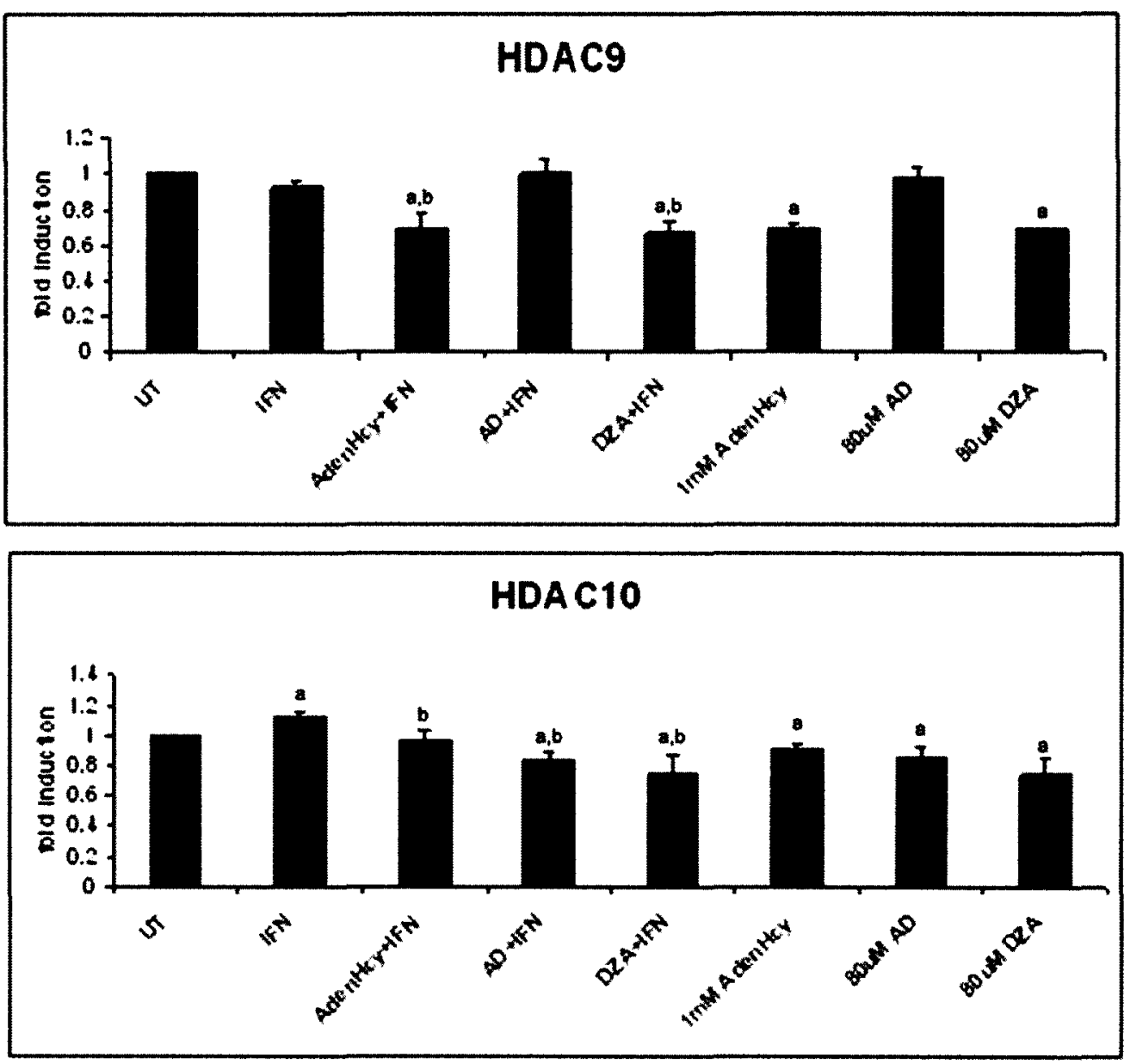

Figure 24: Effect of impaired SAM metabolism on class II HDAC gene induction in human hepatoma cells. Each of the SAM metabolism disruptors (AdenHcy, $A D$, and DZA) significantly reduced induction of HDAC4, HDAC7, and HDAC10 mRNA. Error bars indicate SDM (N=3; $a=P \leq 0.05$ vs UT, $b=P \leq 0.05$ vs (FN). 


\section{Summary of data:}

* SAM metabolism disruptors blocked IFNa-mediated antiviral gene induction and suppression of $\mathrm{HCV}$

- AdenHcy and DZA boosted HCV RNA

* SAM metabolism disruptors blocked IFNa-stimulated STAT1 phosphorylation

- Increased STAT1:PIAS1 association

- Decreased STAT1:PRMT1 association

* SAM metabolism disruptors inhibited HDAC4, HDAC7, and HDAC10 mRNA induction

* SAM supplementation boosted IFNa-mediated antiviral gene induction and suppression of $\mathrm{HCV}$

- SAM alone suppressed HCV RNA

* SAM supplementation reversed the inhibitory action of DZA on the antiHCV action of IFNa 


\section{ACROLEIN AND INTERFERON-ALPHA SIGNALING}

\section{Acrolein inhibits IFNa-mediated antiviral gene expression and anti-HCV}

activity in human hepatoma cells.

$\mathrm{HCV}$ disease progression and response to IFNa therapy depend on a variety of factors including obesity, oxidative stress, and external factors such as smoking, and exposure to environmental pollutants ${ }^{35,117,122}$. Acrolein is a component of cigarette smoke, as well as an environmental pollutant, and can also be formed endogenously through the process of lipid peroxidation ${ }^{54,56,65,90}$. We analyzed the effects of acrolein exposure on IFNa-mediated anti-HCV gene expression in human hepatoma cells. Cells were treated for 30 minutes with acrolein prior to stimulation with IFNa for 2 hours and total RNA was extracted and analyzed by RT-PCR. IFNa treatment caused robust induction of the antiviral genes PKR, OAS, and ISG15, which was significantly inhibited by pretreatment with acrolein (Fig. 25). Acrolein treatment alone significantly reduced PKR mRNA induction compared to UT cells. To determine if the reduction in antiviral gene transcription correlated with reduced anti-HCV activity of IFNa, HCVR cells were treated with acrolein for 30 minutes prior to stimulation with IFNa for 24 hours. IFNa alone suppressed HCV by $35 \%$ and pretreatment with acrolein dosedependently reversed the anti-HCV action. Interestingly, acrolein treatment alone significantly increased HCV RNA (Fig. 25). These data suggest that exposure to acrolein may contribute to $\mathrm{HCV}$ disease progression and poor response to therapy. 

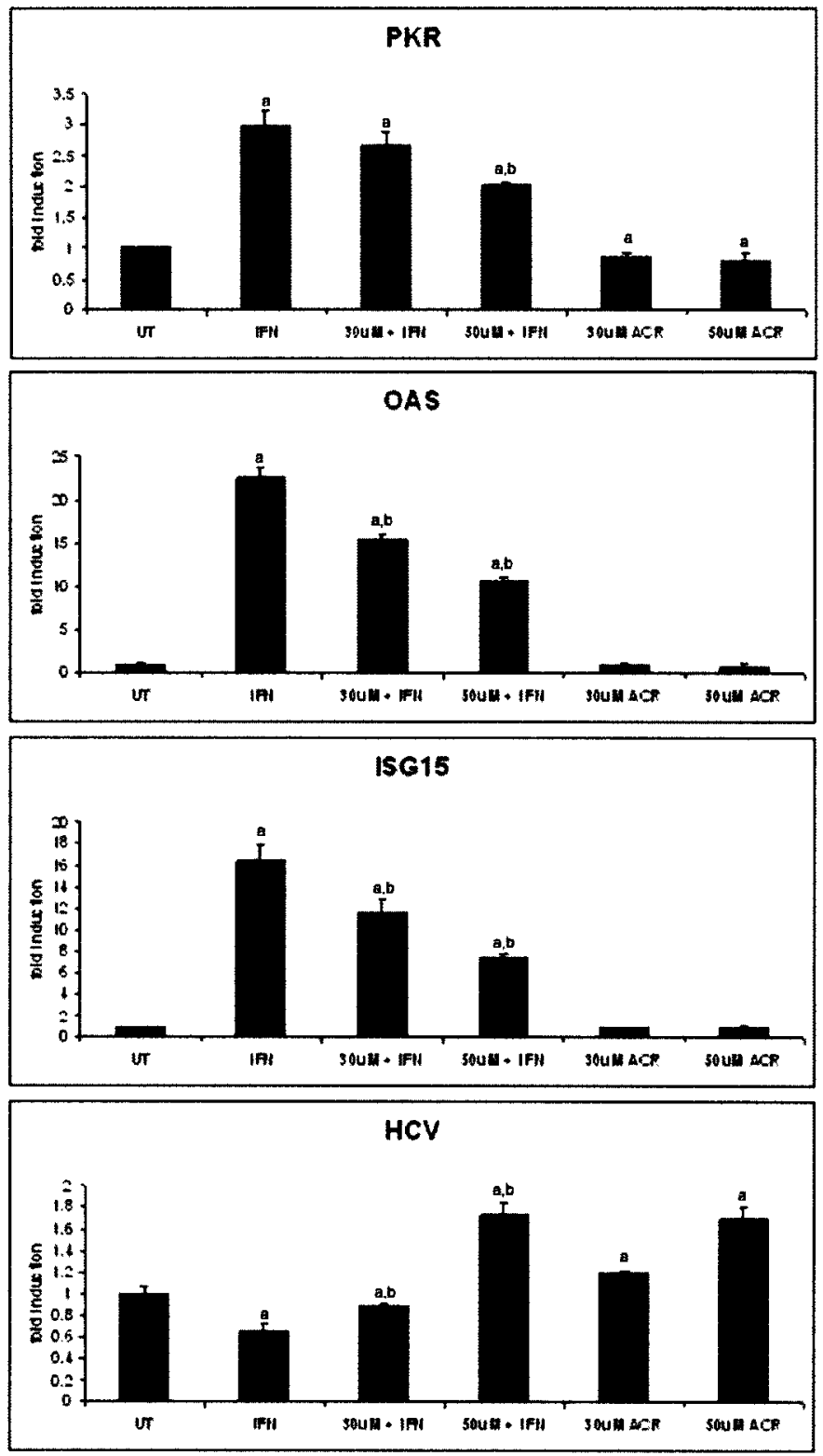

Figure 25: Acrolein inhibits IFNa-mediated antiviral gene expression and anti-HCV activity in human hepatoma cells. Acrolein dose-dependently inhibited IFNa-mediated antiviral mRNA induction and suppression of HCV RNA. Acrolein suppressed PKR mRNA and induced HCV RNA. Error bars indicate $\operatorname{SDM}(N=3 ; a=P \leq 0.05$ vs UT, $b=P \leq 0.05$ vs IFN). 
Acrolein suppresses class I HDAC activity and gene expression in human hepatoma cells.

Based on our previous studies showing the critical role of class I HDACs in IFNamediated anti-HCV signaling, we wanted to determine if acrolein modified HDAC activity and/or gene transcription. Nuclear protein lysates were extracted from human hepatoma cells treated for 3 hours with increasing doses of acrolein. HDAC activity was measured using the Epigenase HDAC Activity Direct Assay Kit as per the manufacturer's protocol and normalized against protein concentration. HDAC activity was decreased in all samples and correlated with acrolein dose (Fig. 26).

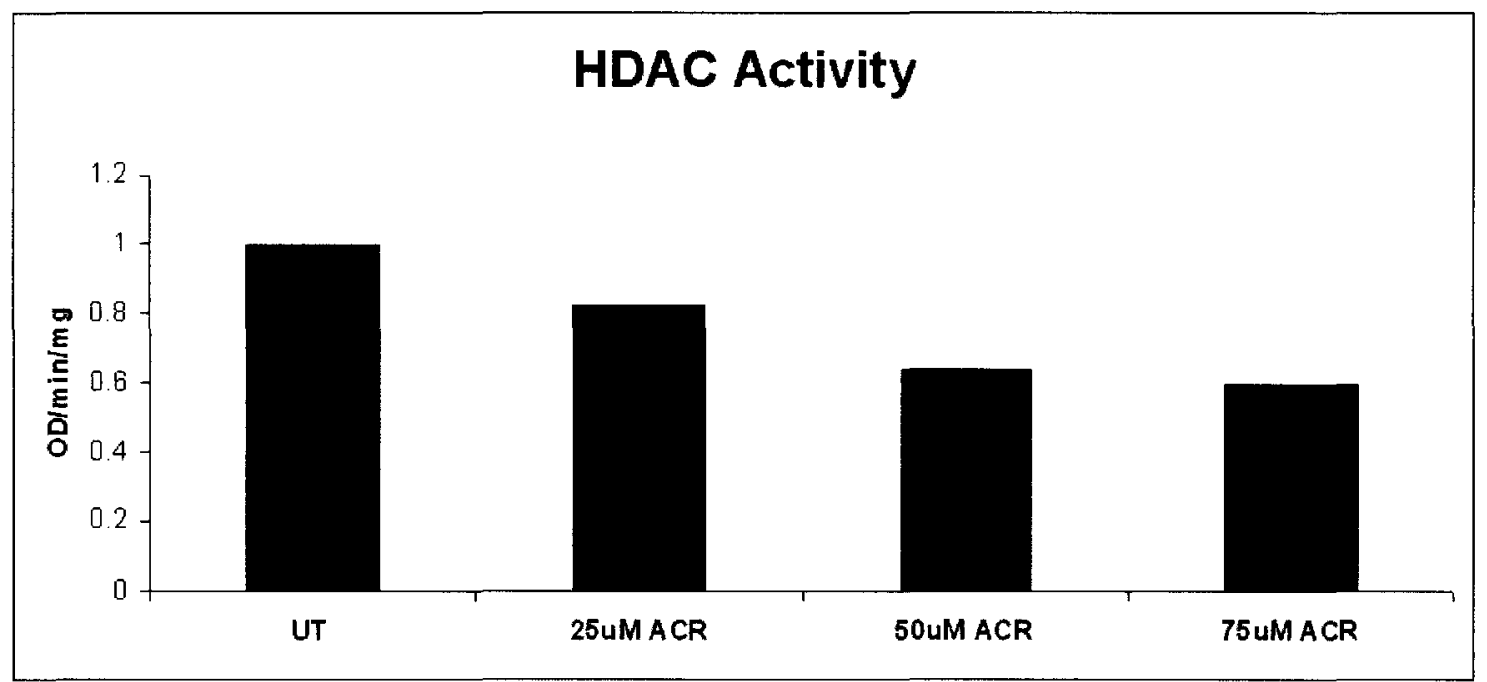

Figure 26: Acrolein decreases HDAC activity in human hepatoma cells. Acrolein reduced HDAC activity in nuclear lysates from Huh7 cells. Data was normalized against protein concentration. Representative of 2 independent experiments. 
In order to see if the decrease in HDAC activity correlated with reduced class I HDAC gene expression, human hepatoma cells were treated for 3 hours with acrolein and total RNA was extracted and analyzed by RT-PCR. As seen in Figure 27, acrolein significantly reduced transcription of all class I HDACs. Taken together, these results suggest that one mechanism by which acrolein inhibits IFNa anti-HCV activity is through inhibition of class I HDACs, which are required for IFNa-mediated antiviral signaling. 

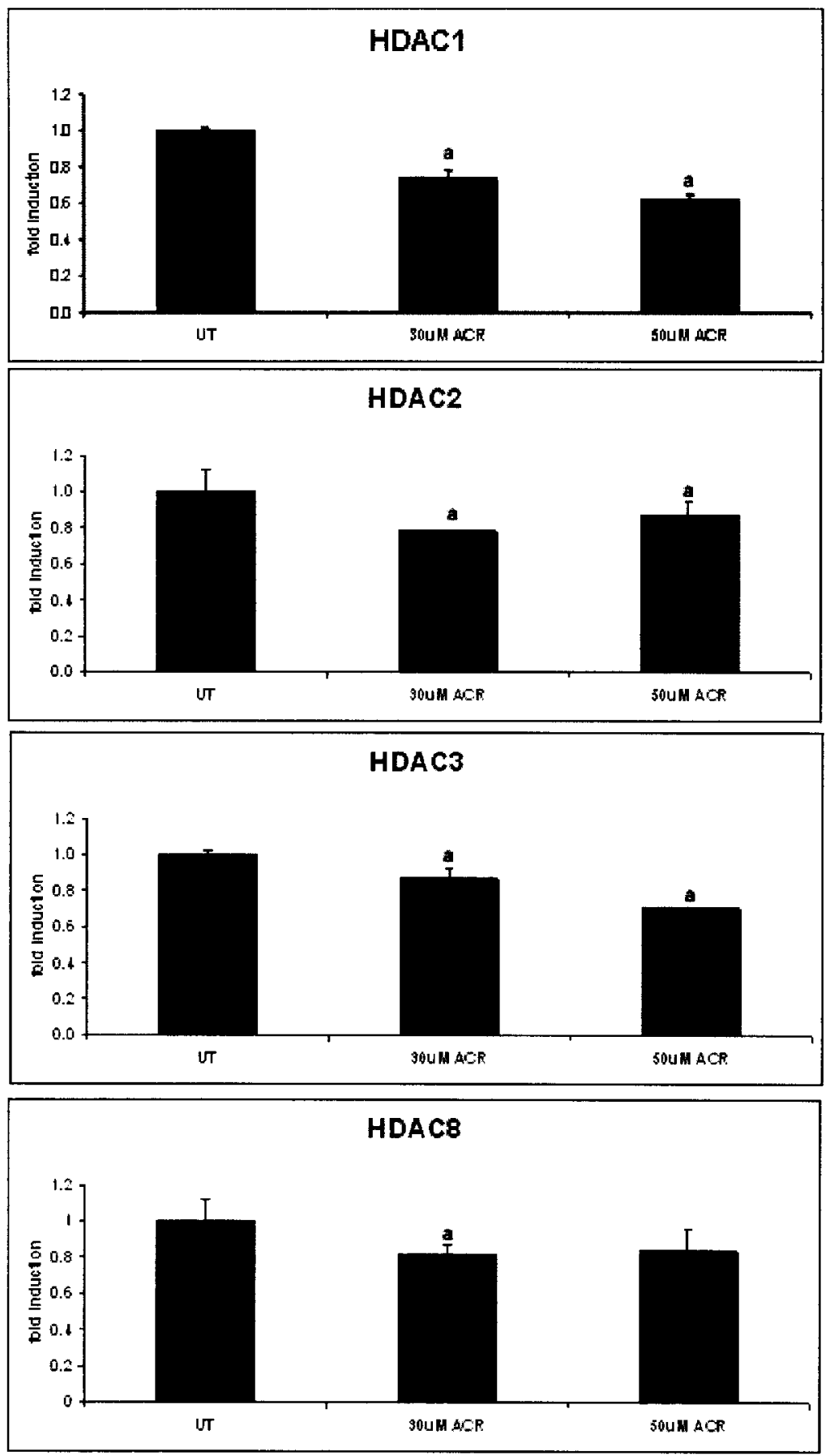

Figure 27: Acrolein decreases class I HDAC gene induction in human

hepatoma cells. Acrolein significantly suppressed HDAC1, HDAC2, HDAC3, and HDAC8 mRNA induction in Huh7 cells. Error bars indicate SDM $(N=3 ; a=$ $P \leq 0.05$ vs UT). 


\section{Summary of data:}

* Acrolein blocked IFNa-mediated antiviral gene induction and suppression of $\mathrm{HCV}$

- Acrolein boosted HCV RNA

* Acrolein suppressed class I HDAC activity and gene expression 


\section{CHAPTER IV}

\section{DISCUSSION}

HCV infection remains one of the leading causes of acute hepatitis and chronic liver disease in the US. Most people infected with HCV will develop chronic infections and approximately $50 \%$ of persons with $\mathrm{HCV}$ do not respond to the traditional IFNa plus ribavirin therapy. Poor response to therapy depends on a variety of factors including viral genotype, viral load, obesity, alcohol

consumption, smoking, and exposure to environmental pollutants ${ }^{5,35}$. Additionally, HCV invokes several countermeasures that inhibit the antiviral actions of IFNa including induction of PP2A, SOCS-1, SOC-3, and oxidative stress $^{11,52,69,104}$. Despite ongoing research on HCV, the molecular mechanisms, which include both host- and virus-specific factors, involved in resistance to therapy are not completely understood. These studies were performed to elucidate the mechanism(s) contributing to resistance to therapy and poor treatment outcomes in the management of $\mathrm{HCV}$.

HDACs were historically identified based on their ability to remove acetyl groups from $\mathrm{K}$ residues on histone tails. The removal of these acetyl groups removes the negative charges that repel DNA, leading to chromatin condensation and 
reduced transcription due to inaccessibility of transcription machinery to gene promoters. In more recent years, there has been a growing body of evidence showing that HDACs also exert action on non-histone proteins, in particular transcription factors, leading to altered gene expression ${ }^{41,87,124}$. The possible role of HDACs in modifying gene expression due to transcription factor modifications must be considered in inducible gene systems.

Taking into account the historical role of HDACs in downregulating gene expression due to chromatin condensation, we expected to see enhanced antiviral gene expression and suppression of HCV RNA when human hepatoma cells were treated with HDAC inhibitors prior to stimulation with IFNa. We instead observed a decrease in antiviral gene expression, which correlated with inactivation of the ISRE, and partial reversal of the anti-HCV action of IFNa. The anti-HCV properties of IFNa are mediated through activation of the JAKISTAT signaling cascade. Critical steps in this pathway include phosphorylation of STAT1 on Y701 and S727, which are required for nuclear translocation and optimal transcriptional activity, respectively ${ }^{38,100,121,127}$. We initially performed Western blot analysis on whole cell protein lysates from appropriately treated cells but did not observe a change in STAT1 phosphorylation in cells that received HDACi prior to stimulation with IFNa. However, when we analyzed STAT1 phosphorylation in cytoplasmic and nuclear protein lysates, we noticed a clear difference in the partitioning of pSTAT1; HDACi pretreated cells showed cytoplasmic accumulation compared to nuclear accumulation in cells stimulated 
only with IFNa. STAT signaling can be inhibited by acetylation of STAT1 in the nucleus, which leads to its translocation out of the nucleus and reduced gene transcription. Acetylation of STAT1 in the nucleus is mediated through binding with the HAT protein $\mathrm{CBP}^{58,61,62}$. Our data showed that IFNa induced formation of a STAT1:HDAC1 complex in the nucleus and HDACi pretreatment inhibited formation of this complex, which correlated to an increase in STAT1 acetylation. It is reasonable to speculate that, in addition to recruiting RNA polymerase to antiviral gene promoters, HDACs play a critical role in regulating IFNa-mediated anti-HCV gene expression by associating with STAT1 to circumvent CBPinduced acetylation and retain activated STATs in the nucleus.

The HDAC inhibitors used in our experiments, TSA and SBHA, are class I HDAC inhibitors and decrease the activity of HDACs $1,2,3$, and 8 . Using siRNA, we identified HDACs 1 and 3 as being critical for IFNa-mediated anti-HCV gene expression. Silencing of HDAC1 or HDAC3 led to a partial, yet significant, decrease in IFNa-stimulated anti-HCV gene expression and also inhibited formation of the STAT1:HDAC1 complex. Taken together, these results suggest: 1) there is redundancy between the HDACs that allows one to compensate when the other is silenced; and 2) HDAC3 plays a role in keeping STATs deacetylated and retained in the nucleus. The role of HDAC3 in keeping STATs deacetylated is supported by other data from our lab showing formation of a STAT2:HDAC3 complex in nuclear lysates from IFNa stimulated cells. Additionally, we observed 
HDACi-induced retention of pSTAT2 in cytoplasmic lysates of IFNa-stimulated cells.

When compared to pretreatment with HDACi, silencing of HDAC1 or HDAC3 by siRNA suppressed IFNa-mediated antiviral gene induction to a much lesser degree. The differences between the results obtained with HDACi versus siRNA are likely due to the fact that TSA and SBHA block activity of all class I HDACs, whereas siRNA blocks induction and expression of the respective HDAC genes. It is reasonable to speculate that double transfection with both siHDAC1 and siHDAC3 may reduce IFNa-stimulated antiviral gene induction to levels similar to those obtained with HDACi pretreatment. Alternatively, there may be redundancy between the HDACs that causes one to be induced when the other is silenced. Further studies are needed to further elucidate the roles of HDAC1 and HDAC3 in IFNa-mediated anti-HCV gene expression.

Recent reports have shown that theophylline induces HDAC activity to modify gene expression ${ }^{22,53}$. To further elucidate the role of HDACs in IFNa-mediated anti-HCV signaling, we used theophylline to boost HDAC gene expression and analyzed its effects on antiviral gene induction. We observed a theophyllineinduced increase in HDAC1 mRNA induction, which correlated with enhanced IFNa-mediated PKR mRNA induction and suppression of HCV RNA. Importantly, theophylline alone induced PKR mRNA and suppressed HCV RNA 
induction. These data are consistent with a recently published report showing that theophylline inhibits replication of hepatitis $B$ virus ${ }^{128}$.

The theophylline doses used in this study were used for proof-of-concept and are not physiologically relevant. However, theophylline is known to boost HDAC activity and is a metabolite of caffeine. Freedman et al have reported that HCV patients who consume coffee have better response to the IFNa plus ribavirin therapy. It is possible that the enhanced antiviral response is partially due to the caffeine found in coffee.

SAM is of pivotal importance in cellular metabolism serving as the major donor of methyl groups in transmethylation and transsulfuration reactions. Elevations in intracellular SAH will disrupt the SAM metabolism pathway and impaired SAM metabolism is a well documented feature of chronic liver injury ${ }^{6,75,77}$. Our data clearly show that disrupting SAM metabolism, by SAHH inhibition or exogenous supplementation of adenosine and homocysteine, dramatically reduced IFNastimulated antiviral gene induction, which correlated with impaired activation of the ISRE, and reversed the anti-HCV action of IFNa. Western blot analysis revealed a decrease in both $\mathrm{pSTAT1} 1^{\mathrm{Y701}}$ and $\mathrm{PSTAT1}{ }^{\mathrm{S727}}$ in whole cell protein lysates from cells treated with SAM metabolism disruptors prior to stimulation with IFNa. Negative regulation of JAK/STAT signaling occurs when STAT1 is bound to PIAS1, an association that is controlled by PRMT1-induced methylation of STAT1. Immunoprecipitation of nuclear lysates with STAT1 antibody revealed 
IFNa-induced formation of a STAT1:PRMT1 complex that was inhibited by pretreatment with SAM metabolism disruptors. Importantly, SAM metabolism disruptors caused an increase in the STAT1:PIAS1 complex compared to cells treated with IFNa alone. Previous data from our lab also revealed methylation of STAT1 that was inhibited by treatment with SAM metabolism disruptors These data suggest a critical role for SAM metabolism in IFNa-mediated anti-HCV gene expression.

Exogenous supplementation of SAM significantly enhanced in IFNa-mediated anti-HCV gene expression and suppression of HCV RNA. Importantly, SAM treatment alone significantly induced PKR, OAS, and ISG15 mRNA induction and suppressed HCV RNA. Previous data from our lab also revealed that SAM supplementation increased methylation of STAT1, which correlated with a decrease in STAT1:PIAS1. Finally, SAM supplementation reversed the inhibitory effects of DZA on IFNa-mediated antiviral gene expression and anti-HCV activity. These data suggest a role for SAM as adjunct therapy in management of HCV. A recently published report by Feld et al indeed showed that SAM improved early response in HCV patients on IFNa plus ribavirin therapy who previously did not respond to the traditional anti-HCV therapy ${ }^{31}$. Additionally, our data showing suppression of HCV by SAM treatment alone suggests that the HCV promoter might be controlled by methylation and points to the need for future studies in this area. 
HDACs are required for IFNa-mediated antiviral gene expression and we specifically identified HDAC1 and HDAC3 as being critical for IFNa anti-HCV activity. Interestingly, none of the SAM metabolism disruptors affected induction of HDAC1 or HDAC3. Next, we analyzed the effects of these disruptors on class II HDAC inductions. HDAC4, HDAC7, and HDAC10 were significantly downregulated in response to each SAM metabolism disruptor used in this study suggesting that these HDACs play an important role in IFNa antiviral signaling as well as SAM metabolism and maintaining the SAM/SAH ratio. Future studies are needed to determine if these HDACs play a role in regulating STATs and/or other transcription factors required for IFNa-mediated anti-HCV gene expression. Additionally, these HDACs may modify the epigenetic landscape, including alterations in chromatin structure, at IFNa antiviral gene promoters. Finally, it is possible that HDACs 4,7 , and 10 affect enzymes in the SAM metabolism pathway, such as MAT1 or SAHH enzymes, thus regulating SAM formation and/or utilization.

Acrolein is a hepatotoxic aldehyde that is a component of smoke, as well as a product and inducer of oxidative stress, and exposure to acrolein might correlate to poor response to IFN $\alpha$ anti-HCV therapy ${ }^{54}$. In fact, smokers have a lower response to IFNa anti-HCV therapy than nonsmokers, which correlates with an increase in liver fibrosis ${ }^{29}$. We used sublethal doses of acrolein, which were also within the physiological range, to show that acrolein downregulated IFNamediated antiviral gene expression and reversed the anti-HCV action of IFNa. 
Importantly, acrolein alone led to an increase in HCV RNA suggesting that exposure to acrolein enhances disease progression and contributes to poor response to therapy. Acrolein also significantly reduced HDAC activity and induction of the class I HDACs: HDAC1, HDAC2, HDAC3, and HDAC8. Previous data from our lab also showed that acrolein impairs IFNa-induced JAKISTAT signaling by inhibiting phosphorylation of STAT1 and STAT2, which correlated to an increase in serine and tyrosine phosphatase activity ${ }^{54}$. These data clearly show a role for acrolein in reducing IFNa-mediated antiviral gene expression and enhancing the progression of $\mathrm{HCV}$. 


\section{CHAPTER V}

CONCLUSIONS

The data presented herein show that HDACs and SAM play critical roles in regulating IFNa antiviral signaling and anti-HCV activity. We have presented convincing evidence that HDACs modify signaling by keeping the transcription factor STAT1 deacetylated, which increases its retention in the nucleus. We also show that HDACs are required for STAT binding to antiviral gene promoters, however, it is reasonable to assume that HDACs also modify local chromatin structure at IFNa-stimulated anti-HCV gene promoters to alter gene transcription. The critical role of HDACs in IFNa anti-HCV signaling is further supported by the fact that SAM metabolism disruptors and acrolein all modified the activity and/or induction of several HDACs.

SAM metabolism is required for IFNa-mediated anti-HCV gene expression and to prevent association between STAT1 and its negative regulator PIAS1. SAM metabolism disruptors significantly reduced induction of $\mathrm{HDAC} 4, \mathrm{HDAC} 7$, and HDAC10 mRNAs. These HDACs may play critical roles in maintaining SAM metabolism and SAM/SAH ratio in hepatocytes. Alternatively, these HDACs may modify other transcription factors in the IFNa anti-HCV signaling pathway. Finally, SAM treatment alone suppressed HCV RNA suggesting that the HCV 
genome may be under methylation control and points to the need for future studies.

Acrolein exposure significantly reduced IFNa-mediated antiviral gene induction and anti-HCV activity. Acrolein suppressed the activity and induction of all class I HDACs: HDAC1, HDAC2, HDAC3, and HDAC8. Importantly, acrolein treatment itself induced HCV RNA induction. Acrolein induces oxidative stress, which correlates with HCV disease progression and poor treatment outcomes, however, it is possible that acrolein-induced inhibition of HDAC activity and/or expression also contributes to poor IFNa anti-HCV response.

Overall conclusion:

We have elucidated the critical roles of HDACs and SAM in IFNa signaling and epigenetic regulation of anti-HCV gene expression. SAM and/or HDAC inducers may be useful as adjunct therapy to improve response to the IFN $\alpha$ anti-HCV treatment regimen. 


\section{REFERENCES}

1) Alberts, B., A. Johnson, et al. (2002). Molecular biology of the cell ( $4^{\text {th }}$ ed.). New York: Garland Science.

2) Adenuga, D. and I. Rahman (2010). "Protein kinase CK2-mediated phosphorylation of HDAC2 regulates co-repressor formation, deacetylase activity and acetylation of HDAC2 by cigarette smoke and aldehydes." Archives of Biochemistry and Biophysics 498(1): 62-73.

3) Antunes, F., A. Marg, et al. "STAT1 Signaling Is Not Regulated by a Phosphorylation-Acetylation Switch." Molecular and Cellular Biology 31(14): 3029-3037.

4) Asselah, T., I. Biëche, et al. (2009). "Gene expression and hepatitis $C$ virus infection." Gut 58(6): 846-858.

5) Avila, M. A., C. Berasain, et al. (2000). "Reduced mRNA abundance of the main enzymes involved in methionine metabolism in human liver cirrhosis and hepatocellular carcinoma." Journal of Hepatology 33(6): 907-914.

6) Avila, M. A., E. R. García-Trevijano, et al. (2002). "S-Adenosylmethionine revisited: its essential role in the regulation of liver function." Alcohol 27(3): 163-167.

7) Bartel, R. L. and R. T. Borchardt (1984). "Effects of adenosine dialdehyde on S-adenosylhomocysteine hydrolase and S-adenosylmethioninedependent transmethylations in mouse L929 cells." Molecular Pharmacology 25(3): 418-424.

8) Bhattacharya, S., R. Eckner, et al. (1996). "Cooperation of Stat2 and p300/CBP in signalling induced by interferon-a." Nature 383: 344-347.

9) Bigger, C. B., B. Guerra, et al. (2004). "Intrahepatic Gene Expression during Chronic Hepatitis C Virus Infection in Chimpanzees." The Journal of Virology 78(24): 13779-13792.

10)Blight, K. J., A. A. Kolykhalov, et al. (2000). "Efficient Initiation of HCV RNA Replication in Cell Culture." Science 290(5498): 1972-1974. 
11)Bode, J. G., S. Ludwig, et al. (2003). "IFN-a antagonistic activity of HCV core protein involves induction of suppressor of cytokine signaling-3." The FASEB Journal 17(3): 488-490.

12)Bolden, J. E., M. J. Peart, et al. (2006). "Anticancer activities of histone deacetylase inhibitors." Nature Reviews Drug Discovery 5(9): 769-784.

13)Cai, J., Z. Mao, et al. (1998). "Differential Expression of Methionine Adenosyltransferase Genes Influences the Rate of Growth of Human Hepatocellular Carcinoma Cells." Cancer Research 58(7): 1444-1450.

14)Cantoni, G. L. (1951). "Activation of methionine for transmethylation." Journal of Biological Chemistry 189(2): 745-754.

15)Chang, H.-M., M. Paulson, et al. (2004). "Induction of interferon-stimulated gene expression and antiviral responses require protein deacetylase activity." Proceedings of the National Academy of Sciences of the United States of America 101(26): 9578-9583.

16)Chebath, J., P. Benech, et al. (1987). "Four different forms of interferoninduced 2 ', $5^{\prime}$-oligo(A) synthetase identified by immunoblotting in human cells." Journal of Biological Chemistry 262(8): 3852-3857.

17)Chevaliez, S. and J.-M. Pawlotsky (2006). HCV Genome and Life Cycle. Hepatitis C Viruses: Genomes and Molecular Biology. S.-L. Tan. Norfolk (UK), Horizon Bioscience: 5-47.

18)Chiang, P., R. Gordon, et al. (1996). "S-Adenosylmethionine and methylation." The FASEB Journal 10(4): 471-480.

19)Chiang, P. K. (1998). "Biological Effects of Inhibitors of SAdenosylhomocysteine Hydrolase." Pharmacology \& Therapeutics 77(2): 115-134.

20)CHIANG, P. K., H. H. RICHARDS, et al. (1977). "S-Adenosyl-Lhomocysteine Hydrolase: Analogues of S-Adenosyl-L-homocysteine as Potential Inhibitors." Molecular Pharmacology 13(5): 939-947.

21)Christova, R., T. Jones, et al. (2007). "P-STAT1 mediates higher-order chromatin remodelling of the human MHC in response to IFNy." Journal of Cell Science 120(18): 3262-3270.

22)Cosio, B. G., L. Tsaprouni, et al. (2004). "Theophylline Restores Histone Deacetylase Activity and Steroid Responses in COPD Macrophages." The Journal of Experimental Medicine 200(5): 689-695. 
23)Dignam, J. (1990). "Preparation of extracts from higher eukaryotes." Methods in Enzymology 182: 194-203.

24)Dixit, N. and A. Perelson (2006). "The metabolism, pharmacokinetics and mechanisms of antiviral activity of ribavirin against hepatitis $C$ virus." Cellular and Molecular Life Sciences 63(7): 832-842.

25)Dorner, M., J. A. Horwitz, et al. (2011). "A genetically humanized mouse model for hepatitis C virus infection." Nature 474(7350): 208-211.

26)Duong, F. H. T., V. Christen, et al. (2006). "S-Adenosylmethionine and Betaine Correct Hepatitis C Virus Induced Inhibition of Interferon Signaling In Vitro." Hepatology 43(4): 796-806.

27)Duong, F. H. T., M. Filipowicz, et al. (2004). "Hepatitis C Virus Inhibits Interferon Signaling Through Up-regulation of Protein Phosphatase 2A." Gastroenterology 126: 263-277.

28)Ellis, D. J. P., Z. K. Lawman, et al. (2008). "Histone acetylation is not an accurate predictor of gene expression following treatment with histone deacetylase inhibitors." Biochemical and Biophysical Research Communications 367(3): 656-662.

29)Feld, J. J. and J. H. Hoofnagle (2005). "Mechanism of action of interferon and ribavirin in treatment of hepatitis C." Nature 436(7053): 967-972.

30)Feld, J. J., G. A. Lutchman, et al. "Ribavirin Improves Early Responses to Peginterferon Through Improved Interferon Signaling." Gastroenterology 139(1): 154-162.e154.

31)Feld, J. J., A. A. Modi, et al. "S-Adenosyl Methionine Improves Early Viral Responses and Interferon-Stimulated Gene Induction in Hepatitis $C$ Nonresponders." Gastroenterology 140(3): 830-839.e833.

32)Fensterl, V. and G. C. Sen (2010). "The ISG56/IFIT1 Gene Family." Journal of Interferon \& Cytokine Research 30(12): 1-8.

33)Freedman, N. D., T. M. Curto, et al. (2011). "Coffee Consumption Is Associated With Response to Peginterferon and Ribavirin Therapy in Patients With Chronic Hepatitis C." Gastroenterology 140(7): 1961-1969.

34)Fu, X. Y., D. S. Kessler, et al. (1990). "ISGF3, the transcriptional activator induced by interferon alpha, consists of multiple interacting polypeptide chains." Proceedings of the National Academy of Sciences 87(21): 85558559 . 
35)Gao, B., F. Hong, et al. (2004). "Host factors and failure of interferon- $\alpha$ treatment in hepatitis C virus." Hepatology 39(4): 880-890.

36)Ginsberg, G., D. Hattis, et al. (2004). "Physiologically Based Pharmacokinetic (PBPK) Modeling of Caffeine and Theophylline in Neonates and Adults: Implications for Assessing Children's Risks from Environmental Agents." Journal of Toxicology and Environmental Health, Part A 67(4): 297-329.

37)Gómez-Gonzalo, M., I. Benedicto, et al. (2004). "Hepatitis C virus core protein regulates $\mathrm{p} 300 / \mathrm{CBP}$ co-activation function. Possible role in the regulation of NF-AT1 transcriptional activity." Virology 328(1): 120-130.

38)Goodbourn, S., L. Didcock, et al. (2000). "Interferons: cell signalling, immune modulation, antiviral response and virus countermeasures." Journal of General Virology 81(10): 2341-2364.

39)Gosert, R., D. Egger, et al. (2003). "Identification of the Hepatitis C Virus RNA Replication Complex in Huh-7 Cells Harboring Subgenomic Replicons." Journal of Virology 77(9): 5487-5492.

40)Guo, L., S. Dial, et al. "Similarities and Differences in the Expression of Drug-Metabolizing Enzymes between Human Hepatic Cell Lines and Primary Human Hepatocytes." Drug Metabolism and Disposition 39(3): 528-538.

41)Haberland, M., R. L. Montgomery, et al. (2009). "The many roles of histone deacetylases in development and physiology: implications for disease and therapy." Nature Reviews 10: 32-42.

42)Haller, O., G. Kochs, et al. (2006). "The interferon response circuit: Induction and suppression by pathogenic viruses." Virology 344(1): 119130.

43)Haller, O., G. Kochs, et al. (2007). "Interferon, Mx, and viral countermeasures." Cytokine \& Growth Factor Reviews 18: 425-433.

44)Harper, H. A., L. W. Kinsell, et al. (1947). "Plasma L-Methionine Levels Following Intravenous Administration in Humans." Science 106(2753): 319-320.

45)Hartman, S. E., P. Bertone, et al. (2005). "Global changes in STAT target selection and transcription regulation upon interferon treatments." Genes \& Development 19(24): 2953-2968. 
46)Hiscott, J. (2007). "Convergence of the NF-kB and IRF pathways in the regulation of the innate antiviral response." Cytokine \& Growth Factor Reviews 18: 483-490.

47)Hoffman, D. R., D. W. Marion, et al. (1980). "S-Adenosylmethionine and $S$-adenosylhomocystein metabolism in isolated rat liver. Effects of $L-$ methionine, L-homocystein, and adenosine." Journal of Biological Chemistry 255(22): 10822-10827.

48)Horio, Y., T. Hayashi, et al. "Cellular and molecular effects of sirtuins in health and disease." Clinical Science 121(5): 191-203.

49)Hovanessian, A. G. "On the discovery of interferon-inducible, doublestranded RNA activated enzymes: The 2'-5'oligoadenylate synthetases and the protein kinase PKR." Cytokine \& Growth Factor Reviews 18(5-6): 351-361.

50)Icardi, L., S. Lievens, et al. "Opposed regulation of type I IFN-induced STAT3 and ISGF3 transcriptional activities by histone deacetylases (HDACS) 1 and 2." The FASEB Journal, in press, Epub ahead of print, retrieved September 30, 2011, from http://www.fasebj.org/content/early/2011/09/27/fj.11-191122.full.pdf+html

51)Ikeda, K., S. Saitoh, et al. (1998). "Disease progression and hepatocellular carcinogenesis in patients with chronic viral hepatitis: a prospective observation of 2215 patients." Journal of Hepatology 28: 930-938.

52)Imanaka, K., S. Tamura, et al. (2005). "Enhanced expression of suppressor of cytokine signalling-1 in the liver of chronic hepatitis C: possible involvement in resistance to interferon therapy." Journal of Viral Hepatitis 12(2): 130-138.

53)Ito, K., S. Lim, et al. (2002). "A molecular mechanism of action of theophylline: Induction of histone deacetylase activity to decrease inflammatory gene expression." Proceedings of the National Academy of Sciences 99(13): 8921-8926.

54)Joshi-Barve, S., K. Amancherla, et al. (2009). "Acrolein, a ubiquitous pollutant and lipid hydroperoxide product, inhibits antiviral activity of interferon-[alpha]: relevance to hepatitis C." Free Radical Biology and Medicine 47(1): 47-54.

55)Kadokura, M., S. Maekawa, et al. "Analysis of the Complete Open Reading Frame of Genotype $2 b$ Hepatitis $C$ Virus in Association with the Response to Peginterferon and Ribavirin Therapy." PLoS ONE 6(9): e24514. 
56)Kehrer, J. P. and S. S. Biswal (2000). "The Molecular Effects of Acrolein." Toxicological Sciences 57(1): 6-15.

57)Kinsell, L. W., H. A. Harper, et al. (1947). "Rate of Disappearance from Plasma of Intravenously Administered Methionine in Patients with Liver Damage." Science 106(2763): 589-590.

58)Klampfer, L., J. Huang, et al. (2004). "Requirement of Histone Deacetylase Activity for Signaling by STAT1." Journal of Biological Chemistry 279(29): 30358-30368.

59)Komyod, W., U.-M. Bauer, et al. (2005). "Are STATS Argininemethylated?" Journal of Biological Chemistry 280(23): 21700-21705.

60)Kouzarides, T. (2007). "Chromatin Modifications and Their Function." Cell 128: 693-705.

61)Kramer, O. H. and T. Heinzel (2010). "Phosphorylation-acetylation switch in the regulation of STAT1 signaling." Molecular and Cellular Endocrinology 315: 40-48.

62)Kramer, O. H., S. K. Knauer, et al. (2009). "A phosphorylation-acetylation switch regulates STAT1 signaling." Genes and Development 23(2): 223235.

63)Kumar, R. and L. Korutla (1995). "Induction of Expression of InterferonStimulated Gene Factor-3 (ISGF-3) Proteins by Interferons." Experimental Cell Research 216(1): 143-148.

64)Lachner, M. and T. Jenuwein (2002). "The many faces of histone lysine methylation." Current Opinion in Cell Biology 14(3): 286-298.

65)Lambert, C., J. Li, et al. (2007). "Acrolein Inhibits Cytokine Gene Expression by Alkylating Cysteine and Arginine Residues in the NF-kB1 DNA Binding Domain." Journal of Biological Chemistry 282(27): 1966619675.

66)Lauer, G. M. and B. D. Walker (2001). "Hepatitis C Virus Infection." New England Journal of Medicine 345(1): 41-52.

67)Li, X., S. Leung, et al. (1996). "Formation of STAT1-STAT2 Heterodimers and Their Role in the Activation of IRF-1 Gene Transcription by Interferon." Journal of Biological Chemistry 271(10): 5790-5794. 
68)Liang, T. J., B. Rehermann, et al. (2000). "Pathogenesis, Natural History, Treatment, and Prevention of Hepatitis C." Annals of Internal Medicine 132(4): 296-305.

69)Lin, W., W. H. Choe, et al. (2005). "Hepatitis C virus expression suppresses interferon signaling by degrading STAT1." Gastroenterology 128(4): 1034-1041.

70)Lin, W., S. S. Kim, et al. (2006). "Hepatitis C Virus Core Protein Blocks Interferon Signaling by Interaction with the STAT1 SH2 Domain." Journal of Virology 80(18): 9226-9235.

71)Lindenbach, B. D., M. J. Evans, et al. (2005). "Complete Replication of Hepatitis C Virus in Cell Culture." Science 309(5734): 623-626.

72)Lindenbach, B. D., T. Heinz-Jurgen, et al. (2007). Flaviviridae: The Viruses and Their Replication. Fields Virology 5th Edition. D. M. Knipe and P. M. Howley. Philadelphia, Lippincott-Raven: 1113-1126.

73)Liu, B., J. Liao, et al. (1998). "Inhibition of Stat1-mediated gene activation by PIAS1." Proceedings of the National Academy of Sciences 95(18): 10626-10631.

74)Lohmann, V., ouml, et al. (1999). "Replication of Subgenomic Hepatitis C Virus RNAs in a Hepatoma Cell Line." Science 285(5424): 110-113.

75)Lu, S. C. and J. M. Mato (2005). "Role of methionine adenosyltransferase and S-adenosylmethionine in alcohol-associated liver cancer." Alcohol 35(3): 227-234.

76)Lu, S. C. and J. M. Mato (2008). S-Adenosylmethionine in cell growth, apoptosis and liver cancer, Blackwell Publishing Asia. 23: S73-S77.

77)Lu, S. C., H. Tsukamoto, et al. (2002). "Role of abnormal methionine metabolism in alcoholic liver injury." Alcohol 27(3): 155-162.

78)Lupberger, J., M. B. Zeisel, et al. (2011). "EGFR and EphA2 are host factors for hepatitis $C$ virus entry and possible targets for antiviral therapy." Nature Medicine 17(5): 589-595.

79)Marie, I., J. Svab, et al. (1990). "Differential expression and distinct structure of 69- and 100-kDa forms of 2-5A synthetase in human cells treated with interferon." Journal of Biological Chemistry 265(30): 1860118607. 
80)Mato, J. M., L. Alvarez, et al. (1997). "S-Adenosylmethionine Synthesis: Molecular Mechanism and Clinical Complications." Pharmacology \& Therapeutics 73(3): 265-280.

81)Melén, K., L. Kinnunen, et al. (2001). "Arginine/Lysine-rich Structural Element Is Involved in Interferon-induced Nuclear Import of STATs." Journal of Biological Chemistry 276(19): 16447-16455.

82)Merali, S., D. Vargas, et al. (2000). "S-Adenosylmethionine and Pneumocystis carinii." Journal of Biological Chemistry 275(20): 1495814963.

83)Meyer, T., A. Begitt, et al. (2002). "Constitutive and IFN-[gamma]-induced nuclear import of STAT1 proceed through independent pathways." The EMBO Journal 21(3): 344-354.

84)Miura, K., K. Taura, et al. (2008). "Hepatitis C virus-induced oxidative stress suppresses hepcidin expression through increased histone deacetylase activity." Hepatology 48(5): 1420-1429.

85)Mowen, K. A., J. Tang, et al. (2001). "Arginine Methylation of STAT1 Modulates IFN[alpha]/[beta]-Induced Transcription." Cell 104(5): 731-741.

86)Nusinzon, I. and C. M. Horvath (2003). "Interferon-stimulated transcription and innate antiviral immunity require deacetylase activity and histone deacetylase 1." Proceedings of the National Academy of Sciences of the United States of America 100(25): 14742-14747.

87)Nusinzon, I. and C. M. Horvath (2005). "Histone Deacetylases as Transcriptional Activators? Role Reversal in Inducible Gene Regulation." Science Signaling (296): re11.

88)Olsavsky, K. M., J. L. Page, et al. (2007). "Gene expression profiling and differentiation assessment in primary human hepatocyte cultures, established hepatoma cell lines, and human liver tissues." Toxicology and Applied Pharmacology 222(1): 42-56.

89)Palmer, J. L. and R. H. Abeles (1976). "Mechanism for enzymatic thioether formation. Mechanism of action of S-adenosylhomocysteinase." Journal of Biological Chemistry 251(18): 5817-5819.

90)Paradis, V., M. Kollinger, et al. (1997). "In situ detection of lipid peroxidation by-products in chronic liver diseases." Hepatology 26(1): 135142. 
91)Penin, F., J. Dubuisson, et al. (2004). "Structural biology of hepatitis $C$ virus." Hepatology 39(1): 5-19.

92)Pflugheber, J., B. Fredericksen, et al. (2002). "Regulation of PKR and IRF1 during hepatitis $C$ virus RNA replication." Proceedings of the National Academy of Sciences 99(7): 4650-4655.

93)Qureshi, S. A., M. Salditt-Georgieff, et al. (1995). "Tyrosinephosphorylated Stat1 and Stat2 plus a 48-kDa protein all contact DNA in forming interferon-stimulated-gene factor 3." Proceedings of the National Academy of Sciences 92(9): 3829-3833.

94)Rahman, I., J. Marwick, et al. (2004). "Redox modulation of chromatin remodeling: impact on histone acetylation and deacetylation, NF-KB and pro-inflammatory gene expression." Biochemical Pharmacology 68(6): 1255-1267.

95)Ramsauer, K., M. Farlik, et al. (2007). "Distinct modes of action applied by transcription factors STAT1 and IRF1 to initiate transcription of the IFN-yinducible gbp2 gene." Proceedings of the National Academy of Sciences 104(8): 2849-2854.

96)Randall, G., M. Panis, et al. (2007). "Cellular cofactors affecting hepatitis $C$ virus infection and replication." Proceedings of the National Academy of Sciences 104(31): 12884-12889.

97)Randall, R. E. and S. Goodbourn (2008). "Interferons and viruses: an interplay between induction, signalling, antiviral responses and virus countermeasures." Journal of General Virology 89(1): 1-47.

98)Sadzak, I., M. Schiff, et al. (2008). "Recruitment of Stat1 to chromatin is required for interferon-induced serine phosphorylation of Stat1 transactivation domain." Proceedings of the National Academy of Sciences 105(26): 8944-8949.

99)Sakamoto, S., R. Potla, et al. (2004). "Histone Deacetylase Activity Is Required to Recruit RNA Polymerase II to the Promoters of Selected Interferon-stimulated Early Response Genes." Journal of Biological Chemistry 279(39): 40362-40367.

100)Samuel, C. E. (2001). "Antiviral Actions of Interferons." Clinical Microbiology Reviews 14(4): 778-809.

101)Schiappa, D. A., C. Mittal, et al. (2002). "Relationship of Hepatitis C Genotype 1 NS5A Sequence Mutations to Early Phase Viral Kinetics and Interferon Effectiveness." The Journal of Infectious Diseases 185(7): 868- 
877.

102)Schoggins, J. W., S. J. Wilson, et al. (2011). "A diverse range of gene products are effectors of the type I interferon antiviral response." Nature 472(7344): 481-485.

103)Shen, C., T. Hu, et al. (2007). "Mutations in ISDR of NS5A gene influence interferon efficacy in Chinese patients with chronic hepatitis $C$ virus genotype $1 \mathrm{~b}$ infection." Journal of Gastroenterology and Hepatology 22(11): 1898-1903.

104)Shimakami, T., R. E. Lanford, et al. (2009). "Hepatitis C: recent successes and continuing challenges in the development of improved treatment modalities." Current Opinion in Pharmacology 9: 537-544.

105)Shimoike, T., S. A. McKenna, et al. (2009). "Translational insensitivity to potent activation of PKR by HCV IRES RNA." Antiviral Research 83: 228237.

106)Shuai, K. (2003). "Serine Phosphorylation: Arming Stat1 against Infection." Immunity 19(6): 771-772.

107)Shuai, K. and B. Liu (2003). "Regulation of JAK-STAT signalling in the immune system." Nature Reviews Immunology 3(11): 900-911.

108)Song, Z., Z. Zhou, et al. (2007). "Alcohol-induced Sadenosylhomocysteine accumulation in the liver sensitizes to TNF hepatotoxicity: Possible involvement of mitochondrial Sadenosylmethionine transport." Biochemical Pharmacology 74(3): 521531.

109)Song, Z., Z. Zhou, et al. (2004). "S-adenosylhomocysteine sensitizes to TNF- $\alpha$ hepatotoxicity in mice and liver cells: A possible etiological factor in alcoholic liver disease." Hepatology 40(4): 989-997.

110)Spange, S., T. Wagner, et al. (2009). "Acetylation of non-histone proteins modulates cellular signalling at multiple levels." The International Journal of Biochemistry \& Cell Biology 41(1): 185-198.

111)Strahl, B. D. and C. D. Allis (2000). "The language of covalent histone modifications." Nature 403(6765): 41-45.

112)Sullivan, D. M. and J. L. Hoffman (1983). "Fractionation and kinetic properties of rat liver and kidney methionine adenosyltransferase isozymes." Biochemistry 22(7): 1636-1641. 
113)Tellinghuisen, T. L., K. L. Foss, et al. (2008). "Regulation of Hepatitis C Virion Production via Phosphorylation of the NS5A Protein." PloS Pathogens 4(3): e1000032.

114)Testoni, B., C. Völlenkle, et al. "Chromatin Dynamics of Gene Activation and Repression in Response to Interferon a (IFNa) Reveal New Roles for Phosphorylated and Unphosphorylated Forms of the Transcription Factor STAT2." Journal of Biological Chemistry 286(23): 20217-20227.

115)Varinou, L., K. Ramsauer, et al. (2003). "Phosphorylation of the Stat1 Transactivation Domain Is Required for Full-Fledged IFN-[gamma]Dependent Innate Immunity." Immunity 19(6): 793-802.

116)Wakita, T., T. Pietschmann, et al. (2005). "Production of infectious hepatitis $\mathrm{C}$ virus in tissue culture from a cloned viral genome." Nature Medicine 11(7): 791-796.

117)Walsh, M. J., J. R. Jonsson, et al. (2006). "Non-response to antiviral therapy is associated with obesity and increased hepatic expression of suppressor of cytokine signalling 3 (SOCS-3) in patients with chronic hepatitis C, viral genotype 1." Gut 55(4): 529-535.

118)Wang, Z., C. Zang, et al. (2009). "Genome-wide Mapping of HATs and HDACs Reveals Distinct Functions in Active and Inactive Genes." Cell 138(5): 1019-1031.

119)Waris, G. and A. Siddiqui (2003). "Regulatory mechanisms of viral hepatitis B and C." Journal of Biosciences 28(3): 311-321.

120)Weber, S., F. Maab, et al. (2009). "PRMT1-mediated arginine methylation of PIAS1 regulates STAT1 signaling." Genes \& Development 23(1): 118-132.

121)Wen, Z., Z. Zhong, et al. (1995). "Maximal activation of transcription by statl and stat 3 requires both tyrosine and serine phosphorylation." Cell 82(2): 241-250.

122)WHO. (2011). "Hepatitis C Fact Sheet No164." Retrieved June, 2011, from http://www.who.int/mediacentre/factsheets/fs164/en/.

123)Yamashita, Y.-i., M. Shimada, et al. (2003). "Histone deacetylase inhibitor trichostatin a induces cell-cycle arrest/apoptosis and hepatocyte differentiation in human hepatoma cells." International Journal of Cancer 103(5): 572-576.

124)Yang, X. J. and E. Seto (2007). "HATs and HDACs: from structure, 
function and regulation to novel strategies for therapy and prevention." Oncogene 26(37): 5310-5318.

125)Yang, X.-J. and E. Seto (2008). "The Rpd3/Hda1 family of lysine deacetylases: from bacteria and yeast to mice and men." Nature Reviews Molecular Cell Biology 9(3): 206-218.

126)Yu, S.-H., K. Nagayama, et al. (2000). "Intrahepatic mRNA Expression of Interferon-Inducible Antiviral Genes in Liver Diseases: dsRNA-Dependent Protein Kinase Overexpression and RNase L Inhibitor Suppression in Chronic Hepatitis C." Hepatology 32(5): 1089-1095.

127)Zhang, X., J. Blenis, et al. (1995). "Requirement of serine phosphorylation for formation of STAT-promoter complexes." Science 267(5206): 1990-1994.

128)Zheng, Z., J. Li, et al. (2011). "Inhibition of HBV replication by theophylline." Antiviral Research 89(2): 149-155.

129)Zhong, J., P. Gastaminza, et al. (2005). "Robust hepatitis $C$ virus infection in vitro." Proceedings of the National Academy of Sciences of the United States of America 102(26): 9294-9299.

130)Zhu, W., T. Mustelin, et al. (2002). "Arginine Methylation of STAT1 Regulates Its Dephosphorylation by T Cell Protein Tyrosine Phosphatase." The Journal of Biological Chemistry 277(39): 3578735790 .

131)Zhu, X., Z. Wen, et al. (1997). "Stat1 serine phosphorylation occurs independently of tyrosine phosphorylation and requires an activated Jak2 kinase." Molecular and Cellular Biology 17(11): 6618-6623. 


\title{
CURRICULUM VITAE
}

\author{
Stephanie A. Mathews, MS \\ 3819 Greenwich Way \\ Louisville, KY 40218 \\ smathews78@hotmail.com
}

\section{EDUCATION}

DEC 2011

Ph.D. in Pharmacology/Toxicology, University of Louisville, Louisville, $\mathrm{KY}$

Dissertation: Role of HDACs and SAM in interferon-alpha signaling and epigenetic regulation of anti-HCV gene expression.

DEC 2008 M.S. in Pharmacology/Toxicology, University of Louisville, Louisville, KY

MAY 2002 B.S. in Agricultural Biotechnology, University of Kentucky, Lexington, $\mathrm{KY}$

\section{RESEARCH EXPERIENCE}

2006-2011

Graduate Research Assistant/Ph.D. Candidate

Dept. of Hepatology/Gastroenterology

University of Louisville, Louisville, KY

Duties: Conducting research on the molecular and epigenetic mechanisms involved in impaired antiviral signaling using a variety of techniques including chromatin immunoprecipitation, siRNA, RT-PCR, real-time PCR, western blot assays, and general cell culture. Analyzing how acrolein modifies interferon antiviral signaling to enhance disease progression. Involved in optimizing protocols used by the lab and mentoring new students. Managed the ordering system for the lab for two years. 
Dept. of Ophthalmology

University of Louisville, Louisville, KY

Duties: Assisted the research associates and postdoc with their experiments in glaucoma research prior to entering the pharmacology/ toxicology program on supervisor's recommendation. Assisted lab manager with ordering and was in charge of organizing the lab, which included inventory and consolidation of common items/equipment.

2002-2004

Research Assistant

Dept. of Plant Pathology

University of Kentucky, Lexington, KY

Duties: Analyzed two plant virus proteins for their roles in gene silencing and suppression of gene silencing using a variety of techniques including protein extraction, transformation of $\boldsymbol{A}$. tumefaciens, agro- infiltration, extraction and purification of DNA and RNA, site-directed mutagenesis, and cloning. Gained experience in PCR primer design and confocal and fluorescence microscopy.

\section{AFFILIATIONS}

2010-2012

2010-2011

2009-2011

2008-2009

2005-2011

1998-2004

American Society for Pharmacology and Experimental Therapeutics ISTCP Division Executive Committee Member (2011-2012)

Ohio Valley Society of Toxicology University of Louisville Alcohol Research Center Ohio Valley Society of Toxicology Black Biomedical Graduate Student Organization Secretary (2008-2009)

Professional Development Series Coordinator (2008-2010) Minorities in Agriculture, Natural Resources, and Related Sciences

University of Kentucky Charter Member (1998)

University of Kentucky Chapter Vice-president (2000-2001)

Region III Graduate Vice-president (2003-2004)

\section{HONORS/AWARDS} Meeting 
Research!Louisville Postgraduate Award Selection Committee

2010 $3^{\text {rd }}$ Place, Research!Louisville Graduate Student Poster Competition

2010 Platform Presentation, Ohio Valley Society of Toxicology Regional Meeting

2008 $3^{\text {rd }}$ Place, Research!Louisville Graduate Student Poster Competition

2007 Honorable Mention, Ohio Valley Society of Toxicology Regional Meeting

\section{FELLOWSHIPS/GRANTS}

2009-2011

NIH Environmental Health Sciences Training Grant T32ES011564

2007-2009 NIAAA Supplemental Grant 3-R01-AA015970-03S1

2005-2007 Integrated Programs in Biomedical Sciences Fellowship

\section{LEADERSHIP/TEACHING}

Mentored $2^{\text {nd }}$ year medical student on his summer research project (2011)

Implemented the Professional Development Series for biomedical students at the University of Louisville (2008)

Mentored $2^{\text {nd }}$ year medical student on her summer research project (2008)

Chartered University of Kentucky chapter of Minorities in Agriculture, Natural Resources, and Related Sciences (1998)

Tutored several undergraduate students in math and science (1996-2004)

\section{PRESENTATIONS}

Mathews, S (2011) "Impaired S-adenosylmethionine Metabolism Inhibits IFNamediated Anti-HCV Gene Expression"

FASEB Poster Presentation

Mathews, S (2011) "Histone Deacetylases Play a Critical Role in Regulating IFNa-mediated Anti-HCV Gene Expression"

SOT Poster Presentation 
Mathews, S (2010) "Epigenetic Modifications of Histones Play a Critical Role in Regulating IFNa-mediated Anti-HCV Gene Expression"

FASEB Poster Presentation

Ohio Valley Society of Toxicology Platform Presentation

Research!Louisville Poster Presentation

Mathews, S (2009) "How to Give a Good Oral Presentation"

Black Biomedical Graduate Student Organization Professional Development

Series

Mathews, S (2008) "Epigenetic Modifications of Histones Play a Critical Role in Regulating IFNa-mediated Anti-HCV Gene Expression"

Research!Louisville Poster Presentation

Mathews, S (2007) "4-Hydroxynonenal (4-HNE) Inhibits STAT-2 Activation and Decreases Anti-HCV Activity of Interferon Alpha in CD4+ T Lymphocytes"

Research!Louisville Poster Presentation

Ohio Valley Society of Toxicology Poster Presentation

Mathews, S (2004) "Control of Reporter Gene Expression by the M and P Proteins of Sonchus Yellow Net Nucleorhabdovirus"

American Society for Virology Poster Presentation

Minorities in Agriculture, Natural Resources and Related Sciences Poster

Presentation

Mathews, S (2003) "Agrobacterium tumefaciens: Pathogen and Tool"

University of Kentucky Dept. of Plant Pathology Seminar

\section{PUBLICATIONS}

Joshi-Barve, S., Amancherla, K., Patil, M., Bhatnagar, A., Mathews, S., Gobejishvili, L., Cave, M., McClain, C., and Barve, S. Acrolein, a ubiquitous pollutant and lipid hydroperoxide product, inhibits antiviral activity of interferonalpha: relevance to hepatitis C. Free Rad. Biol. Med. 47(1): 47-54 (2009).

Goodin, M., Yelton, S., Ghosh, D., Mathews, S., and Lesnaw, J. Live-cell imaging of rhabdovirus-induced morphological changes in plant nuclear membranes. Mol. Plant Microbe Interact. 18(7):703-709 (2005).

\section{ABTRACTS}

Mathews, S., Joshi-Barve, S., McClain, C., and Barve, S. Impaired Sadenosylmethionine metabolism inhibits IFNa- mediated anti-HCV gene expression. FASEB J. 2011 25:1090.9 [Meeting Abstract] 
Mathews, S., Ademosu, F., Joshi-Barve, S., McClain, C., and Barve, S. Histone Deacetylases Play a Critical Role in Regulating IFNa-mediated Anti-HCV Gene Expression. OVSOT 2010 [Meeting Abstract]

Mathews, S., Ademosu, F., Joshi-Barve, S., McClain, C., and Barve, S. Histone Deacetylases Play a Critical Role in Regulating IFNa-mediated Anti-HCV Gene Expression. FASEB J. 2010 24:966.7 [Meeting Abstract] 